ANL-86-17

ARGONNE NATIONAL LABORATORY

9700 South Cass Avenue

Argonne, Illinois 60439

ANL $-86-17$

DE86 012088

HEAT EXTRACTION FROM THE ANL RESEARCH SALT GRADIENT SOLAR POND

by

J. R. Hull, A. B. Scranton, J. M. Mehta, S. H. Cho,* and K. E. Kasza

Components Technology Division

February 1986 
Argonne National Laboratory, with facilities in the states of Illinois and Idaho, is owned by the United States government, and operated by The University of Chicago under the provisions of a contract with the Department of Energy.

\section{DISCLAIMER}

This report was prepared as an account of work sponsored by an agency of the United States Government. Neither the United States Government nor any agency thereof, nor any of their employees, makes any warranty, express or implied, or assumes any legal liability or responsibility for the accuracy, completeness, or usefulness of any information, apparatus, product, or process disclosed, or represents that its use would not infringe privately owned rights. Reference herein to any specific commercial product, process, or service by trade name, trademark, manufacturer, or otherwise, does not necessarily constitute or imply its endorsement, recommendation, or favoring by the United States Government or any agency thereof. The views and opinions of authors expressed herein do not necessarily state or reflect those of the United States Government or any agency thereof.

Printed in the United States of America

Available from

National Technical Information Service

U. S. Department of Commerce

5285 Port Royal Road

Springfield, VA 22161

NTIS price codes

Printed copy: A06

Microfiche copy: A01 


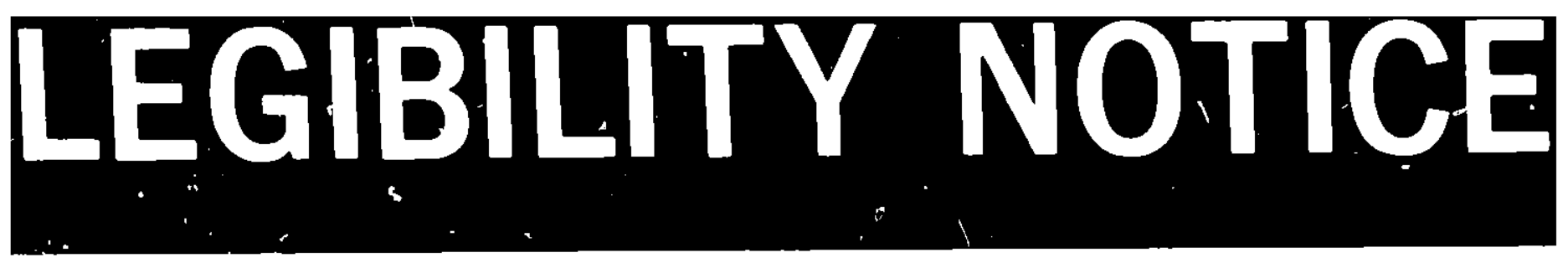

\section{A major purpose of the Techni-} cal Information Center is to provide the broadest dissemination possible of information contained in DOE's Research and Development Reports to business, industry, the academic community, and federal, state and local governments.

\section{Although a small portion of this} report is not reproducible, it is being made available to expedite the availability of information on the research discussed herein. 


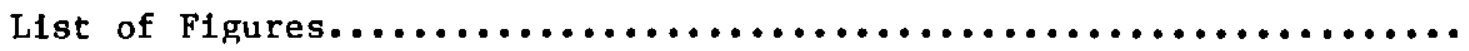

L1st of Tables......................................

1. INTRODUCTION...................................... 1

1.1 Background................................... 1

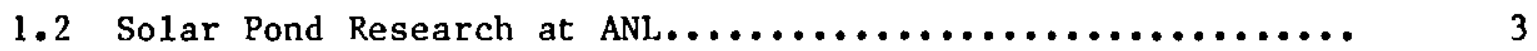

1.2 .1 Objectives and Approach...................... 3

1.2.2 Experimental Factlity....................... 5

1.2.3 Description of Projects..................... 5

1.2 .4 Important Results.......................... 7

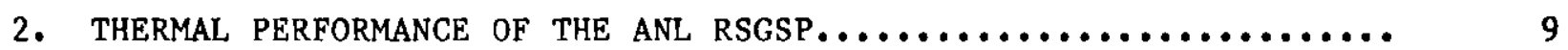

2.1 Thermal History............................... 9

2.2 Calculated Thermal Performance.................... 15

3. DESIGN OF SUBMERGED HEAT EXCHANGER...................... 19

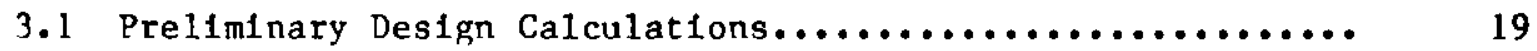

3.1.1 Fresh Water through Plast1c Tubes................ 22

3.1.2 Alr through Plastic Tubes..................... 25

3.1.3 Liquid-to-Air Heat Exchanger................... 25

3.2 Final Design of Submerged Heat Exchanger System........... 30

3.2.1 Submerged Plastic-Tube Heat Exchanger............. 32

3.2.2 Liquid Pumping System....................... 37

3.2 .3 Alr Handling System....................... 38

3.2 .4 Instrumentation.......................... 41

4. LABORATORY TESTING OF THE SUBMERGED HEAT EXCHANGER............ 42

4.1 Int roduction................................. 42

4.2 Flow Uniformity Test........................... 42

4.3 Liquid Loop Leak Test and Instrumentation Check.......... 43

4.4 Control of the A1r Flow Rate through the Duct........... 43

4.5 Heat Transfer Experiments with the Submerged Heat

Exchanger...................................... 45

4.5.1 Experimental Configuration and Procedure.......... 45

4.5 .2 Resuits and Analysis........................ 46

4.6 Heat Transfer Experiments with the Liquid-to-Alr Heat

Exchanger..................................... 48

4.6.1 Experimental Configuration and Procedure........... 49

4.6.2 Results and Analysis......................... 49

4.7 Extended Operation of the Entire System............... 53 
5. EXPERIMENTAL RESULTS FOR THE SUBMERGED HEAT EXCHANGF SYSTEM AT

THE RSGSP...................................... 54

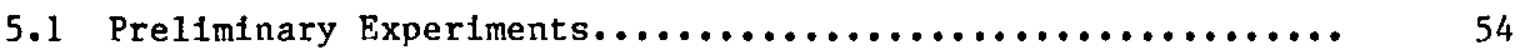

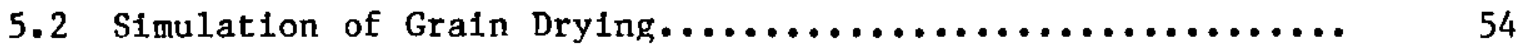

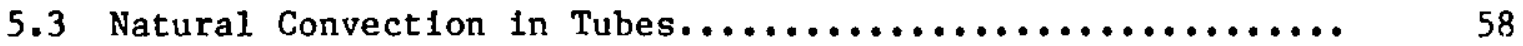

5.4 Removal of Submerged Heat Exchanger.................. 65

6. EFFECTS OF STRATIFICATION ON HEAT TRANSFER PERFORMANCE......... 65

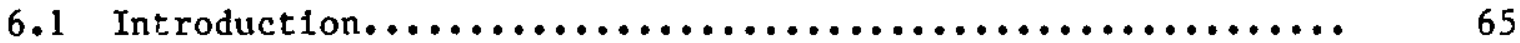

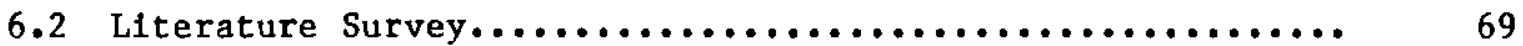

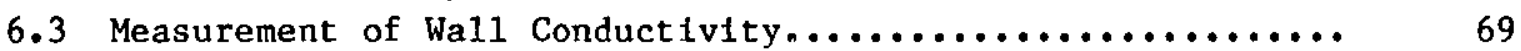

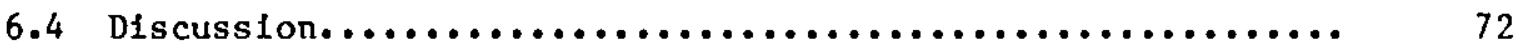

7. BRINE WITHDRAWAL HEAT EXTRACTION SYSTEM................. 73

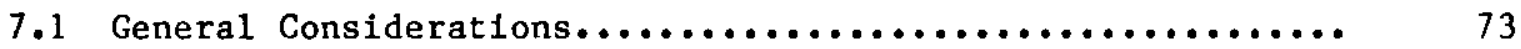

7.1.1 Effect of Brine Extraction on Solar Pond Stability.. 73

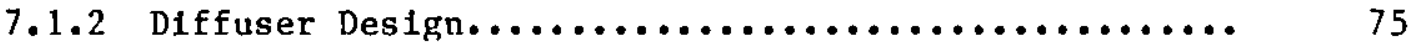

7.1 .3 Effects of Brine Saturation................. 77

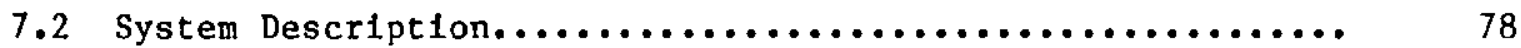

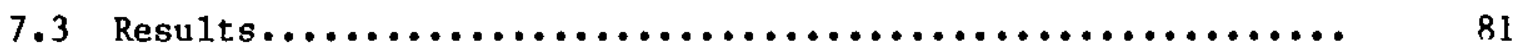

8. CORROSION OF MATERIALS IN SALT GRADIENT SOLAR PONDS........... 93

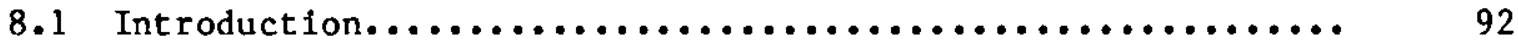

8.2 Corrosion Properties of Materials..................... 92

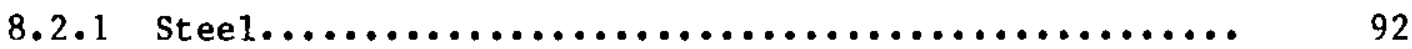

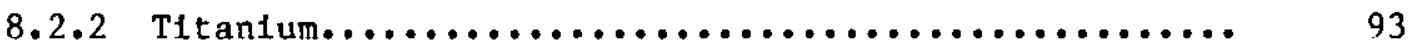

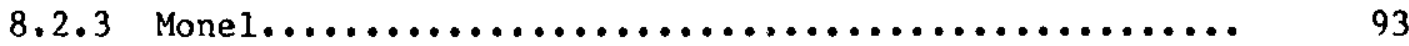

8.2 .4 Copper.................................. 93

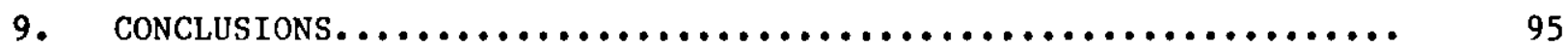

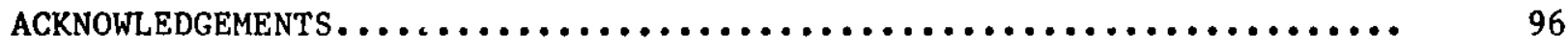

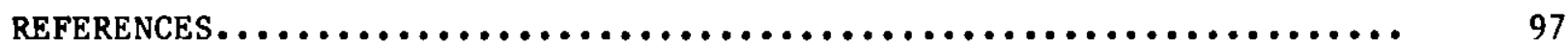




\section{FIGURES}

1 Schematic of salt gradtent solar pond..................... 2

2 Submerged mode of heat extraction........................ 4

3 Brine withdrawal mode of heat extraction................... 4

4 Temperature history of RSGSP heat storage zone.............. 10

5 Temperature history of ground below the RSGSP............. 11

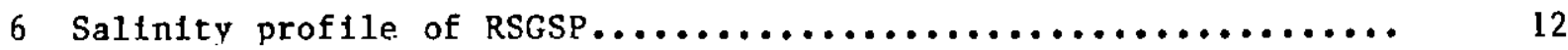

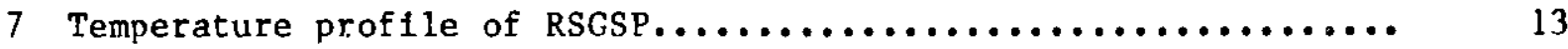

8 Calculated thermal efficiency of $\operatorname{RSGSP} \ldots \ldots \ldots \ldots \ldots \ldots \ldots \ldots \ldots \ldots \ldots$

9 Location of submerged heat exchanger in RSGSP.............. 20

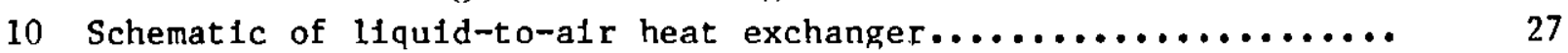

11 Schematic of submerged plastic tube heat exchange system....... 31

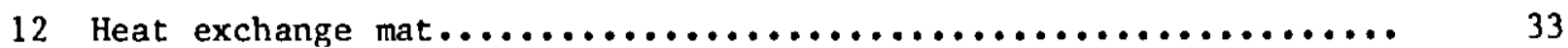

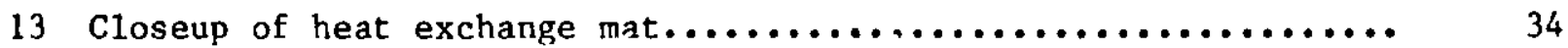

14 Submerged heat exchange mats before final deployment.......... 36

15 Liquid-to-air heat exchanger seen from air outlet side........ 39

16 Liquid-to-air heat exchanger seen from air inlet side........ 40

17 Temperature histories during submerged heat extraction......... 55

18 Thermal power output during submerged heat extraction........ 56

19 Temperature profiles before, during, and after submerged heat extraction.................................. 57

20 Temperature profile after teat extraction, showing pond

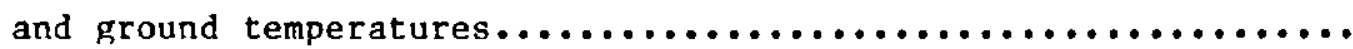

21 Total heat exchanger effectiveness during grain drying

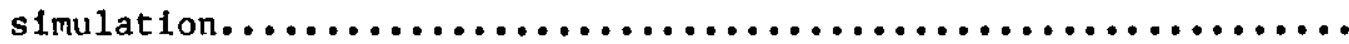

22 Alr-side effectiveness during graln drying simulation..........

23 Liquid-side effectiveness during grain drying simulation.......

24 Injection diffuser...............................

25 Temperature historles during brine withdrawal heat

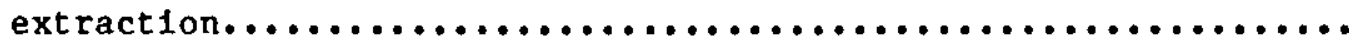

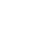

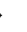
(1) 2 13 18

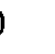
1 3 4 9 0 56

26 Thermal power output during brine withdrawal heat

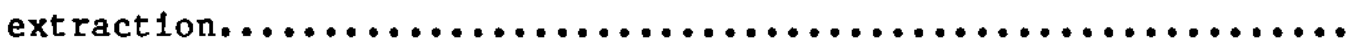

27 Heat exchanger effectiveness during brine withdrawal heat ext raction........................................ 85

28 Temperature profile before brine withdrawal heat extract.ton.... 86

29 Temperature profiles during first phase of brine withdrawal heat extraction....................................

30 Temperature profiles during second phase of brine withdrawal heat extraction....................................

31 Temperature profiles after extraction diffuser reposi-

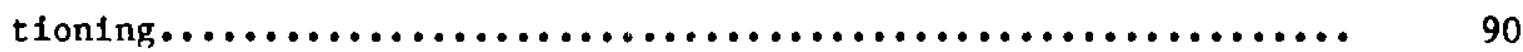

32 Temperature profile after brine withdrawal heat extraction...... 
1 Thermal Performance of Polypropylene Heat Exchanger as

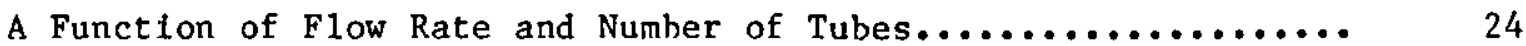

2 Cost of Submerged Heat Extraction System.................. 30

3 Experimental Data for the Submerged Heat Exchanger........... 46

4 Overall Heat Transfer Coefficient for the Submerged

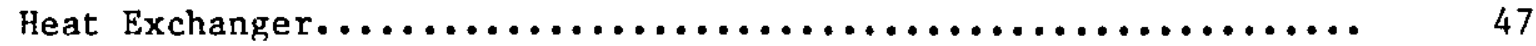

5 Lahoratory Effectiveness of the Submerged Heat Exchanger....... 48

6 Experinental Data for the Liquid-to-Air Heat Exchanger......... 50

7 Comparison of the Heat Gained by the Alr Stream and the Heat Lost by the Water Stream of the Liquid-to-Air Heat

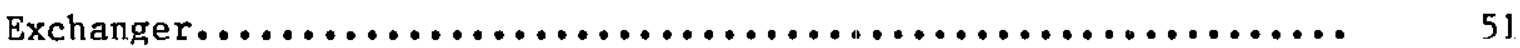

8 Overal.1 Heat Transfer Coefficient of the Liquid-to-Alr

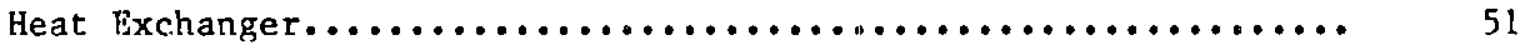

9 Effectiveness of the Liquid-to-Air Heat Exchanger............. 52

10 Steady-State Water Temperatures for Experimental Hot Water

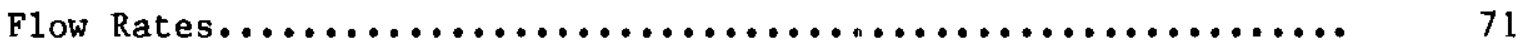

11 Results of Calculations for Experimental Flow Rates........... 71

12 Cost of Brine Withdrawal Heat Extraction System.............. 81 


\title{
HEAT EXTRACTION FROM THE ANL RESEARCH SALT GRADIENT SOLAR POND
}

\author{
by
}

J. R. Hull, A. B. Scranton, J. M. Mehta, S. H. Cho and K. E. Kasza

\author{
ABSTRACT
}

This report documents the design considerations and test results of two heat extraction systems for the ANL Research Salt Gradient Solar Pond (RSGSP). Since operation began in November 1980, the RSGSP has been used to study a wide variety of solar pond phenomena, and the behavior of the RSGSP without heat extraction has been well characterized. Heat extraction equipment was installed in the spring of 1984, with heat extraction experiments conducted the following summer and fall and in the fall of 1985. The experiments simulated the use of the solar pond for grain drying.

Two methods of heat extraction are compared. For both methods the heat exchangers are sized for $30 \mathrm{~kW}$, with a peak load capability of $60 \mathrm{~kW}$. In the first method, ethylene glycol solution is circulated through a plastic-tube heat exchanger submerged in the pond to a liquid-to-air fin-tube heat exchanger external to the pond. In the second method, hot brine is withdrawn from the bottom of the pond, circulated through a brine-to-air heat exchanger, and the cooled brine is returned to the bottom of the pond. The brine-to-air heat exchanger is constructed from copper-nickel to minimize corrosion.

The effects of both heat extraction methods on the stability of the salt gradient are investigated. The submerged heat exchanger has a minimal effect on the gradient because the disturbances associated with the natural convection caused by the heat extraction remain in the heat storage zone and do not reach the gradient zone boundary. The disturbances associated with brine withdrawal are also shown to have a negligible impact.

\section{INTRODUCTION}

\subsection{BACKGROUND}

A salt-gradient solar pond combines the collection and storage of solar energy into a single operation. Solar radiation is absorbed and stored in the water at the lower levels of the pond. The water temperature at the lower levels of the pond can be as high as $70-90^{\circ} \mathrm{C}\left(160-194^{\circ} \mathrm{F}\right)$, while the surface 


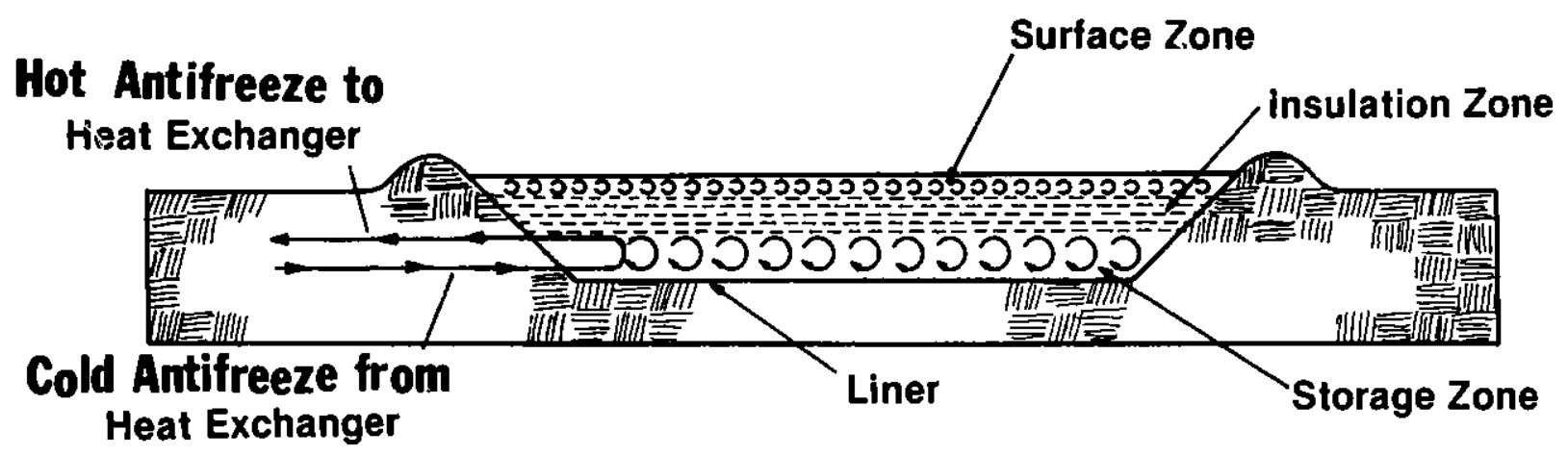

Fig. I. Schematic of salt gradient solar pond

temperature remains very close to the ambient ajr temperature. Convection is prevented by establishing a salt gradient in the pond such that the salt concentration varies from about zero at the surface to about $20-25 \%$ at the bottom. As a result of the presence of the salt gradient, fluid densities at the lower levels of the pond are higher than those near the surface, thus preventing the hotter fluid at the lower levels from moving upward. The concept of collecting and storing solar energy by means of salt-gradient solar ponds was derived from studies of various natural lakes that contain salt concentration gradients. As shown in Fig. 1, a salt gradient solar pond normally consists of three zones:

A thin convective zone at the surface,

A nonconvective gradient zone that provides thermal insulation in the middle, and

A heat storage zone at the bottom.

The pond collects and stores solar energy all year, and the available thermal energy in the pond can be extracted via a heat exchanger.

A Research Salt Gradient Solar Pond (RSGSP) was constructed at Argonne National Laboratory (ANL) by the Components Technology Division in 1980 [1,2]. Since its inauguration the RSGSP has been the focus for a wide variety of solar pond research (see Sec. 1.2). In June 1983, ANL received research grant ENR AE12 from the Illinois Department of Energy and Natural Resources. The purpose of the grant was to initiate a series of heat extraction experiments using the RSGSP. According to the proposal for the grant, the heat extraction was to be similar to that used for grain drying; i.e., the energy extracted 
from the solar pond was used to heat air. Two types of heat extraction were performed:

- One system used a submerged heat exchanger (Fig. 2), and

- The other extracted hot brine from the storage zone of the solar pond (Fig. 3).

With the submerged heat exchanger, a mixture of fresh water and ethylene glycol is passed through plastic tubes submerged in the heat storage zone (HSZ) of the solar pond, where the fluid mixture receives energy from the pond and becomes hot. The hot water/glycol mixture is then passed through a liquid-to-air heat excharger, located outside the pond. With the brine extraction system, hot brine is extracted from the top of the pond's HSZ. This hot brine is passed through a brine-to-air heat exchanger, located outside the pond. Then the cooled brine is returned to the pond at the bottom of the HSZ.

This report documents the design considerations and test results of the heat extraction experiments for the ANL RSGSP. Portions of this report have appeared in conference proceedings $[3,4]$.

\subsection{SOLAR POND RESEARCH AT ANL}

\subsubsection{Objectives and Approach}

The objective of solar pond research at Argonne National Laboratory (ANL) is to advance the basic knowledge of solar pond technology. The work focuses on applications that utilize the seasonal heat and storage capability of the solar pond for low-temperature thermal processes. The results of the research, however, are directly applicable to electricity-generating and other applications.

Experimental and theoretical research is centered around the $1080 \mathrm{~m}^{2}$ ANL Research Salt Gradient Solar Pond (RSGSP), which has been operating since Nov. 1980. The temperature of the heat storage zone has cycled between approximately 40 and $77^{\circ} \mathrm{C}$ on an annual basis. The challenge of operating a solar pond in a climate with ambient winter temperatures as $10 \mathrm{w}$ as $-30^{\circ} \mathrm{C}$ and high-velocity winds at various times of the year has provided ample opportunity to learn the practical details of solar pond operation. Close collaboration also exists with a number of researchers from universities within the region. In addition to basic solar pond studies, these collaborators have conducted experiments at the RSGSP to aid understanding of basic oceanographic and double-diffusive convection phenomena. 


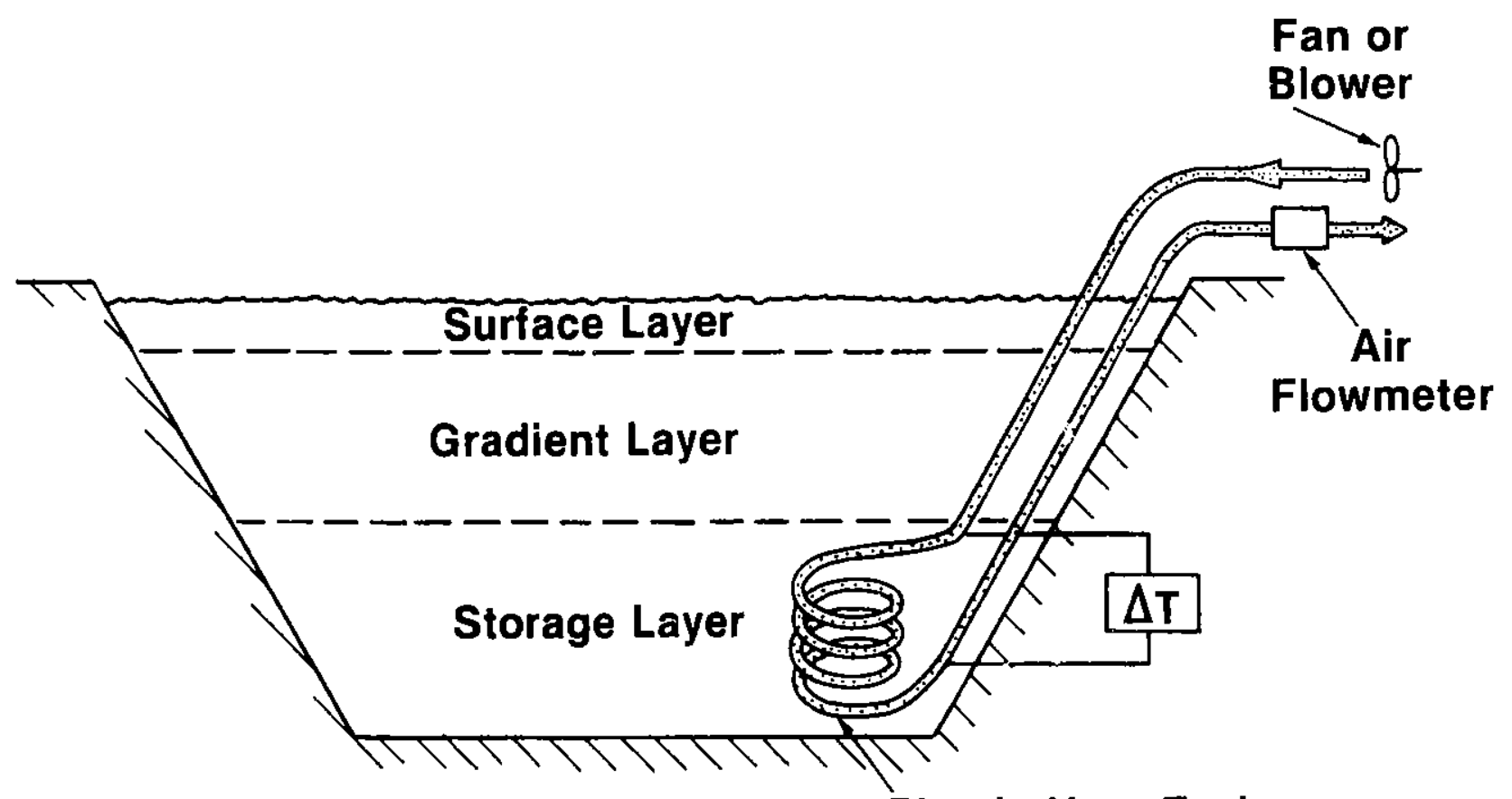

Plastic Heat Exchanger

Fig. 2. Submerged mode of heat extraction

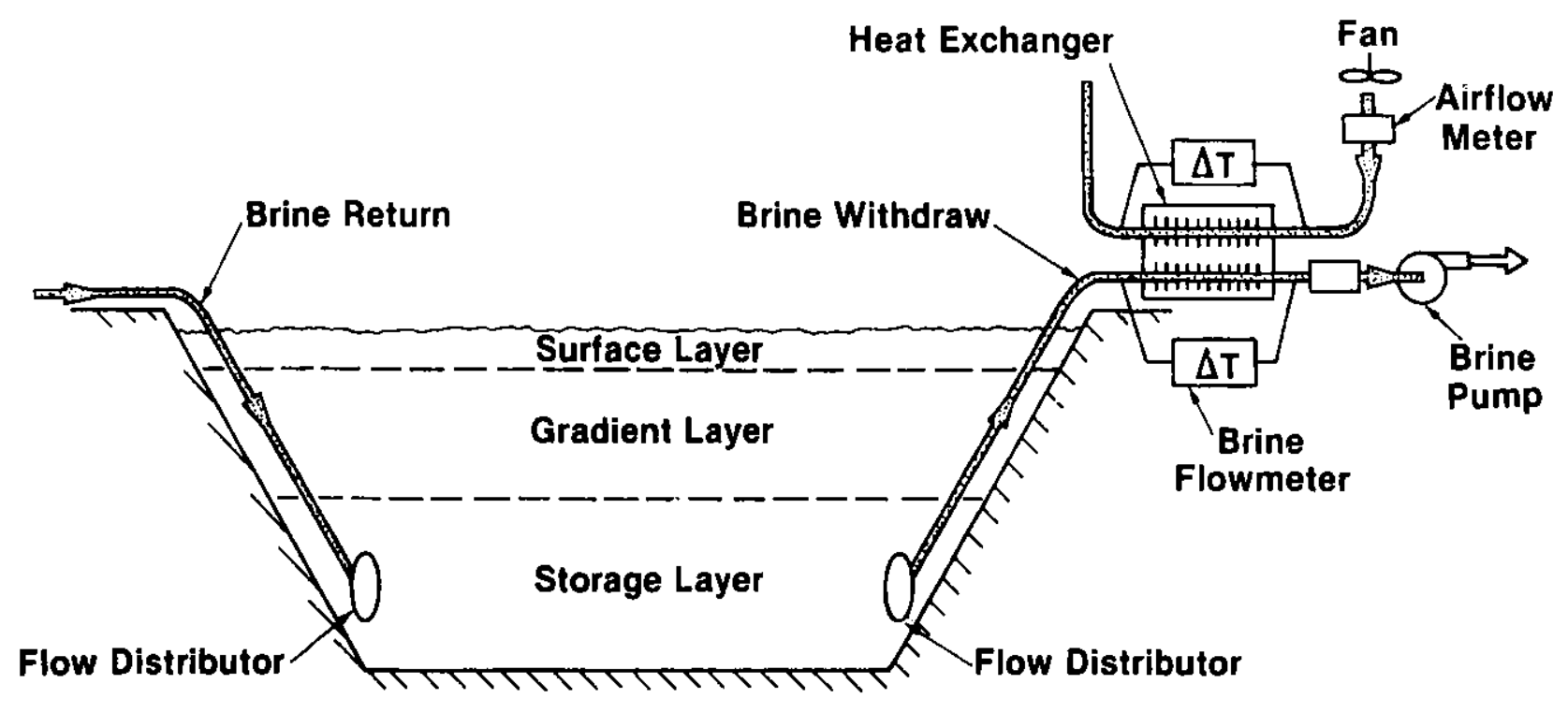

iig. 3. Brine withdrawal mode of heat extraction 


\subsubsection{Experimental Facility}

The ANL RSGSP is $43 \mathrm{~m}(142 \mathrm{ft})$ by $25 \mathrm{~m}(82 \mathrm{ft})--1 / 4$ acre--at the top with sides tapered at 45 degrees to a depth of approximately $4.3 \mathrm{~m}$ (14 $\mathrm{ft})$. It contains approximately $3030 \mathrm{~m}^{3}(800,000 \mathrm{gal}$.$) of water and 640,000 \mathrm{~kg}(700$ tons) of salt. The heavy clay soil around the pond is compacted enough to be stable at the 1-to-1 slope. Investigation of either shallow or deep heatstorage zones is accomplished by regulating the depth to which the pond is filled. The top of the berms slope slightly away from the pond and are covered with polyethylene plastic to drain rainfall away from the pond. The pond proper is lined with XR-5 plastic, manufactured by Shelter Rite" in Millersburg, Ohio. The plastic liner is used to prevent leakage of the salt water into the surrounding ground. A drainage tile line that leads to a sump is located underneath the pond liner for leakage detection. Under optimal circumstances, in the course of a year the pond can provide approximately $10^{12} \mathrm{~J}\left(10^{9} \mathrm{Btu}\right)$ of heat, enough energy to dry 80,000 bushels of corn.

The ANL RSGSP is equipped with 165 underground thermocouples. A vertical scanning system, suspended from a cable that passes over the pond, measures the temperature and salinity profiles within the pond. Salinity is measured with an electrodeless conductivity probe. Insolation and weather data are collected at the RSGSP site, as well as several other locations at the laboratory.

The method of data collection varies with the details of the particular experiment, but usually the data are channeled through a data logger, with direct printout and cassette tape storage. Information from the tapes is regularly transmitted to a mainframe computer. The information is accessible by other institutions through several different computer networks. For example, researchers at MIT have received data from the ANL RSGSP to test their model of surface effects on solar pond behavior. Further details of the construction and operation of the ANL RSGSP can be found in Refs. 1 and 2 .

\subsubsection{Description of Projects}

A variety of theoretical and experimental solar pond projects have been conducted at ANL. The detailed results from most of the projects are described in the references, and only a brief summary of each activity is given here.

Early in the ANL research, it was recognized that understanding of basic solar pond phenomena could greatly benefit by the availability of a computer model of solar pond fluid dynamics. ANL researchers had previously

\footnotetext{
*Reference to any specific commercial product, process, or service by trade name, trademark, manufacturer, or otherwise does not necessarily constitute or imply its endorsement, recommendation, or favoring by this United States government or any agency thereof.
} 
developed COMMIX-1A, a very powerf'll three-dimensional thermalhydraulic computer code, which solves a first-order approximation of the complete Navier-Stokes equations. The investment of many years of development in COMMIX-1A has resulted in a code that has been very successful in modeling very difficult fluid problems in nuclear reactors. A subroutine for salt conservation was added to this code to obtain a solar pond fluid model. To test the limits of this computer model, it was applied to the very difficult problem of predicting instability in a double-diffusive system, in a geometry for which an analytical solution was available [5]. The computer code was successfully able to predict both the qualitative and quantitative aspects of the instability. The critical parameters were correctly predicted to an accuracy within that expected, given the numerical diffusion limits of a first-order approximation.

It was also recognized that relatively simple models of solar pond thermal performance were needed as design tools. Computer models of pond thermal behavior have been available for some time [6], and it was known that the most sensitive parameters in these models are brine transparency and ground heat loss. The optical part of the solar pond model was improved by a careful theoretical analysis of the effects of reflectivity from the pond bottom [7]. The ground heat loss from solar ponds was investigated both theoretically and experimentally $[8,9]$ in collaboration with researchers at the Ohio State University. The effects of different perimeter insulation strategies were also investigated. A recent theoretical advance in this area has been the development of a method to calculate the ground heat loss to a moving water table [10]. The availability of solar pond thermal performance models allows the study of system performance for any location. One unusual study of this type was the combination of a solar pond heat source with an OTEC cold-water pipe for an electricity generating plant [11].

Another important factor in determining solar pond thermal performance is the depth of the upper convecting zone. Currently, no complete understanding of the dynamical behavior of this zone is available. A onedimensional model of this zone was developed [12] using models that had previously been used in oceanography and 1 imnology. This model was then used to compare the effects of wind, night cooling, and evaporation on the growth of the upper convective zone. It is expected that data from the RSGSP can be used to improve this model.

Analysis of data from the ANL RSGSP has produced several important results. The temperature and salinity profiles have been used to verify an empirical relationship, developed by Prof. C. E. Nielsen of the Ohio State University, governing the growth and erosion of gradient zones [2]. A deptr sounding instrument has been used to examine sound-reflecting structures in the solar pond [13]. These measurements, coupled with analysis of the salinity and temperature profiles, have demonstrated that salt piles can be effectively used to automatically control the position of the lower boundary of the gradient zone [14]. In addition, a perforated barrier has been designed to automatically control both the top and bottom boundaries of the 
gradient zone [15]. Prof. T. A. Newell of the University of Illinois has used data from the RSGSP to partially verify a theory of gradient-zone constraint [16].

Potential environmental degradation due to salt runoff from solar ponds is an important factor in an agricultural area, such as the Midwest region surrounding ANL. Several analyses have been performed on the use of fertilizer salts in solar ponds $[17,18]$. From the analyses, a design has been derived to minimize the environmental impact of salt gradient solar ponds. The need for the development of inexpensive nonsalt solar ponds has long been recognized, and several theoretical studies have explored this topic [1921]. In addition, several small-scale experiments using highly viscous silicone oil to suppress convection have been conducted.

The ANL RSGSP has also served as a facility for the training of other solar pond researchers. In addition to the many scientists who have visited the facility for shorter periods of time, researchers from Taiwan, Togo, and Korea have studied at the RSGSP for periods greater than one week. Students from the Illinois Institue of Technology, University of Illinois, University of Iowa, Otterbein College, Swarthmore College, University of Michigan and Purdue University have also studied for extended periods of time at the RSGSP.

ANL has served as a solar pond consultant to USAID for projects in Jordan, Kuwait, Spain, and Togo. ANL was asked by USDOE to write the summary chapter on solar ponds for all USDOE research conducted during the last 10 years [22] and has been asked to write a book on salt-gradient solar ponds by the CRC Press.

\subsubsection{Important Results}

This section briefly summarizes several important technical results from the solar pond research at ANL.

- Reflectivity from the pond bottom is an important factor in pond thermal performance. A general way to incorporate this factor into thermal efficiency calculations is presented in Ref. 7 .

- Night cooling at the surface plays an equal role to wind effects in the erosion of the upper gradient zone boundary. Thus, even with a perfect wave suppression system, there is a minimum size attainable for the thickness of the upper convecting zone (Ref. 12).

- The effective thermal conductivity of clay soils around solar ponds is significantly higher than most handbook values would indicate (Refs. 8 and 9 ). 
- Sloping side walls result in less ground heat loss than vertical side walls, even though the side wall area is much greater. Heat loss from sloping side walls is approximately equal to well-insulated vertical side walls (Ref. 8).

- The presence of a moving water table plays a significant role in determining the thermal efficiency of a solar pond. A method to calculate ground heat loss to a moving water table is presented in Ref. 10.

- Salt piles in the heat-storage zone provide an effective method of stabilizing the position of the lower boundary of the gradient zone (Ref. 14).

- Simple depth-sounding instruments are valuable tools for determining the position of gradient zones in solar ponds. They are aiso capable of identifying debris layers that may not be visible to the eye (Ref. 13).

- Ammonium sulfate, a fertilizer salt, can be used as a salt for solar ponds. The salt is as economical as sodium chloride, and the runoff is environmentally benign because it fits well in the fertilizer cycle of agricultural systems (Refs, 17 and 18). 
2. THERMAL PERFORMANCE OF THE ANL RSGSP

\subsection{THERMAL HISTORY}

Since the initial operation of the ANL RSGSP in November 1980 , the solar pond has continued to successfully accumulate and store heat, gradually warming the ground underneath the pond. The temperature history of the RSGSP's heat storage zone (HSZ) is shown in Fig. 4. A similar temperature history for several thermocouple locations in the ground under the center of the pond is shown in Fig. 5. A salinity profile (Fig. 6) and a temperature profile (Fig. 7) are typical for the late summer/early fall period, when the pond is hottest. The data were taken at a point $3.5 \mathrm{~m}$ north and $12.5 \mathrm{~m}$ west of the pond center. This position represents an average depth for the sloping bottom of the pond.

The position of the boundary between the gradient zone and the upper convecting zone varies somewhat through the year [14]. Typically, the upper boundary moves downward as the pond temperature increases, due to the increasing temperature gradient at the top of the gradient zone. The boundary moves upward as the pond temperature decreases and as ice forms on the pond surface. For the most part, this boundary remained relatively constant (say to within $10 \mathrm{~cm}$ ) since the present salt gradient was established in late July 1981 through 1984. In 1985 this boundary moved down about 40 or $50 \mathrm{~cm}$. This behavior sharply contrasts with behavior reported for several other solar ponds [23-25], which have experienced substantial downward erosion of their upper boundaries. The reason for the unexpectedly stable performance of the upper boundary in the RSGSP is unknown at this time. One contributing factor might be the rather large $(\sim 1 \mathrm{~m})$ upper convective zone that was created by heavy rainfall on the pond surface during the pond's operating history. The excess of rainfall over evaporation has been so great that $\sim 70 \mathrm{~cm}$ of surface water had to be removed from the pond in December 1982 and $-100 \mathrm{~cm}$ removed in the spring of 1984 . This slightly salty $(1-2 \%)$ surface water was pumped into the ANL laboratory sewer system. A second contributing factor to the boundary stability might be the partitioning of the upper convective zone into two or more zones, each separated by a thin gradient zone. These partitions usually are created after relatively heavy rain, and may last for days to months, depending on the position and strength of the thin gradient zone.

The position of the boundary between the gradient zone and the HSz also has been fixed during most of the operational history of the RSGSP. The reason for the stability of this lower boundary is the presence of two large salt piles at the bottom of the pond, together covering $\sim 50 \%$ of the southern half of the pond. The top of the salt pile defines the position of the lower boundary. The physical phenomena causing the boundary stability are similar to those used by Akbarzadeh and MacDonald [26] in stabilizing their solar pond. However, rather than external tanks and pipes, only a salt pile is needed in the RSGSP. In 1985, as salt continued to dissolve, the height of the salt pile decreased, and the lower boundary moved down about $30 \mathrm{~cm}$. 
Storage Zone Temperature

ANL Salt Gradient Solar Pond

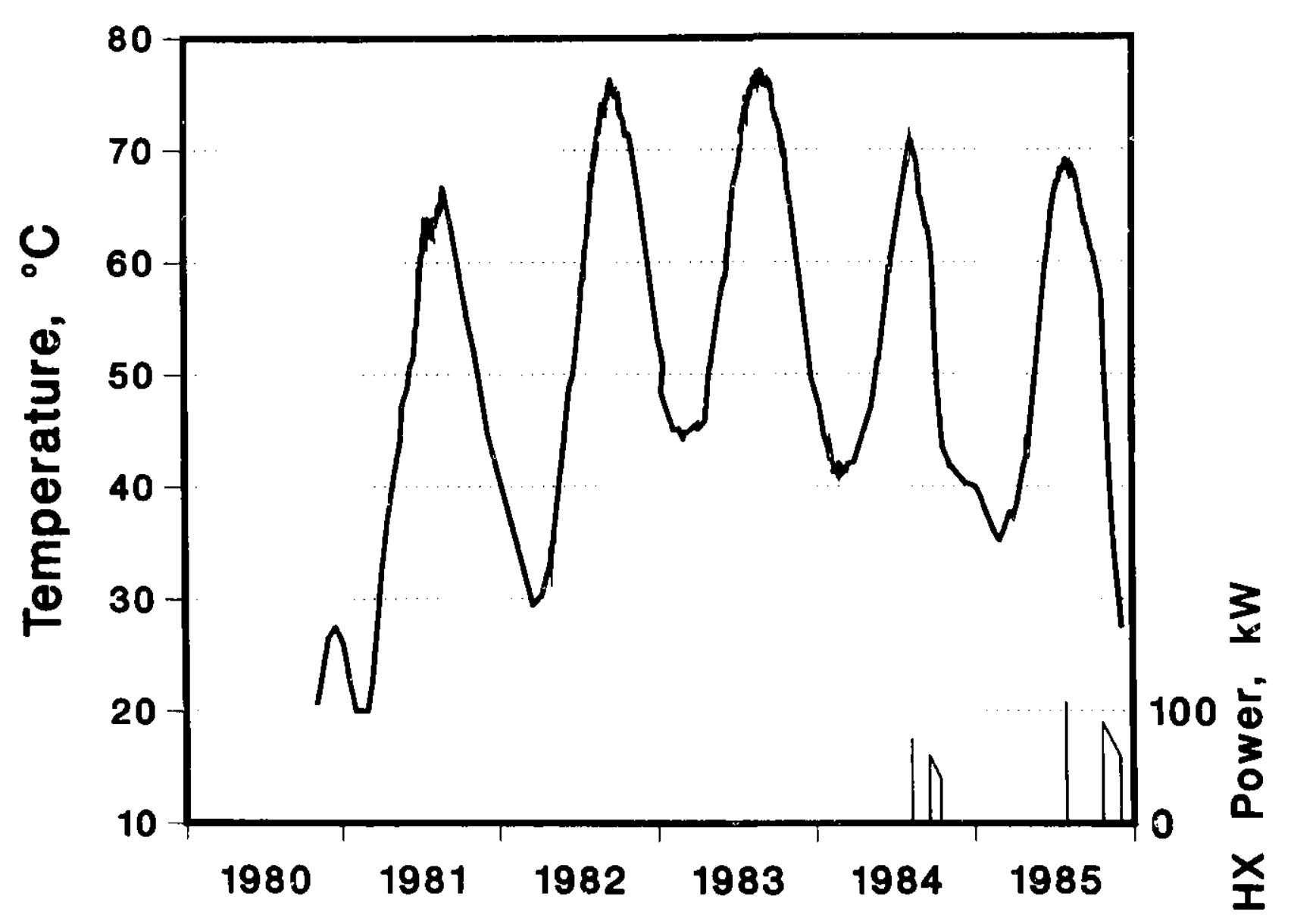

Fig. 4. Temperature history of RSGSP heat storage zone 


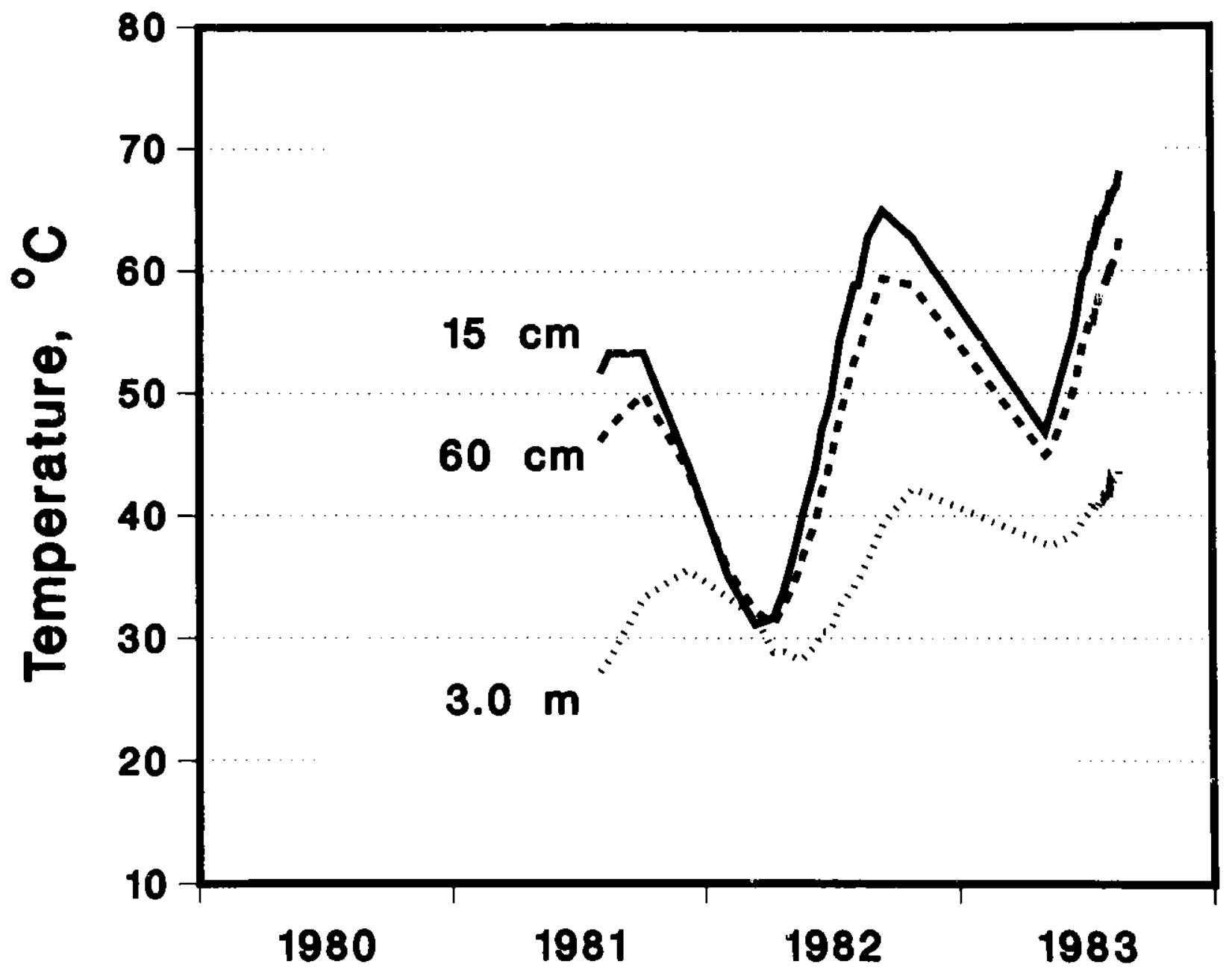

Fig. 5. Temperature history of ground below the RSGSP 


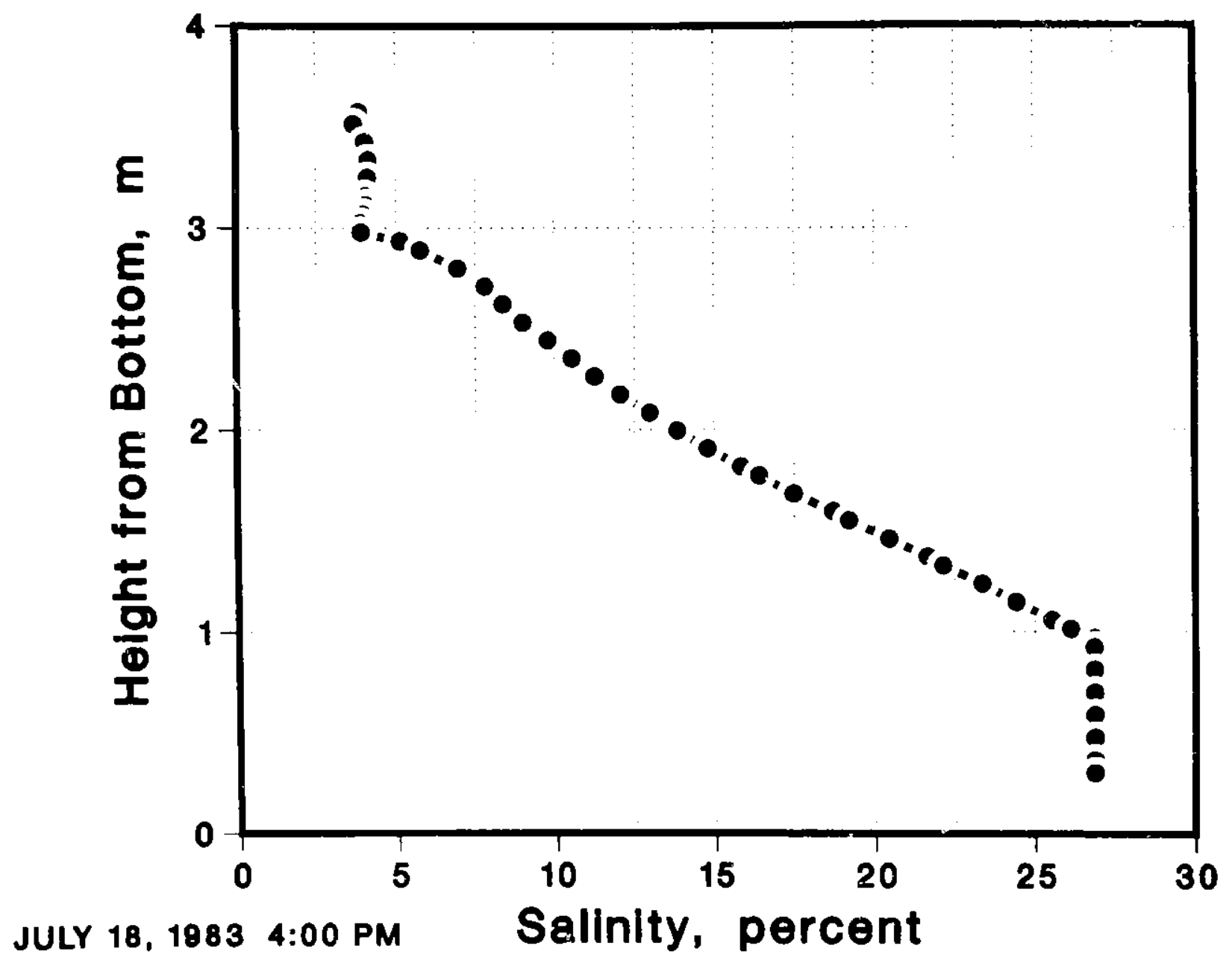

Fig. 6. Salinity profile of RSGSP 


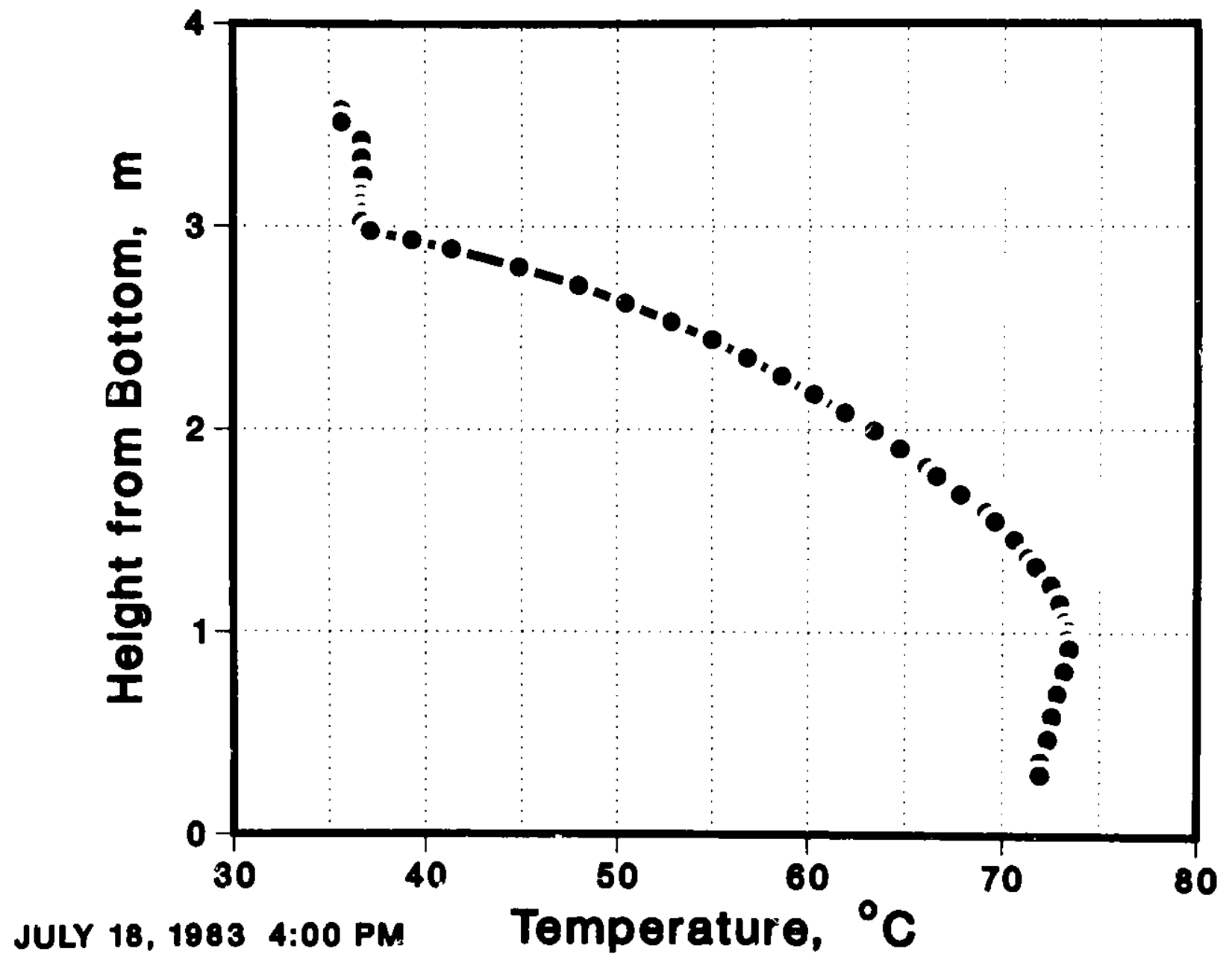

Fig. 7. Temperature profile of RSGSP 
Stabilization of the lower boundary is understood to occur as follows: Assume as an initial condition that the HSZ consists of a saturated salt solution and that the top of the salt pile is identical to the position of the lower boundary. A linear salt gradient exists above the boundary. If the boundary moves upward, then the homogeneous salt solution below the boundary must become less than saturated in order to conserve salt. Salt crystals from the salt pile begin to dissolve into solution. This saturated solution near the salt pile is saltier, and hence heavier, than the rest of the solution in the HSZ. The heavier solution tends to fall toward the bottom of the pond. Thus, all positions below the top of the salt pile become saltier, restoring the boundary to its original position. If the boundary moves downward due to diffusion--which would happen if the HSZ were temperature-stratified (which it usually is)--then the part of the salt pile above the boundary is surrounded by less salty fluid than the pile below the boundary. Dissolution of the pile above the boundary is faster than the dissolution below the boundary. Again the process restores the boundary to the top of the salt pile.

The discussion above ignores the details of salt dissolution kinetics, as well as the temperature dependence of the solubility. This dependence plays an important role in fouling of the heat exchanger in the brine extraction system.

The presence of salt piles, the sloping bottom of the RSGSP [1], and the effects of ground heat loss combine to further stabilize the lower boundary. Most solar ponds have a relatively flat bottom, on which a large fraction of the incident sunlight is absorbed. This bottom heating produces convection in the HSZ. The plumes associated rith this convection act to erode the gradient [27]. In the RSGSP the sloping bottom and salt piles combine to absorb the radiation at the bottom of the pond more or less uniformly throughout the HSZ. This uniform absorption, combined with heat loss to the ground, results in thermal stratification of the HSZ (examine the lower $m$ in Fig. 7). Because there is no convection in the HSZ, there is no erosion of the boundary. Thermal stratification in the heat storage zone has been observed since the first summer of operation in 1981 .

One of the problems associated with using a saturated salt solution at the bottom of the solar pond is the likelihood of crystallization as the pond cools off during the winter. This occurs because the solubility of sodium chloride $(\mathrm{NaCl})$ increases slightly as the temperature increases. The white $\mathrm{NaCl}$ crystals at the bottom of the pond will cause the reflectivity of the bottom to greatly increase, thus reducing the amount of 1 ight absorbed in the HSZ and reducing pond thermal efficiency. This effect has been known for some time [28]. In practice this has not been a large problem at the ANL pond. Because of the large ground heat loss, the pond reaches its maximum temperature in late August to early September and gradually cools off after that. But the crystals do not appear until well into November, when there is 1 ittle insolation anyway. Furthermore, shortly thereafter, ice forms on the pond surface, and there is little penetration of 1 ight into the HSZ. In the early spring, as the pond begins to warm, all the crystals have settled to the bot- 
tom (or top of the salt piles), and the dirt and debris that were trapped in the gradient zone during the fall have fallen on top of the crystals. The bottom is once again black, with the dirty salt crystals forming a cavity-like surface with very low reflectivity.

The reason for the delay in crystal formation after the pond begins to cool is two-fold. First, during the time that the HSZ is warming, the salt is not quite at saturation. Because the increase in solubility is small, the HSZ solution is near saturation, and further dissolution occurs at a slow rate. Second, the $\mathrm{NaCl}$ solution will supercool slightly.

\subsection{CALCulated thermal PERFormanCE}

A first approximation of the thermal performance of a solar pond can be made using the steady-state analysis of Kooi [28, 29] as modified below. The thermal efficiency of the solar pond is

$$
e=t a-\frac{K}{d-z_{I}} \frac{\Delta T}{H}-g \frac{\Delta T}{H}
$$

where

e is efficiency,

ta is the transmission-absorptance product,

$\mathrm{K}$ is the thermal conductivity of water, in $\mathrm{W} \mathrm{m}^{-1}{ }^{\circ} \mathrm{C}^{-1}$,

$z_{1}$ is the depth of the upper zone boundary from the surface, in $m$,

$d$ is the depth of the lower zone boundary from the surface, in $\mathrm{m}$,

$\Delta \mathrm{T}$ is the temperature difference across the gradient zone, in ${ }^{\circ} \mathrm{C}$,

$\mathrm{H}$ is the surface insolation, in $\mathrm{W} \mathrm{m}^{-2}$, and

$g$ is the ground heat loss coefficient, in $\mathrm{W} \mathrm{m}^{-2}{ }^{\circ} \mathrm{C}^{-1}$.

The transmission-absorptance product ta can be estimated by the method of Hull [7]. For a moderately conservative initial design, we assume a bottom reflectivity of $R=0.2, z_{1}=1.0 \mathrm{~m}, \mathrm{~d}=3.0 \mathrm{~m}$, and an average total pond depth $D=4.0 \mathrm{~m}$. We further assume a relatively transparent pond, represented by the four-part radiation transmission function [7]

$$
h_{1}(z)=h_{1}(0) \sum_{i=1}^{4} s_{i} \exp \left(-m_{i} z \sec B\right),
$$

where

$z$ is the depth measured from the surface,

$h_{1}(z)$ is the radiation intensity at depth $z$,

$m_{i}$ is the extinction coefficient of the ith interval,

$B$ is the angle that the penetrating solar beam makes with the vertical, 
$h_{1}(0)$ is the fraction of radiation intensity within the pond at the surface, which has been reduced from the total surface insolation $H$ by Fresnel reflections at the surface, and $s_{i}$ is the fraction of the original insolation in the ith interval,

where

$$
\begin{array}{ll}
s_{1}=0.237, & m_{1}=0.032 \mathrm{~m}^{-1}, \\
s_{2}=0.193, & m_{2}=0.45 \mathrm{~m}^{-1}, \\
s_{3}=0.167, & m_{3}=3.0 \mathrm{~m}^{-1}, \\
s_{4}=0.179, & m_{4}=35.0 \mathrm{~m}^{-1} .
\end{array}
$$

We assume $B=30^{\circ}$, which would represent the average angle during the heating season, and $\mathrm{K}=0.62 \cdot \mathrm{W} \mathrm{m}^{-1}{ }^{\circ} \mathrm{C}^{-1}$.

The ground heat loss coefficient $g$ can be calculated using the analysis of Hull et al. [8]:

$$
g=\left(a / D_{g}+b P_{b} / A_{b}\right) K_{g},
$$

where

$a$ and $b$ are constants,

$\mathrm{K}_{\mathrm{g}}$ is the effective ground thermal conductivity,

$P_{b}$ is the pond perimeter at the bottom of the sloping side walls,

$A_{b}$ is the pond surface area at the bottom of the sloping side walls, and

$D_{g}$ is the distance from the bottom of the pond to the water table.

For the RSGSP

$$
\begin{aligned}
\mathrm{a} & =0.99, \\
\mathrm{~b} & =0.9025, \\
\mathrm{~K}_{\mathrm{g}} & =2.0 \mathrm{~W} \mathrm{~m}-1{ }^{\circ} \mathrm{C}^{-1}, \\
\mathrm{D}_{\mathrm{g}} & =30 \mathrm{~m}, \\
\mathrm{P}_{\mathrm{b}} & =101 \mathrm{~m} \\
\mathrm{~A}_{\mathrm{b}} & =562 \mathrm{~m}^{2}, \text { and } \\
\mathrm{g} & =0.39 \mathrm{~W} \mathrm{~m}^{-2}{ }^{\circ} \mathrm{C}^{-1} .
\end{aligned}
$$

These numbers are used in the calculation of solar pond thermal efficiency for the RSGSP according to Eq. 1. The results are shown in Fig. 8 , which shows pond efficiency $e$ as a function of $\Delta T / H$. This calculation does not take into account seasonal variations, but is good enough for a first approximation.

If the desired temperature of the heat storage zone is known, then the total amount of thermal power $P$ available from the pond $c a n$ be estimated according to

$$
\mathrm{P}=\mathrm{e} \mathrm{AH},
$$


where $e$ is found from Fig. 8 for a given $\Delta T / H, A$ is the pond surface area, and $H$ is the surface insolation. For the RSGSP

$$
\begin{aligned}
& A=1000 \mathrm{~m}^{2} \text { and } \\
& H=150 \mathrm{~W} \mathrm{~m}^{-2},
\end{aligned}
$$

although the average $\mathrm{H}$ in the summer might be better estimated as $200 \mathrm{~W} \mathrm{~m}^{-2}$. 


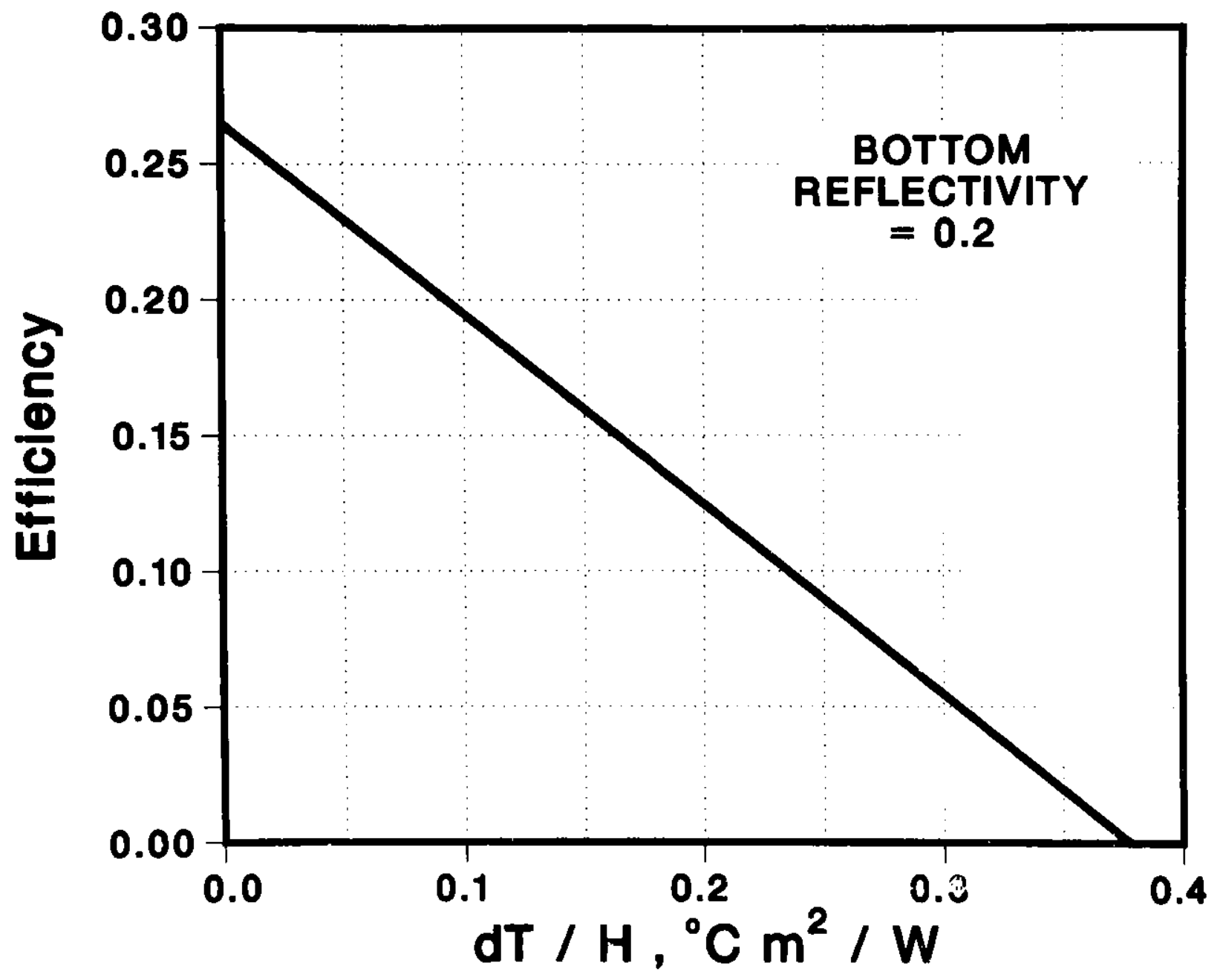

Fig. 8. Calculated thermal efficiency of RSGSP 


\section{DESIGN OF SUBMERGED HEAT EXCHANGER}

The submerged heat exchanger (SHEX) used in the RSGSP was donated by the Calmac Manufacturing Corp., Englewood, New Jersey. The heat exchanger consists of plastic tubes placed in the heat storage zone of the pond. A mixture of approximately $50 \%$ freshwater and $50 \%$ ethylene glycol is circulated in the tubes to extract heat from the solar pond. The tube material is polypropylene with $0.95 \mathrm{~cm}(3 / 8 \mathrm{in.})$ inside diameter, and $1.27 \mathrm{~cm}(1 / 2 \mathrm{in.})$ outside diameter. Polypropylene should easily withstand the high temperatures and salinity encountered in the solar pond. The tubes are similar to the polyethylene heat exchange tubes used previously in a phase-change material experiment at ANL [30].

\subsection{PRELIMINARY DESIGN CONSIDERATIONS}

This section examines the considerations involved in the design of the submerged heat exchange system.

There will be about 50 tubes in the submerged heat exchanger, each $\sim 30$ $\mathrm{m}$ (100 ft) long. There will be a separate inlet and outlet manifold for the tubes; each manifold will be located on shore for ease of maintenance. The heat exchanger is a double-pass unit, with each tube entering the pond from the bank, looping back after $\sim 12 \mathrm{~m}(40 \mathrm{ft})$ and returning to the same bank. The submerged heat exchanger will be located in the northwest quadrant of the solar pond, oriented in an east-west direction, as shown in Fig. 9. The tubes will enter and leave the pond on the west bank.

by

The amount of heat extracted by the submerged heat exchanger is given

$$
q_{\text {ext }}=\left(m C_{p}\right)\left[1-\exp \left(\frac{-U A}{m C_{p}}\right)\right]\left(T_{H S Z}-T_{i n, p l a s}\right),
$$

where

$$
\begin{aligned}
& \mathrm{q}_{\text {ext }} \text { is the rate at which heat is extracted, } \\
& \mathrm{m} \text { is the flow rate of the fluid within the tubes, } \\
& \mathrm{C}_{\mathrm{p}} \text { is the heat capacity of the fluid within the tubes, } \\
& \mathrm{J} \text { is the heat transfer coefficient of the heat exchanger, } \\
& \mathrm{A} \text { is the surface area of the heat exchanger, } \\
& \mathrm{T}_{\mathrm{HSZ}} \text { is the temperature of the heat storage zone, and } \\
& \mathrm{T}_{\text {in,plas }} \text { is the fluid inlet temperature to the plastic tubes. }
\end{aligned}
$$

The heat transfer between the tubes and the solar pond is due to natural convection, and can be estimated from

$$
R a_{D}=\frac{g \alpha \Delta T D^{3}}{\nu k},
$$




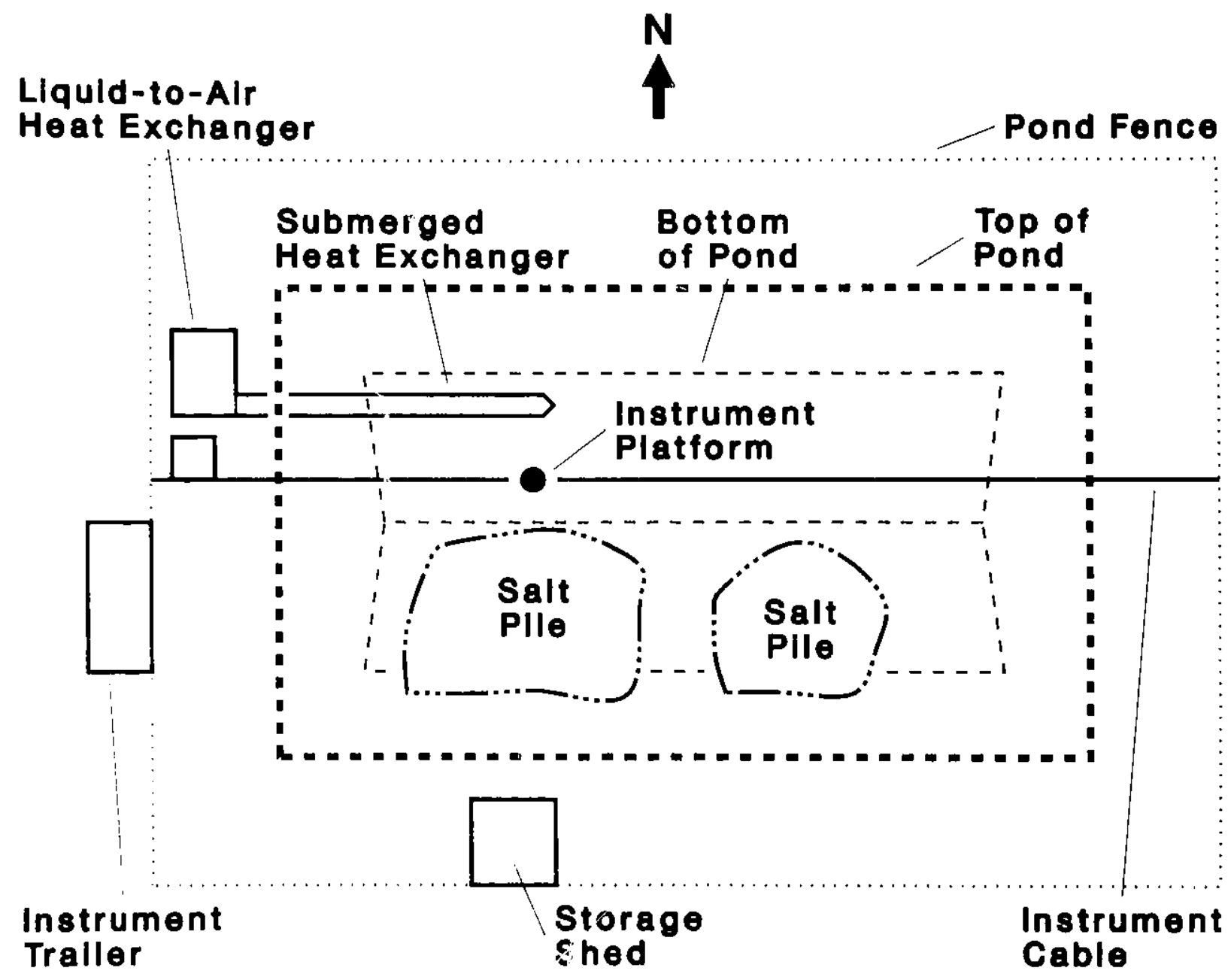

Fig. 9. Location of submerget heat exchanger in RSGSP 
where

Ra is the thermal Rayleigh number,

$g=9.8 \mathrm{~m} \mathrm{~s}^{-2}$, is the acceleration of gravity,

$\alpha$ is the coefficient of thermal expansion,

$\Delta \mathrm{T}$ is the temperature difference between the outside surface of the tubes and the pond,

$D=1.27 \mathrm{~cm}$ is the tube outside diameter,

$\checkmark$ is the kinematic viscosity of the pond fluid, and

$\kappa$ is the thermal diffusivity of the pond fluid.

According to the table of salt water physical properties [31], for a salinity of $20 \%$

$$
\begin{aligned}
& \mathrm{T}=30^{\circ} \mathrm{C} \quad \mathrm{T}=50^{\circ} \mathrm{C} \quad \mathrm{T}=70^{\circ} \mathrm{C} \\
& \begin{array}{llll}
\nu= & 1.1 \times 10^{-6} \mathrm{~m}^{2} \mathrm{~s}^{-1} & 7.4 \times 10^{-7} \mathrm{~m}^{2} \mathrm{~s}^{-1} & 5.6 \times 10^{-7} \mathrm{~m}^{2} \mathrm{~s}^{-1} \\
\kappa= & 1.8 \times 10^{-9} \mathrm{~m}^{2} \mathrm{~s}^{-1} & 2.8 \times 10^{-9} \mathrm{~m}^{2} \mathrm{~s}^{-1} & 4.0 \times 10^{-9} \mathrm{~m}^{2} \mathrm{~s}^{-1} \\
\alpha= & 4.2 \times 10^{-4}{ }^{\circ} \mathrm{C}^{-1} & 5.2 \times 10^{-4}{ }^{\circ} \mathrm{C}^{-1} & 4.8 \times 10^{-4}{ }^{\circ} \mathrm{c}^{-1}
\end{array} \\
& \begin{aligned}
\operatorname{Ra}_{D}= & 4.8 \times 10^{7}\left(\Delta \mathrm{T}=10^{\circ} \mathrm{C}\right) \\
& 4.8 \times 10^{6}\left(\Delta \mathrm{T}=1.0^{\circ} \mathrm{C}\right) \\
& 1.6 \times 10^{6}\left(\Delta \mathrm{T}=0.3^{\circ} \mathrm{C}\right)
\end{aligned}
\end{aligned}
$$

The heat flow for laminar free convection ( $\mathrm{Ra}<10^{9}$ ) from a horizontal cylinder is given by Eq. 6-47 and Table 6 of Ref. 32 as

$$
\mathrm{Nu}=0.47 \mathrm{Ra}^{0.25} \text {, }
$$

where $\mathrm{Nu}$ is the Nusselt number, which is the ratio of total heat flow to purely conductive heat flow.

$$
\begin{aligned}
& \mathrm{Nu}=39 \text { for } \Delta \mathrm{T}=10^{\circ} \mathrm{C}, \\
& \mathrm{Nu}=22 \text { for } \Delta \mathrm{T}=1.0^{\circ} \mathrm{C}, \text { and } \\
& \mathrm{Nu}=17 \text { for } \Delta \mathrm{T}=0.3^{\circ} \mathrm{C} \text {. }
\end{aligned}
$$

A good approximation of the heat transfer is

$$
h_{\text {nat }}=\mathrm{Nu} K / \mathrm{D} \text {, }
$$

where $h_{\text {nat }}$ is the heat flow conductance due to natural convection. For $\Delta T=1.0^{\circ} \mathrm{C}$,

$$
\mathrm{h}_{\mathrm{nat}}=(22)\left(0.62 \mathrm{~W} \mathrm{~m}^{-1}{ }^{\circ} \mathrm{C}^{-1}\right) /(0.0127 \mathrm{~m})=1.07 \mathrm{~kW} \mathrm{~m}{ }^{-2}{ }^{\circ} \mathrm{c}^{-1}
$$

The tube wall conductance $h_{\text {tube }}$ can be estimated as

$$
h_{\text {tube }}=k_{\text {tube }} / d \text {, }
$$


where $k_{\text {tube }}$ is the thermal conductivity of the tube and $d=1.59 \times 10^{-3} \mathrm{~m}(1 / 16$ in.) is the tube wall thickness.

The handbook value [33] for the thermal conductivity of polypropylene ranges from 0.084 to $0.173 \mathrm{~W} \mathrm{~m}^{-10} \mathrm{C}^{-1}$. We have chosen the lower value for calculation here. We note that polyethylene has a thermal conductivity of $0.33-0.42 \mathrm{~W} \mathrm{~m}^{-1}$ ${ }^{\circ} \mathrm{C}^{-1}$, and high-density polyethylene has a thermal conductivity of $0.46-0.52 \mathrm{~W}$ $\mathrm{m}^{-1}{ }^{\circ} \mathrm{C}^{-1}[33]$. Newer formulations of high-density polyethylene, that can withstand high temperature, may be appropriate for a solar pond heat exchanger; however, most varieties of commercially available polyethylene cannot be used at the design temperature of the pond. Using the conservative value for $k_{\text {tube, }}$

$$
h_{\text {tube }}=(0.084) /(0.00159)=52.8 \mathrm{w} \mathrm{m}^{-2}{ }^{\circ} \mathrm{C}^{-1} \text {. }
$$

Note that $h_{\text {tube }}$ is about $5 \%$ of $h_{\text {nat }}$. Thus, even though $h_{\text {nat }}$ will vary along the length of the tube, the tube conductivity will be the dominating thermal resistance along most of the heat exchanger. However, because $h_{\text {nat }}$ is a function of $\Delta \mathrm{T}$, which changes along the length of the tube, we will need to calculate $\Delta T$ at several positions along the tube in the final calculation.

It is expected that dirt and other debris settling into the pond, as well as possible algae growth, will contribute to fouling of the outside of the submerged heat exchanger. We estimate a conservative outside fouling conductance of

$$
\mathrm{h}_{\mathrm{fo}}=1.14 \mathrm{~kW} \mathrm{~m}-2{ }^{\circ} \mathrm{C}^{-1} \text {. }
$$

Again, this is very large compared with $h_{\text {tube }}$.

\subsubsection{Fresh Water through P1astic Tubes}

To determine the heat transfer coefficient for the heat exchanger, we need the thermal conductance from the heat exchange fluid to the tubes. If fresh water is the fluid, the system will be closed. We ignore the conductance of forced convection within the tubes, which will be very large. But we will use an inside fouling conductance of

$$
\mathrm{h}_{\mathrm{fi}}=2.84 \mathrm{~kW} \mathrm{~m}{ }^{-2}{ }^{\circ} \mathrm{C}^{-1} \text {. }
$$

The overall heat transfer coefficient $U$ is given by

$$
1 / \mathrm{U}=1 / \mathrm{h}_{\text {nat }}+1 / \mathrm{h}_{\mathrm{fo}}+1 / \mathrm{h}_{\text {tube }}+\left(\mathrm{A}_{\mathrm{o}} / \mathrm{A}_{\mathrm{i}}\right) / \mathrm{h}_{\mathrm{fi}}
$$

where $A_{0}$ is the outside surface area, and $A_{i}$ is the inside surface area of the heat exchange tubes. In our case $A_{0} / A_{i}=1.34$, and 
$\mathrm{U}=47.1 \mathrm{~W} \mathrm{~m}^{-2}{ }^{\circ} \mathrm{C}^{-1}$

For $\mathrm{N}$ tubes of $30 \mathrm{~m}$ length,

$$
q_{e x}=\left(m c_{p}\right)\left[1-\exp \left(\frac{-U A_{\text {tube }} N}{m C_{p}}\right)\right]\left(T_{H S Z}-T_{1 n, t u b e}\right) .
$$

For the propylene tubes,

$$
A_{\text {tube }}=\pi D L=(3.14159)(0.0127 \mathrm{~m})(30 \mathrm{~m})=1.02 \mathrm{~m}^{2}
$$

and

$$
\begin{aligned}
\mathrm{m} \mathrm{C}_{\mathrm{p}} & =1.32 \mathrm{~kW}{ }^{\circ} \mathrm{C}^{-1} \text { at } 0.019 \mathrm{~m}^{3} / \mathrm{min}(5 \mathrm{gpm}) \\
& =2.64 \mathrm{~kW}{ }^{\circ} \mathrm{C}^{-1} \text { at } 0.038 \mathrm{~m}^{3} / \mathrm{min}(10 \mathrm{gpm}) \\
& =6.60 \mathrm{~kW}{ }^{\circ} \mathrm{C}^{-1} \text { at } 0.095 \mathrm{~m}^{3} / \mathrm{min}(25 \mathrm{gpm}) .
\end{aligned}
$$

We assume $\mathrm{T}_{\mathrm{HSZ}}=60^{\circ} \mathrm{C}$, and $\mathrm{T}_{\text {In, tube }}=30^{\circ} \mathrm{C}$.

$$
\begin{aligned}
q_{e x} & =(39.6 \mathrm{~kW})[1-\exp (-0.043 \mathrm{~N})] \text { for } 0.019 \mathrm{~m}^{3} / \mathrm{min}, \\
& =(79.2 \mathrm{~kW})[1-\exp (-0.021 \mathrm{~N})] \text { for } 0.038 \mathrm{~m}^{3} / \mathrm{min}, \\
& =(198 \mathrm{~kW})[1-\exp (-0.0086 \mathrm{~N})] \text { for } 0.095 \mathrm{~m}^{3} / \mathrm{min} .
\end{aligned}
$$

With a constant heat storage zone temperature $T_{H S Z}$, the outlet temperature from the heat exchanger is given by

$$
\mathrm{T}_{\text {out }, \text { tube }}=\mathrm{T}_{\mathrm{HSZ}}-\left(\mathrm{T}_{\mathrm{HSZ}}-\mathrm{T}_{\text {In, tube }}\right) \exp \left(\frac{-\mathrm{UA_{ \text {tube } } \mathrm { N }}}{\mathrm{m \textrm {C } _ { \mathrm { p } }}}\right) \text {. }
$$

The amount of extracted heat and the outlet temperature as a function of flow rate and number of tubes are presented in Table 1. The optimum number of tubes is probably 50, which results in acceptable outlet temperatures for a heat extraction rate between 30 and $60 \mathrm{~kW}$. If the thermal conductivity of the polypropylene tubes is higher than the conservative value used in the calculations, then the thermal performance of the heat exchanger would be better. The foullng factor is not well known, but presumably would be low because a brush could be Iun over the tubes perlodically. 
Table 1. Thermal Performance of Polypropylene Heat Exchanger as a Function of Flow Rate and Number of Tubes*

\begin{tabular}{|c|c|c|c|}
\hline $\begin{array}{c}\text { Flow Rate } \\
\mathrm{m} \\
\mathrm{m}^{3} / \mathrm{min} \\
\end{array}$ & $\begin{array}{l}\text { No. of } \\
\text { Tubes } \\
(\mathrm{N})\end{array}$ & $\begin{array}{l}\text { Heat } \begin{array}{l}\text { Extracted } \\
\mathrm{q}_{\mathrm{ex}} \\
\mathrm{kW} \\
\end{array} \\
\end{array}$ & $\begin{array}{l}\text { Outlet Temp. } \\
\mathrm{T}_{\text {out }} \text {, tube } \\
{ }^{\circ} \mathrm{C} \\
\end{array}$ \\
\hline 0.019 & 10 & 13.9 & 40.5 \\
\hline 0.019 & 20 & 22.8 & 47.3 \\
\hline 0.019 & 50 & 35.0 & 56.5 \\
\hline 0.019 & 100 & 39.1 & 59.6 \\
\hline 0.038 & 10 & 15.0 & 35.7 \\
\hline 0.038 & 20 & 27.2 & 40.3 \\
\hline 0.038 & 50 & 51.5 & 49.5 \\
\hline 0.038 & 100 & 69.5 & 56.3 \\
\hline 0.095 & 10 & 16.0 & 32.6 \\
\hline 0.095 & 20 & 31.5 & 34.8 \\
\hline 0.095 & 50 & 69.3 & 40.5 \\
\hline 0.095 & 100 & 114.2 & 47.3 \\
\hline
\end{tabular}

To calculate the pressure drop through the heat exchanger, we need the Reynolds number

$$
\mathrm{Re}=\mathrm{u}_{\mathrm{av}} \mathrm{D}_{\text {in }} i v \text {, }
$$

where $v=5.6 \times 10^{-7} \mathrm{~m}^{2} \mathrm{~s}^{-1}$ for fresh water at $50^{\circ} \mathrm{C}$ and $u_{a v}$ is the average flow velocity given by $u_{a v}=m /(r A N)$,

where $r$ is the fluid density and $A$ is the flow area of a single tube. At $m=$ $0.038 \mathrm{~m}^{3} / \mathrm{min}(10 \mathrm{gpm}), \mathrm{u}_{\mathrm{av}}=0.18 \mathrm{~m} \mathrm{~s}^{-1}$ and $\mathrm{Re}=3050$. For a relatively smooth pipe at this Reynolds number, the friction factor is [34]

$$
f=0.05 \text {. }
$$

The pressure drop is given by

$$
\begin{aligned}
\mathrm{dP} & =\frac{\mathrm{f} \mathbf{r} \mathbf{u}_{\mathrm{av}}^{2} \mathrm{dx}}{2 \mathrm{D}_{\mathrm{ln}}}, \\
& =2560 \mathrm{~Pa} .
\end{aligned}
$$

This 1s equivalent to $0.37 \mathrm{psi}$. The total pressure drop probably is about $14,000 \mathrm{~Pa}(\sim 2 \mathrm{ps}:)$ when bends and couplings are considered. 


\subsubsection{Air through Plastic Tubes}

Again, using a 50 tube heat exchanger, we will calculate heat exchanger performance when air is used as the heat exchange medium. In this case the system probably would be open, i.e., ambient air would enter at the inlet and the heated air would exit the heat exchanger and pass directly to the load.

The density of air is $1.3 \mathrm{~kg} \mathrm{~m}^{-3}$. The heat capacity is about $1000 \mathrm{~J} \mathrm{~kg}^{-1}$. The kinematic viscosity of air is $1.8 \times 10^{-5} \mathrm{~m}^{2} \mathrm{~s}^{-1}$. If we wish to obtain a heat extraction of $50 \mathrm{~kW}$ with a temperature increase of $15^{\circ} \mathrm{C}$, we need an air flow rate of $2.58 \mathrm{~m}^{3} \mathrm{~s}^{-1}(5470 \mathrm{cfm})$. At $30 \mathrm{~kW}$ and the same temperature increase, the air flow rate would be $1.55 \mathrm{~m}^{3} \mathrm{~s}^{-1}(3280 \mathrm{cfm})$. For our calculations, we chose $1.89 \mathrm{~m}^{3} \mathrm{~s}^{-1}(4000 \mathrm{cfm})$.

The Reynolds number in the tubes is given by Eq. 13 with

$$
u_{\mathrm{av}}=\frac{1.89}{50 \pi(0.00475)^{2}}=533 \mathrm{~m} \mathrm{~s}-1 \text {, }
$$

and

$$
\operatorname{Re}=2.8 \times 10^{5}
$$

The friction factor [34] is 0.02 , and from Eq. 14, the pressure drop is

$$
\Delta \mathrm{P}=\frac{(0.02)(1.3)(533)^{2}(30)}{2(0.0095)}=1.16 \times 10^{7} \mathrm{~Pa}
$$

This is equivalent to 100 atmospheres of pressure. The equipment needed to generate this much pressure would be too expensive and energy-intensive for economic use in solar pond applications, so this option is not considered.

\subsubsection{Liquid-to-Air Heat Exchanger}

The liquid-to-air heat exchanger uses hot fluid from the solar pond to heat ambient air. In a commercial application the heated air would then be used to dry grain, heat a building, etc.

A schematic diagram of the liquid-to-air heat exchanger is shown in Fig. 10. Starting from the inlet on the left, an air blower sends ambient air through a duct system consisting of filter, flow straighteners, diverting vanes, heat exchanger, flow control gate, and exit. The filter bank keeps fouling of the external part of the heat exchanger to a minimum and prevents dust and debris from entering the space to be heated. The air flow is measured in the flow straightener section. The optional diverter vanes are used if there is more than one brine loop, so that parts of the heat exchanger can be idle, depending on the particular operating conditions. The heat exchanger consists of tubes filled with hot brine (or water) from the pond. The air is 
heated as it passes over the tubes. The gate near the exit is used to control the air flow rate, in lieu of a variable-speed motor for the blower.

\section{Estimation of Flow Rates}

We use the effectiveness method (see Sec. 18-4 in Ref. 31) for the design approach. Typical effectiveness values can be assigned, along with desired energy extraction rates and temperatures, for determination of system flow rates. Effectiveness values up to 0.65 are typical of this type of exchanger. Values of 0.5 are common and more probable for site-built systems. For an initial estimate, we assume an effectiveness $e=0.5$. The desired extraction rate from the ANL pond is $30 \mathrm{~kW}$ (60 kW peak), which is $\sim 30 \mathrm{~W} \mathrm{~m}^{-2}$ $\left(60 \mathrm{~W} \mathrm{~m}^{-2}\right.$ peak).

We assume an average summer temperature of $\sim 30^{\circ} \mathrm{C}$, and an average $\mathrm{HSZ}$ temperature of $60^{\circ} \mathrm{C}$. Unless too much heat is extracted, this temperature difference should persist well into the fall. Under these conditions

$$
q_{\text {ext }}=e C_{\min }\left(T_{h, \text { in }}-T_{c, \text { in }}\right) \text {, }
$$

where

$$
\begin{aligned}
& q_{\text {ext }} \text { is the net rate at which heat is extracted, in } W \text {, } \\
& e \text { is the effectiveness of the heat exchanger, } \\
& \mathrm{C}_{\text {mir. }}=\mathrm{mC}_{\mathrm{p}} \text { is the minimum of } \mathrm{C}_{\text {air }} \text { and } \mathrm{C}_{1 \text { iq }} \text {, } \\
& \text { in is the mass flow rate, in } \mathrm{kg} \mathrm{s}^{-1} \text {, } \\
& \mathrm{C}_{\mathrm{p}} \text { is the heat capacity of the fluid, in } \mathrm{J} \mathrm{kg}^{-1}{ }^{\circ} \mathrm{C}^{-1} \text {, } \\
& \mathrm{T}_{h \text {, in }} \text { is the inlet temperature of the hot side (i.e. pond } \\
& \text { side) of the heat exchanger, and } \\
& \mathrm{T}_{\mathrm{c} \text {, in }} \text { is the inlet temperature of the cold side (i.e. air } \\
& \text { side) of the heat exchanger. }
\end{aligned}
$$

We obtain $\mathrm{C}_{\min }$ by

$$
\mathrm{C}_{\min }=(30 \mathrm{~kW}) /(0.5)\left(30^{\circ} \mathrm{C}\right)=2 \mathrm{~kJ} \mathrm{~s}^{-1}{ }^{\circ} \mathrm{C}^{-1}
$$

If we assume that both the liquid and air sides of the heat exchanger will have essentially the same r.ass flow rates, i.e., $C_{\min }=C_{\mathrm{H}_{2} \mathrm{O}}=\mathrm{C}_{\mathrm{air}}$, and with

$$
\begin{aligned}
& C_{p, H_{2} \mathrm{O}}=4.2 \mathrm{~kJ} \mathrm{~kg}^{-1}{ }^{\circ} \mathrm{C}^{-1}, \\
& \mathrm{C}_{\mathrm{p}, \mathrm{air}}=1.0 \mathrm{~kJ} \mathrm{~kg}^{-1}{ }^{\circ} \mathrm{C}^{-1},
\end{aligned}
$$

then

$$
\mathrm{m}_{\mathrm{H}_{2} \mathrm{O}}=\mathrm{C}_{\mathrm{min}} / \mathrm{C}_{\mathrm{p}, \mathrm{H}_{2} \mathrm{O}}=0.476 \mathrm{~kg} \mathrm{~s}^{-1}(7.5 \mathrm{gpm})
$$




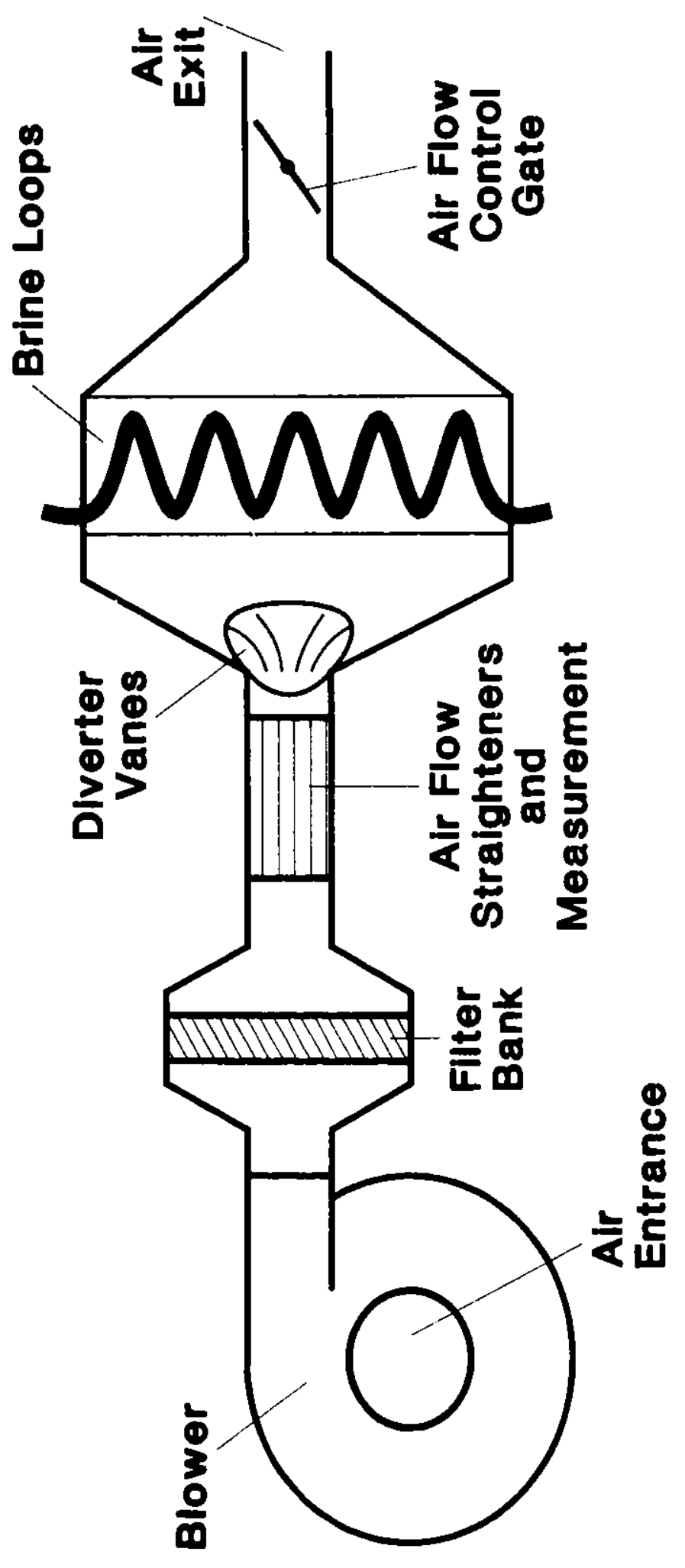

Fig. 10. Schematic of liquid-to-air heat exchanger 
and

$$
m_{a i r}=c_{\min } / C_{p, a i r}=2.0 \mathrm{~kg} \mathrm{~s}^{-1}(3500 \mathrm{cfm}) \text {. }
$$

These flow rates seem reasonable and are within available equipment ranges. The temperature differences for this case are:

$$
\Delta \mathrm{T}_{\text {air }}=\Delta \mathrm{T}_{\mathrm{H}_{2} \mathrm{O}}=15^{\circ} \mathrm{C},
$$

which also appear reasonable.

Duct sizing

From the previous estimate, air flows of $\sim 3500 \mathrm{cfm}$ are expected for average conditions. Assuming that a peak demand essentially doubles the air flow (to maintain a similar $\mathrm{dT}_{a i r}$ ), duct sizing will be estimated on the basis of $7500 \mathrm{cfm}$.

Reasonable duct velocities are $2000 \mathrm{fpm}$ to keep friction losses at a minimum, so the duct area is

$$
A_{\text {duct }}=7500 \mathrm{cfm} / 2000 \mathrm{fpm}=0.348 \mathrm{~m}^{2}\left(3.75 \mathrm{ft}^{2}\right) \text {. }
$$

Although friction losses are different for rectangular and circular ducts, for now we assume that they are the same. The duct should be $\sim 60$ by $60 \mathrm{~cm}$ ( 24 by 24 in.), or $\sim 66 \mathrm{~cm}$ in diameter for a circular duct. The actual shape will depend on the blower and heat exchanger configurations.

\section{Heat Exchanger}

From manufacturers' catalogs (e.g., p. 103 of Ref. 35), the 1iquid-toair heat exchanger size can be estimated. For a typical model (\#1208) with a liquid flow rate of $0.75 \mathrm{~L} / \mathrm{s}(12 \mathrm{gpm})$ and an air flow rate of $0.566 \mathrm{~m}^{3} \mathrm{~s}^{-1}$ $(1200 \mathrm{cfm})$,

$$
\begin{aligned}
& \mathrm{q}_{\text {ext }}=2.5 \mathrm{~kW}(70,000 \mathrm{Btu} \mathrm{hr}-1), \\
& \mathrm{T}_{\mathrm{h}, \text { in }}=82.2^{\circ} \mathrm{C}\left(180^{\circ} \mathrm{F}\right), \\
& \mathrm{T}_{\mathrm{h}, \text { out }}=75.7^{\circ} \mathrm{C}\left(168.3^{\circ} \mathrm{F}\right), \text { and } \\
& \mathrm{T}_{\mathrm{c}, \text { out }}=45.3^{\circ} \mathrm{C}\left(113.5^{\circ} \mathrm{F}\right) .
\end{aligned}
$$

We can solve for

$$
T_{c, \text { in }}=T_{c, \text { out }}-q_{\text {ext }} / c_{a i r}
$$


Assuming an average $r C_{p, a i r}=1150 \mathrm{~J} \mathrm{~m}^{-3}{ }^{\circ} \mathrm{C}^{-1}$,

$$
\mathrm{T}_{\mathrm{c}, \text { in }}=13.8^{\circ} \mathrm{C}\left(56.8^{\circ} \mathrm{F}\right) \text {. }
$$

We must next determine $C_{\min }$.

$$
\begin{aligned}
& \mathrm{C}_{1 \mathrm{iq}}=\left(0.886 \mathrm{~kg} \mathrm{~s}^{-1}\right)\left(4186 \mathrm{~J} \mathrm{~kg}^{-1}{ }^{\circ} \mathrm{C}^{-1}\right)=3710 \mathrm{~W}^{\circ} \mathrm{C}^{-1}, \\
& \mathrm{C}_{\mathrm{air}}=\left(0.651 \mathrm{~kg} \mathrm{~s}^{-1}\right)\left(1000 \mathrm{~J} \mathrm{~kg}^{-1}{ }^{\circ} \mathrm{C}^{-1}\right)=651 \mathrm{~W}^{\circ} \mathrm{C}^{-1}
\end{aligned}
$$

$C_{a i r}$ is the minimum. Now calculate the effectiveness e by

$$
e=q_{\text {act }} / q_{\max } \text {, }
$$

where

$$
\begin{aligned}
& q_{\text {act }} \text { is the actual rate of heat removal and } \\
& q_{\max } \text { is the maximum possible rate of heat extraction, } \\
& \text { determined by setting } e=1.0 \text { in Eq. } 15 . \\
& e=(20,500) /[(651)(82.2-13.8)]=0.460 .
\end{aligned}
$$

According to the catalog, the physical parameters of the exchanger are 15 by 20-in. face area, two tube rows, $10 \mathrm{fins}$ per inch (FPI), and $7 / 8$ in. diameter tubes.

The heat extraction rate is a little more than $20 \mathrm{~kW}$, so three parallel units of the above exchanger would give adequate peaking capacity for the pond.

Two units of the above exchanger can be arranged in series to obtain a higher air outlet temperature under the same flow conditions. The effectiveness of each unit $(e=0.46)$ is the same. The effectiveness of this four-row exchanger (assuming the previous given conditions) would be

$$
\begin{aligned}
q_{1} & =20.5 \mathrm{~kW}, \\
q_{2} & =c_{\min }\left(T_{2 h, \text { in }}-T_{2 c, \text { in }}\right)=(0.460)\left(651 \mathrm{w}^{\circ} \mathrm{C}^{-1}\right)\left(75.7^{\circ} \mathrm{C}-45.3^{\circ} \mathrm{C}\right) \\
& =9.1 \mathrm{~kW}, \\
q_{\text {tot }} & =q_{1}+q_{2}=29.6 \mathrm{~kW} .
\end{aligned}
$$

The overall effectiveness of this series of two unit exchangers is

$$
e=(29600) /[(651)(82.2-13.8)]=0.665
$$


The outlet temperatures from the second stage are

$$
\begin{aligned}
& \mathrm{T}_{\text {liq, out }}=75.7-(9100) /(3710)=73.2^{\circ} \mathrm{C}\left(163.8^{\circ} \mathrm{F}\right), \\
& \mathrm{T}_{\text {air, out }}=45.3+(9100) /(651)=59.3^{\circ} \mathrm{C}\left(138.7^{\circ} \mathrm{F}\right) .
\end{aligned}
$$

In this case, two parallel banks of the two unit series would give the needed peaking capacity. The face area dimensions are then 30 by $20 \mathrm{in.}$, with four tube rows and $10 \mathrm{FPI}$.

\subsection{FINAL DESIGN OF SUBMERGED HEAT EXCHANGER SYSTEM}

In this section the complete SHEX system is fully described, including construction, deployment, and system instrumentation. Figure 11 shows a schematic of the system, which consists of the following components:

- Submerged plastic-tube heat exchanger,

- Liquid pumping system,

- Liquid-to-air heat exchanger,

- Air handling system, and

- Instrumentation.

The approximate cost of the submerged heat extraction system is summarized in Table 2 .

Table 2. Cost of Submerged Heat Extraction System

\begin{tabular}{lr}
\hline & $\begin{array}{r}\text { Cost, } \\
\text { Item } \\
\end{array}$ \\
\hline & \\
Submerged HX & 4,500 \\
Pump & 750 \\
Filter & 500 \\
Hoses, Valves, \& Insulation & 500 \\
Liquid-to-Air HX & 900 \\
Blower & 1,150 \\
Ductwork & 2,000 \\
Electrical & 500 \\
\multicolumn{1}{c}{ Total } & \\
& \\
\hline
\end{tabular}




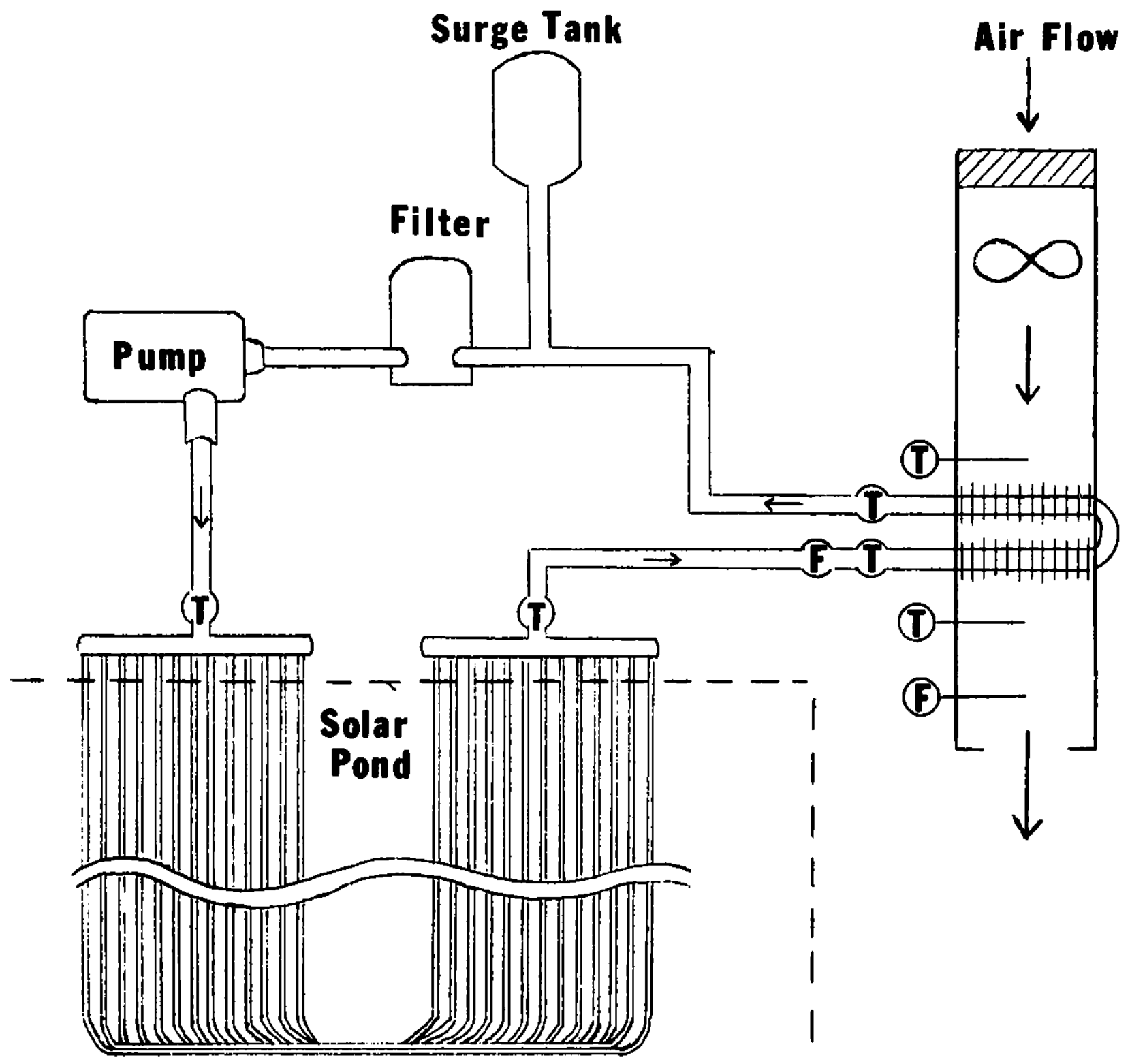

Fig. 11. Schematic of submerged plastic tube heat exchange system 


\subsubsection{Submerged P1astic-Tube Heat Exchanger}

The plastic-tube heat exchanger includes two sets of polypropylene tubes. Each set contains twenty-three tubes that are $45.7 \mathrm{~m}$ long, have an inner diameter of $0.94 \mathrm{~cm}$, and a wall thickness of $0.16 \mathrm{~cm}$. Each tube connects to a cPVC inlet header, runs horizontally for about half of its length, then loops around and returns to a CPVC outlet header that is adjacent to the inlet header. Polypropylene strips containing circular slots are used to keep the tubes evenly spaced. The strips attach to the tubes perpendicularly, and are spaced about $0.45 \mathrm{~m}$ from each other.

To provide more rigidity to each set of polypropylene tubes, a backbone structure was constructed of $2 \mathrm{in.} \mathrm{Schedule} 80$ CPVC pipe. The backbone consists of three $16 \mathrm{~m}$ lengths of pipe running the length of the tubes, and three $1.8 \mathrm{~m}$ lengths of pipe lashed perpendicularly to the longer lengths to keep them evenly spaced. The cross pipes are spaced about $5 \mathrm{~m}$ apart, and are banded to the longer lengths by plastic cables. Two heat exchange mats with planar dimensions of about $25 \mathrm{~m}$ by $2 \mathrm{~m}$ were fabricated by attaching each of the two sets of polypropylene tubes to its own backbone structure using plastic cable ties. Photographs of one of the heat exchange mats are shown in Figures 12 and 13.

All the submerged portions of the heat exchange mats are made of polypropylene or CPVC because these materials are reliable under the temperature and salinity conditions of the solar pond. These two plastics do not experience the corrosion problems that most metals do in the salt water of a solar pond, and, unlike some other plastics, they are able to withstand its high temperatures. Because of its higher thermal conductivity, polyethylene would be preferred over polypropylene for the fabrication of the heat exchange tubes. But experience in the $U$. $S$. has indicated that high-density polyethylene cannot withstand the high temperatures of solar ponds. Pacetti and Principi [36] indicate that a type of high-density polyethylene pipe that appears to be able to withstand solar pond temperatures has recently become available in Europe. If this type of polyethylene proves reliable, it could be used in future solar pond heat exchangers.

When installed in the solar pond, the submerged plastic-tube heat exchanger has the following configuration. The inlet header is situated on the berm of the pond so that the plastic joints between the header and the tubes can be easily accessed. From the inlet header the tubes follow the pond bank down for about $6 \mathrm{~m}$ of tube length into the heat storage zone of the pond. Once in the storage zone, the tubes attach to the backbone structure and run horizontally for about $16 \mathrm{~m}$ before looping back and returning to the bank from which they started. From there, they detach from the backbone structure and follow the bank for about $6 \mathrm{~m}$ until they reach the outlet header, which is a acent to the inlet header. In this configuration, the first and the last 6 $\mathrm{m}$ pass through the gradient zone of the pond. This leaves about $34 \mathrm{~m}$ that lie horizontally at the top of the heat. storage zone, about $1 \mathrm{~m}$ above the pond bottom. 


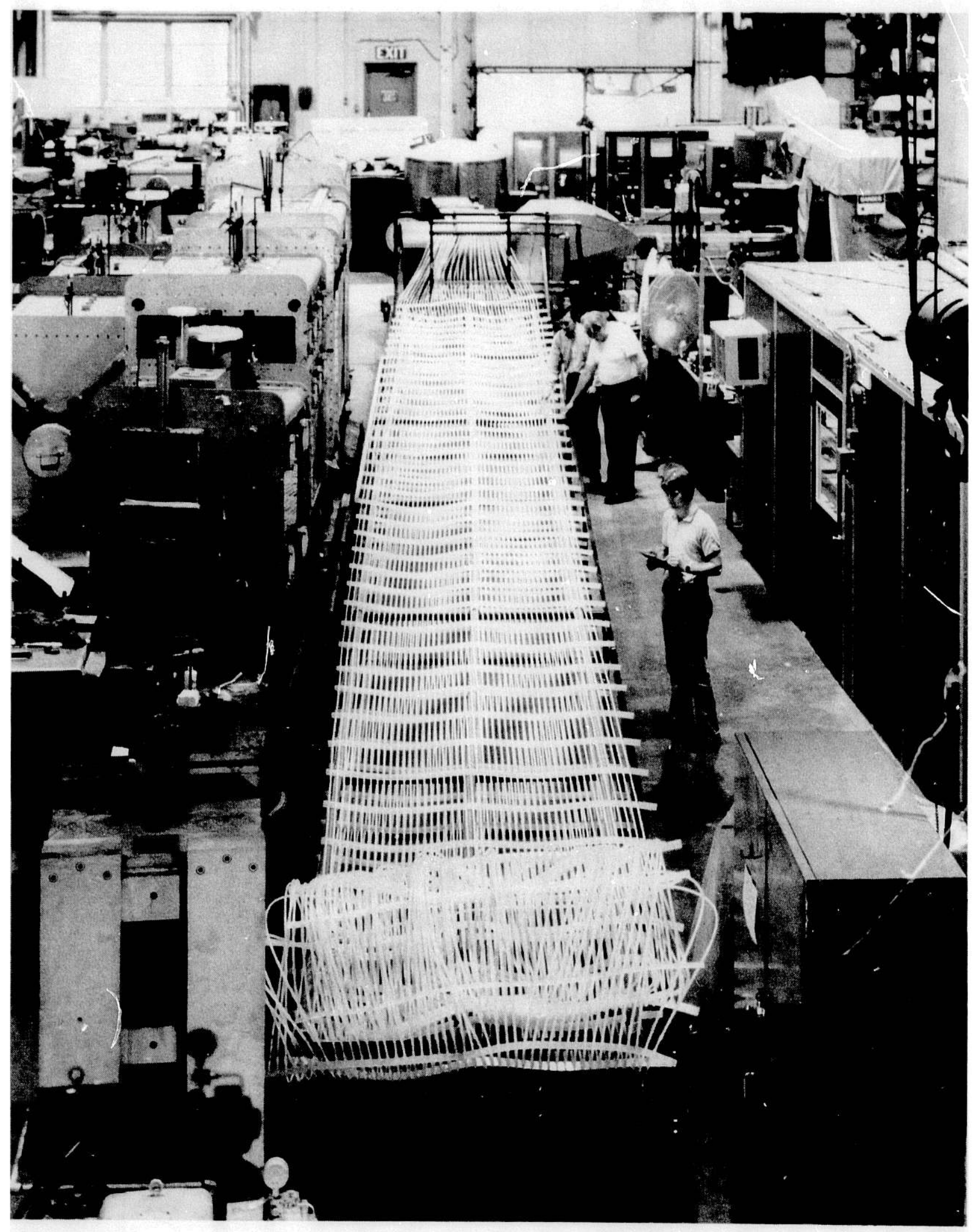

Fig. 12. Heat exchange mat 


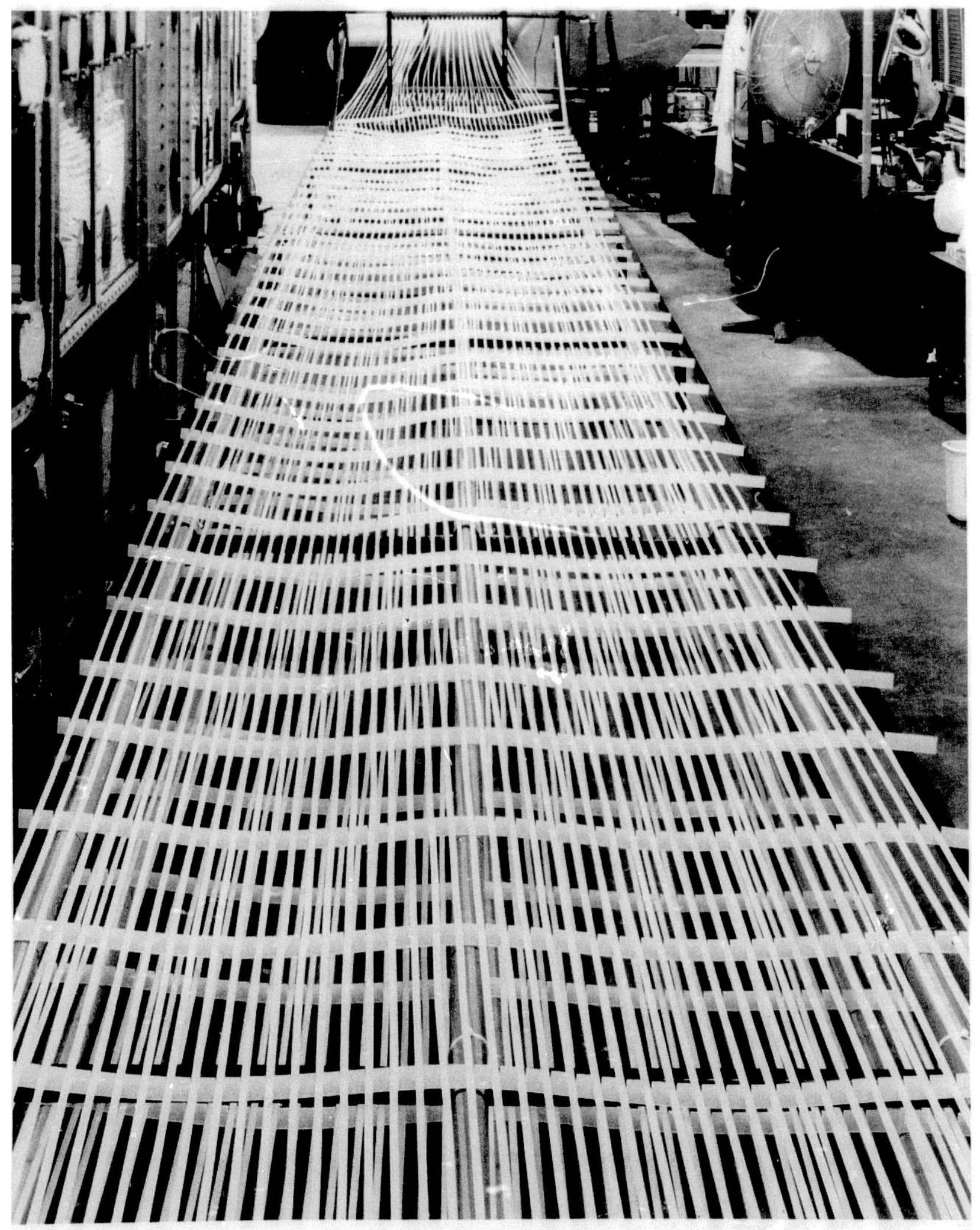

Fig. 13. Closeup of heat exchange mat 
The horizontal portion of the submerged heat exchanger is maintained in its position by suspending it from three lengths of stainless steel aircraft cable that run across the surface of the pond. In order for this method to work, the heat exchanger must sink in the pond's salt water. It was determined that if the mats were filled with a 50/50 mixture of ethylene glycol and water, and were placed in the heat storage zeine of the pond, then a net upward buoyant force of about $200 \mathrm{~N}$ would exist on each mat. To ensure that the mats would sink in the pond's salt water, extra weight was added by distributing cement-filled polypropylene bottles evenly across the mat structures. The mats were then heavy enough to sink in the salt water, and could be suspended from the three lengths of aircraft cable.

When the weights were distributed across the mat structure, the heat exchange mats floated on the pond surface as shown in Fig. 14 when the tubes were filled with air, but sank when filled with the mixture of ethylene glycol and watex. This convenient fact was used to position the mats in the solar pond. The three lengths of aircraft cable that the mats would be suspended from were strung across the pond, then the mats were floated into place between them. Six lengths of polypropylene rope about $3.5 \mathrm{~m}$ long were tied to each mat and to the aircraft cable so that when the mats sank they would be suspended about $3.5 \mathrm{~m}$ from the surface, which is about a meter from the bottom. The ethylene glycol and water mixture was then pumped into the mats, and they sank to their required positions.

When the submerged heat exchangers were installed in the pond, they were situated in the northwest quadrant of the pond, parallel to the north bank. The inlet and outlet manifolds are located on the west bank about $6 \mathrm{~m}$ from the north bank. As described earlier, the heat exchange tubes follow the bank down from the manifolds, through the gradient zone, into the heat storage zone of the pond where they run horizontally about a meter above the pond's bottom. To reduce heat loss from the tubes as they pass through the relatively cold gradient zone of the pond, the inlet and outlet tubes were collected into separate bundles and were wrapped in an insulating material for the upper $5 \mathrm{~m}$ of their length.

It should be emphasized that the SHEX is designed mostly as a research tool and is probably not representative of a commercial device. In a commercial solar pond, where the heat exchanger could be deployed before the pond was filled, the heat exchanger could be anchored to weights placed on the pond bottom. The manifolds would be placed in the HSZ with a single inlet and outlet hose running through the gradient zone to the rest of the heat exchange system. This design was not used in the ANL system because one of the design criteria was that all parts of the system with potential for leaks (e.g., joints between the header and the tubes) were to be easily accessible. In a commercial system, this criterion would not be necessary. 


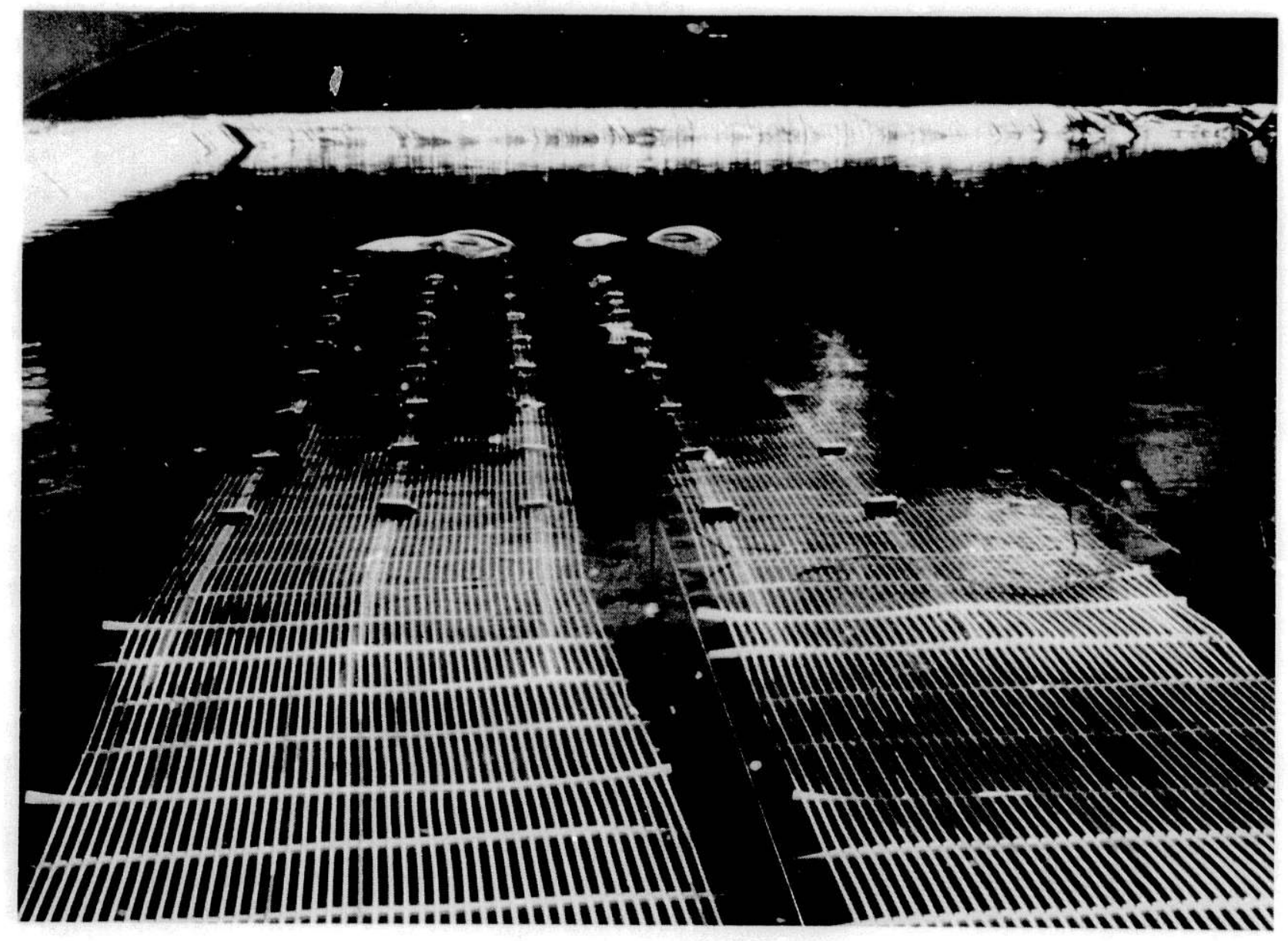

Fig. 14. Submerged heat exchange mats before final deployment 


\subsubsection{Liquid Pumping System}

As shown in Figure 11, the mixture of ethylene glycol and water is pumped through a heat exchange loop, which includes the submerged heat exchanger, a pump, a filter, a surge tank, and the liquid-to-air heat exchanger. The suction side of the pump is connected to the filter and the surge tank, while the pressure side is connected to the submerged heat exchanger. It is a $2 \mathrm{HP}$ centrifugal pump, and is constructed out of CPVC. The filter contains 20micron polypropylene elements, suitable for both fresh water and ethylene glycol soluitions. The filter is placed immediately before the pump on the suction side in order to keep the pump free of any particles that could damage its plastic impeller. Pressure gauges mounted on either side of the filter show a large pressure drop across the filter when the filter tubes need changing. The pressure at the inlet side of the filter is slightly above ambient since it is adjacent to the $2 \mathrm{~m}$ head of the surge tank. The size of the surge tank was chosen by determining the volume change that the ethylene glycol mixture would undergo due to thermal expansion, then selecting a surge tank that was large enough to accommodate this volume change. Because the volume change was estimated to be less than one gallon, a five gallon stainless steel tank was chosen as the surge tank. The surge tank is completely enclosed except for a small hole on top that is open to the atmosphere.

From the manufacturer's pump rating, it was determined that the pump could support a total pressure drop through the loop of about 2.5 atm. This head loss rating was used to select the size of the tubing and hose used to connect the loop components. Pressure drop calculations were performed, assuming various sizes for the tubing, then a satisfactory size was chosen from the tubing readily available in stock. Tubing and hose with an inner diameter of $0.0381 \mathrm{~m}(1.5 \mathrm{in.})$ was chosen since the resulting pressure drop for the system was calculated to be about $1.4 \mathrm{~atm}$, which is under the punp's limit by a safe margin.

The liquid-to-air heat exchanger is a bank of three fin-tube blower coils stacked on top of each other. Eacn coil has four staggered rows of copper tubes covered with aluminum fins on the air side, and has an inlet and an outlet for the ethylene glycol mixture on the liquid side. Each heat exchange coil has a ball valve on the liquid inlet line, and a globe valve on the outlet line. The globe valves allow the flow rate through each coil to be adjusted and controlled, while the ball valves allow any of the coils to be cut of f from flow. In addition, the network contains a bypass line that runs directly from the inlet line to the outlet line. The bypass contains a ball valve, and allows all or part of the flow to be diverted around the liquid-toair heat exchanger. Ball valves are also located on the inlet and outlet of each submerged heat exchanger mat, allowing either or both of the mats to be cut off from flow. 


\subsubsection{Air Handling System}

The air handling system includes a blower, a panel of filters, the fintube liquid-to-air heat exchanger, two aluminum velocity control plates, and associated ductwork. The air side system was designed so that the ambient air would flow through a panel of filters into a blower, which would thrust it through the duct network containing the liquid-to-air heat exchanger and the velocity control plates. The panel of filters is housed in the duct on the suction side of the blower. The filters remove dust and debris from the air entering the blower and therefore limit the fouling on the air side of the liquid-to-aic heat exchanger, and prevent dust from entering the space to be heated. A nonoverloading centrifugal type blower powered by a 3 HP motor was chosen because it is efficient, and can deliver a flow rate larger then the design flow rate of $101 \mathrm{~m}^{3} / \mathrm{min}$. The air flow rate is coitrolled by adjusting two movable aluminum plates at the exit end of the ductwork. These plates block tie exit cross-sectional area of the duct as much as needed, thus controlling the back pressure and the flow rate. When the plates were completely removed, the average air velocity was measured to be $5.92 \mathrm{~m} / \mathrm{s}$, which corresponds to a $225 \mathrm{~m}^{3} / \mathrm{min}$ flow rate.

The duct system that accompanies the blower, filter, and liquid-to-air heat exchanger is shown in Figures 15 and 16 . There are four component ducts in the duct network: a duct to house the air filter, a transition duct that goes from the blower outlet to the flow straightening duc', the flow straightening duct, and the exit duct. The liquid-to-air heat exchanger is housed between the flow straightening duct and the exit duct. All the ducts are fabricated of 20 gage galvanized ste $\epsilon$, and all were built with angle iron frames on their ends to give them extra support and to make it easier to bolt them together.

The duct that houses the panel of air filters is shown in Figures 15 and 16. The duct makes a transition from a round section with a diameter of $0.74 \mathrm{~m}$, which fits on the suction end of the blower, to a $1.22 \mathrm{~m}$ by $1.22 \mathrm{~m}$ square section that houses the filters. The entrance of the duct is sloped down'vard and is covered with a bird screen. The bird screen keeps large objects such as rocks from entering the duct, while the downward sloping configuration keeps leaves or rain water from falling directly in.

The transition duct fits the exit from the blower on one end, and has the same dimensions as the liquid-to-air heat exchanger on the other end. In order to fit the blower's exit, the entrance of the duct is $0.55 \mathrm{~m}$ wide, and $0.74 \mathrm{~m}$ tall. In about half a meter the duct makes the transition to a width of $0.51 \mathrm{~m}$ and a height of $1.24 \mathrm{~m}$, which it keeps for the rest of its $1.1 \mathrm{~m}$ length. The flow straightener duct is $0.51 \mathrm{~m}$ wide, $1.24 \mathrm{~m} \mathrm{tall,} \mathrm{and} 0.5 \mathrm{~m}$ long, and was originally designed to house flow straighteners. However, it was decided that the air flow would be fairly uniform without the flow straighteners, so they were left out to avoid the extra pressure drop. The liquid-to-ajr heat exchanger is housed between the straightening duct and the exit duct. The exit duct is $0.51 \mathrm{~m}$ wide, $1.24 \mathrm{~m} \mathrm{tall}$, and $0.91 \mathrm{~m}$ long. A 


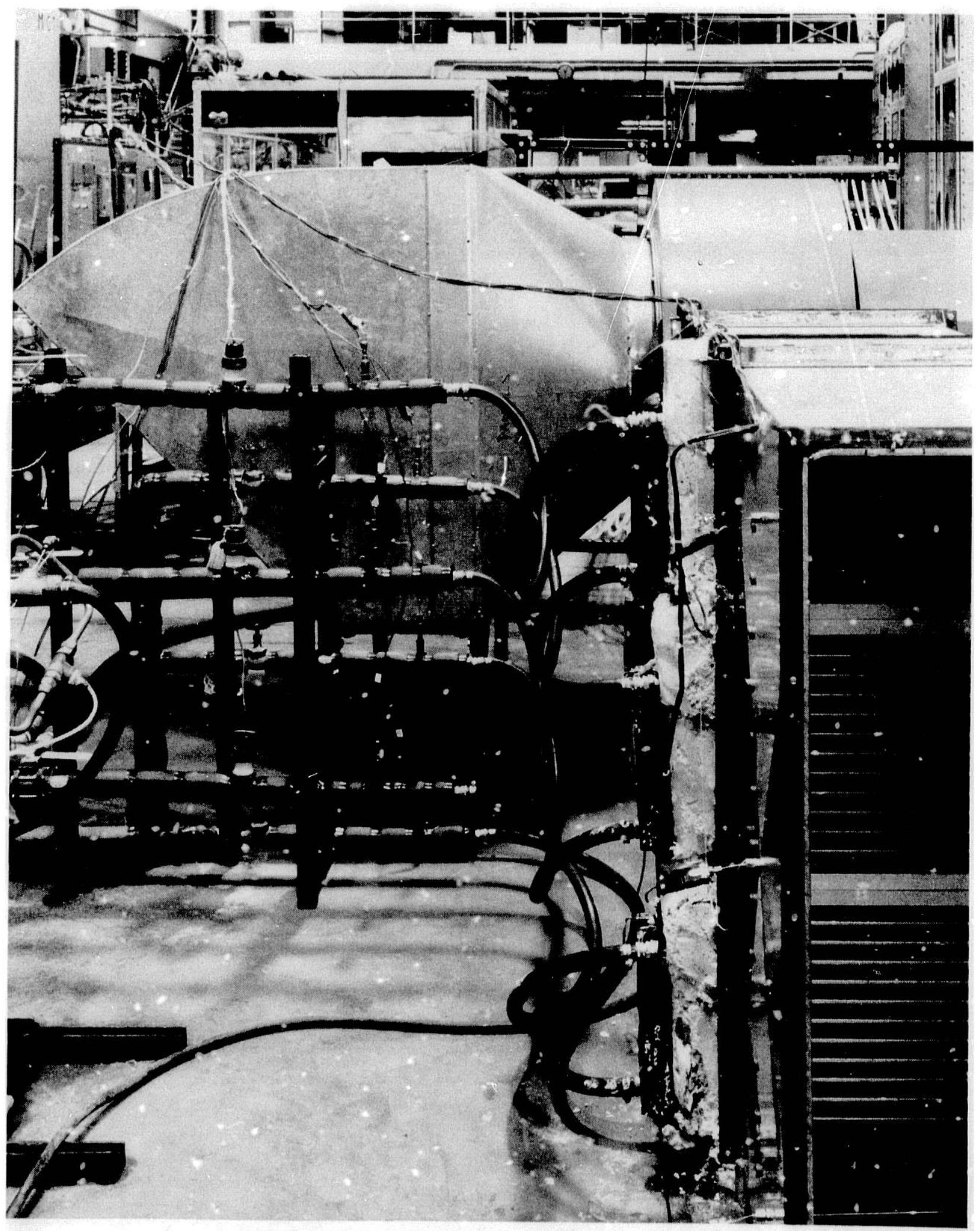

Fig. 15. Liquid-to-air heat exchanger seen from air outlet side 


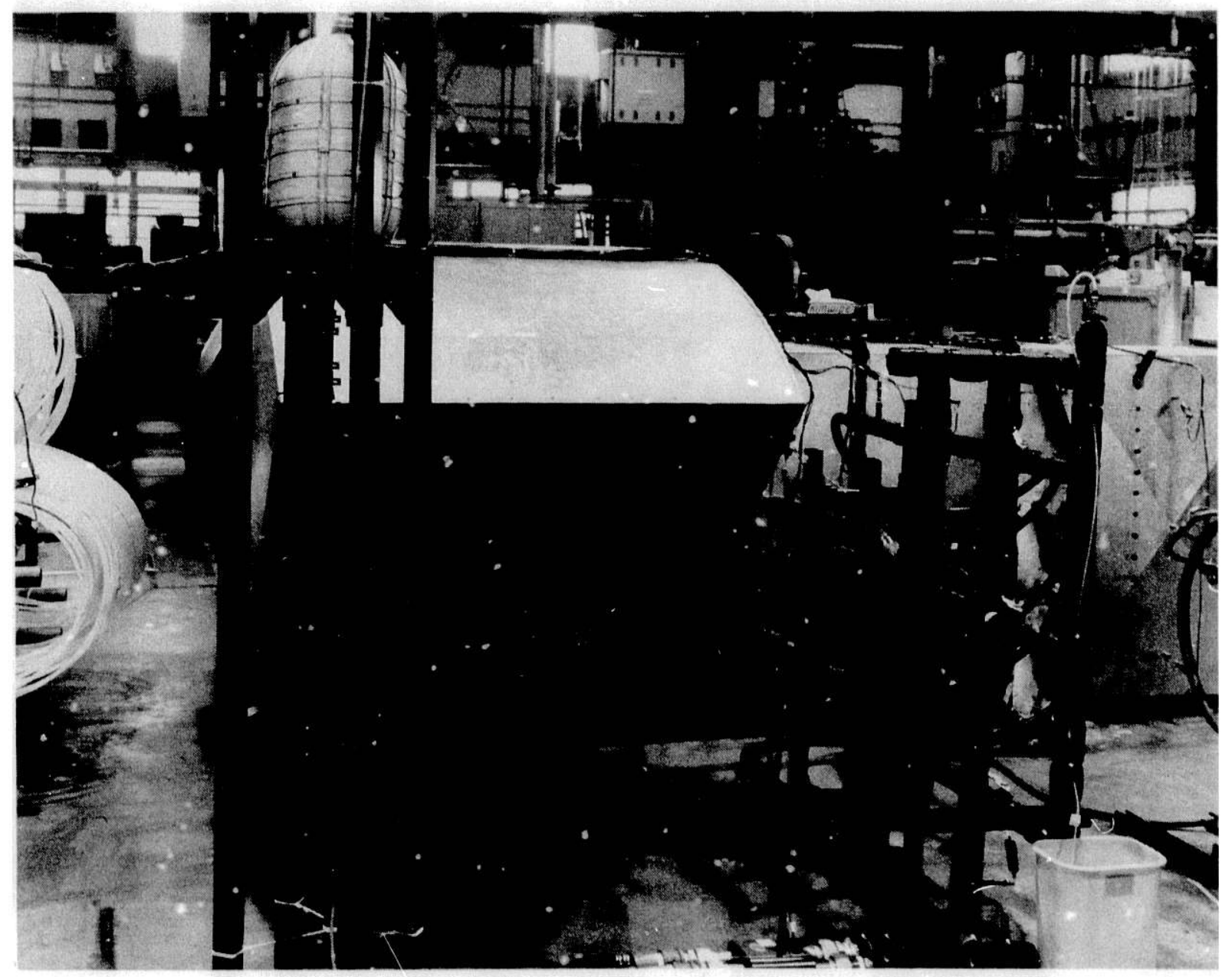

Fig. 16. Liquid-to-air heat exchanger seen from air inlet side 
series of holes were drilled from the top of the duct to the bottom so that a velocity traverse could be made using a velocity meter. The movable velocity control plates attach to the end of the exit duct.

\subsubsection{Instrumentation}

Temperature measurements are performed by T-type thermocouples. The locations of these thermocouples are shown in Figure 11 by symbol $T$. Thermocouples are placed in the inlet and the exit lines of the submerged heat exchanger to measure the increase in the temperature of the ethylene glycol mixture due to gaining heat from the pond, and thermocouples are placed in the inlet and exit lines of the liquid-to-air heat exchanger to measure the decrease in the temperature of the liquid due to losing heat to the air. These thermocouples are installed such that the tip of each thermocouple is in the center of the pipe. Thermocouples are also placed in the air duct at three different heights on each side of the liquid-to-air heat exchanger to measure the increase in air temperature.

Flow meters are mounted in each inlet line to the liquid-to-air heat exchanger. These commercially available flow meters contain an open core paddle wheel, with a small magnet in each of the four paddles. Each sensor is housed in a tee such that the paddle is perpendicular to the flow through the pipe. As the incoming flow rotates the wheel, the magnets induce a signal in a pickup coil at the top of the flow meter. The frequency of the signal is linearly proportional to the paddle wheel rotation rate, which is determined by the fluid flow velocity and the viscosity. The sensors, which have an accuracy of approximately $0.01 \mathrm{~m} / \mathrm{s}$, were chosen because of their accuracy, convenience, and resistance to corrosion.

Air velocity is measured by a calibrated pitot probe. This probe is inserted into the air flow through access ports in the side wall of the exit air duct. The access ports are a series of 16 holes drilled every 3 in. on a vertical line from the top of the duct to the bottom. Because the velocity probe is longer than the width of the duct, both a horizontal and a vertical velocity traverse can be made using the access ports. While the velocity probe is being inserted into one of the ports, all the others are plugged with plastic caps. 


\section{LABORATORY TESTING OF THE SUBMERGED HEAT EXCHANGER}

\subsection{INTRODUCTION}

Before the submerged heat extraction system was installed in the solar pond, several laboratory tests were run on the system. The tests were performed using the Mixing Components Test Facility (MCTF), a large facility used for a variety of experiments involving fluid flow. The MCTF facility is equipped with state-of-the-art instrumentation providing such options as laser flow visualization and computer control and data aquisition. For the tests performed on the submerged heat extraction system, however, few of these capabilities were required. system:

The following laboratory tests were performed on the heat extraction

- The uniformity of flow through the submerged heat exchanger mats was examined.

- The liquid loop was tested for leaks and the system's instrumentation was checked.

- The volumetric flow rate of air through the duct as a function of the position of the control plates was investigated.

- The heat transfer coefficient and effectiveness of the heat exchange mats were determined.

- The heat transfe coefficient and effectiveness of the liquid-to-air he: changer were determined.

- The pump was installed in the loop and the system was allowed to run for an extended period of time.

\subsection{FLOW UNIFORMITY TEST}

A qualitative test was performed to determine whether the distribution of flow through the submerged heat exchange mats was uniform. Recall that each heat exchange mat contains a set of 23 polypropylene tubes that begin in one header, run horizontally for half their length, then loop around and return to a second header that is adjacent to the first one. To check the distribution of the flow in a mat, one of its headers had to be removed. The tubes were held in place while the header was absent by placing a piece of unistrut on either side and clamping the two pieces together. Foam rubber was placed between the unistrut and the tubes so that the tubes would not be crushed. 
With the header gone, the water flowing through each tube could be seen, and the uniformity of the flow through the mat could be judged.

Water was pumped into the connected header at a rate of $2.3 \mathrm{~L} / \mathrm{s}$, the same flow rate as would be used when the mats were installed in the solar pond. The water flowed from the header into the tubes, around the 180 degree turn, and back toward the second header (which had been removed). The distribution of the flow through the heat exchange mat was determined by observing how far the jets of water squirted from the different tubes. If the flow was poorly distributed, and some tubes carried more water than others, then the jets of water from these tubes would squirt farther than the jets from the other tubes. When the test was conducted, all the jets were about 8 in. long, so the flow was deemed to be uniformly distributed.

\subsection{LIQUID LOOP LEAK TEST AND INSTRUMENTATION CHECK}

The entire liquid loop was tested for leaks by circulating water through the system using the MCTF loop as a water source. Leaks were discovered at hose fittings, threaded brass fittings, and a copper union. The leaking hose fittings were repaired by tightening the hose clamps. The leaky union was taken out of the system and replaced by a short length of hose, and the leaky brass fittings were repaired by dressing the threads with a commercially available resin-based sealant. These repairs stopped the leaks.

The operation of the system thermocouples was investigated to make sure that they were all working properly. The locations of the thermocouples are shown in Figure 11. The operation of the thermocouples was checked by circulating warm water of known temperature through the liquid loop and recording the temperatures registered by the thermocouples. The thermocouple readings were consistent with each other for several different water temperatures (corresponding readings were within half a degree Celcius of each other) so it was decided that the thermocouples were working properly.

The paddlewheel flow meters were calibrated by measuring the voltage that they delivered for various flow rates. The flow rates were measured by letting water run through the flow meter pipe into a container on a scale, and measuring the mass of water collected during a known period of time. The voltage delivered by each flow meter was measured for five flow rates, and linear regression analysis was performed on each set of data. The result of the analysis was a linear equation giving the voltage in terms of the flow rate for each of the flow meters.

\subsection{CONTROL OF THE AIR FLOW RATE THROUGH THE DUCT}

A method was devised to control the volumetric flow rate of air through the liquid-to-air heat exchanger. The control method was based on the fact 
that the air output of the blower depends on the static pressure in the duct, as shown in the following table, which was supplied by the manufacturer:

$\begin{array}{llllll}\text { Static pressure (Pa) } & 250 & 375 & 500 & 675 & 750 \\ \text { Air flow, }\left(\mathrm{m}^{3} / \mathrm{mj} \mathrm{n}\right) & 260 & 240 & 215 & 190 & 155\end{array}$

Therefore the volumetric flow rate of air in the duct can be controlled by controlling the static pressure.

It was decided that static pressure in the duct would be controlled using adjustable aluminum plates on the outlet of the last duct of the network. The plates have slots on the top and on the bottom so that they can be adjusted by merely loosening a couple of wing nuts and sliding the plates. The static pressure and thus the flow rate are controlled by adjusting the flates to block as much of the exit cross sectional area as required. The air flow rate was measured by inserting a velocity probe into one of the access ports in the last duct.

In the laboratory, horizontal and vertical velocity traverses were made for three plate positions to determine how the flow rate depended on plate position. For each access port, velocity readings were taken with the probe inserted one-quarter, one-half, and three-quarters of the way into the duct. Traverses were made with the plates completely off, covering half of the exit area, and covering three-fourths of the exit area. The measurements revealed that the air velocity was highest along the wall of the duct closest to the blower inlet, and decreased as the probe was moved toward the opposite wall. This velocity distribution is a result of the 90 degree bend in the ductwork at the blower. The rear portion of the blower blades are somewhat starved for air because they do not receive as much air as the portions of the blades closest to the inlet. To evaluate the effect of the control plate position on the volumetric flow rate, the average velocity was computed for each of the three plate positions, and the volumetric flow rate was computed. The results are given below:

Plate Position

Plates completely of $\mathrm{f}$

Blocking half of exit

Blocking three fourths of exit
Volumetric Flow Rate through Duct

$240 \mathrm{~m}^{3} / \mathrm{min}$
$214 \mathrm{~m}^{3} / \mathrm{min}$
$172 \mathrm{~m}^{3} / \mathrm{min}$

These measurements were made without the filter panel in the system. Later, at the pond, the velocity traverse was repeated with the filter panel installed and seven evenly spaced horizontal readings were taken at each access port. This set of measurements yielded a volumetric flow rate of 225 $\mathrm{m}^{3} / \mathrm{min}$ when the velocity control plates were completely off. 


\subsection{HEAT TRANSFER EXPERIMENTS WITH THE SUBMERGED HEAT EXCHANGER}

Laboratory experiments were conducted to evaluate the heat transfer performance of the submerged heat exchanger. Experimental data were collected by circulating hot water from the MCTF system through the liquid loop, then recording the temperatures registered by the thermocouples. Three hot water temperatures were used, and for each temperature, readings were taken for three or four water flow rates. The experimentally obtained temperatures were used to calculate performance parameters such as the overall heat transfer coefficient and the effectiveness.

\subsubsection{Experimental Configuration and Procedure}

Figure 11 is a schematic of the submerged heat extraction system installed in the solar pond. For the laboratory tests, the system was assembled as shown in the figure, except the pump was replaced by the MCTF system as the source of water. The filter, surge tank, liquid-to-air heat exchanger, and instrumentation were all installed during the tests. Figures 15 and 16 show some of the system components during the tests. Figure 15 shows the surge tank in front of the blower inlet duct in the center of the picture. The liquid-to-air heat exchanger inlet and outlet headers are on the far right of the picture, and the very tips of the heat exchange mats are on the far left of the picture. Figure 16 shows the liquid-to-air heat exchanger headers in front of the blower's inlet duct. The right side of the picture is loooking straight up the outlet duct of the blower. The fins and tubes of the liquid-to-air heat exchanger are clearly visible in the duct.

Figures 12 and 13 show the configuration of the heat exchange mats during the laboratory tests. The mats were suspended in the air one on top of the other, suppported by a unistrut structure. The bottom mat was supported about $15 \mathrm{in}$. above the floor, and the top mat was supported about $30 \mathrm{in}$. above the floor. The last one or two meters of the mats were allowed to double back on themselves due to space limitations in the lab.

The configuration of the heat exchange mats in the pond will be different from these tests. First, the mats will be side by side in the pond rather than one on top of the other. They were placed one on top of the other for the tests due to space limitations in the lab. A second difference is that the mats were suspended in relatively stagnant air for the tests, and will be submerged in stagnant salt water when installed in the pond. The natural convective heat transfer in air $(\operatorname{Pr}=0.7)$ is different from that in salt water $(\mathrm{Pr}=3-10)$, so the heat transfer coefficient in the pond will be higher then the one measured in the lab. In the solar pond, most of the resistance to heat transfer will be due to the low thermal conductivity of the plastic tube walls. In the lab, however, the heat transfer resistance due to convection between the air and the tube walls should be comparable to the resistance of the tube walls. Because convective heat transfer is fairly well understood, the results obtained in air should be easily related to results in 
salt water. The tests should give a good estimate of the nonconvective heat transfer resistances.

The experiment was conducted by circulating hot water from the MCTF system through the liquid loop and recording the temperatures registered by the thermocouples. The MCTF system had the capability to supply water at any temperature between about $5^{\circ} \mathrm{C}$ and $94^{\circ} \mathrm{C}$, and any flow rate between 0 and 2.5 $\mathrm{L} / \mathrm{s}$. The experiment was run with three water temperatures, and readings were taken for several flow rates at each temperature. Runs were made with hot water flowing through only the top mat and with the water flowing through both mats to see how they affected each other. The blower was always run, sometimes with the control plates off, sometimes with them on. The voltages delivered by the paddlewheel flow meters were recorded for each run. From the temperatures registered by the thermocouples, the heat lost by the water could be determined, and the heat transfer characteristics of the mats evaluated.

\subsubsection{Experimental Results and Analysis}

The results for all ten of the test runs are given in Table 3 .

Table 3. Experimental Data for the Submerged Heat Exchanger

\begin{tabular}{rrrrr}
\hline $\begin{array}{c}\text { Run } \\
\text { No. }\end{array}$ & $\begin{array}{c}\text { Flow Rate, } \\
\text { L/s }\end{array}$ & $\begin{array}{c}\text { Inlet Temp., } \\
{ }^{\circ} \mathrm{C}\end{array}$ & $\begin{array}{c}\text { Outlet Temp., } \\
{ }^{\circ} \mathrm{C}\end{array}$ & $\begin{array}{c}\text { Heat Extracted, } \\
W\end{array}$ \\
\hline 1 & & & & \\
2 & 2.1 & 41.0 & 40.1 & 7,680 \\
3 & 0.8 & 41.1 & 39.3 & 5,960 \\
4 & 2.1 & 49.0 & 47.8 & 10,500 \\
5 & 1.2 & 49.1 & 47.0 & 10,450 \\
6 & 0.8 & 48.8 & 45.9 & 9,590 \\
7 & 0.4 & 48.4 & 43.9 & 7,040 \\
8 & 2.1 & 70.4 & 67.7 & 29,100 \\
9 & 1.3 & 71.6 & 67.1 & 23,300 \\
10 & 0.8 & 71.3 & 64.7 & 22,000 \\
& 66.9 & 66.9 & 62.4 & 46,000 \\
\hline
\end{tabular}

During the first nine runs, the hot water flowed through the top heat exchange mat only. During the tenth run, the hot water was allowed to flow through both mats. The rate of heat extraction was calculated by multiplying together the flow rate, heat capacity, and temperature change of the water as shown in Eq. 15:

$$
Q=m C_{p} d T \text {. }
$$


From the experimental data, the overall heat transfer coefficient was calculated using the following equation:

$$
Q=U A d T_{1 m}
$$

where $U$ is the overall heat transfer coefficient, $A$ is the area of heat transfer, and $\mathrm{dT}_{1 \mathrm{~m}}$ is the logarithmic mean temperature difference.

For the experimental situation, the logarithmic mean temperature difference is defined by

$$
\mathrm{dT}_{1 \mathrm{~m}}=\left(\mathrm{dT}_{1}-\mathrm{dT}_{2}\right) / \ln \left(\mathrm{dT}_{1} / \mathrm{dT}_{2}\right)
$$

where $\mathrm{dT}_{1}$ is the inlet water temperature minus the air temperature and $\mathrm{dT}_{2}$ is the outlet water temperature minus the air temperature.

The results of the overall heat transfer coefficient calculations are given in Table 4. These results show that the heat transfer coefficient is not very sensitive to inlet water temperature or flow rate. The value for run number six is probably in error due to the large relative error in the flow rate measurement for the low flow rate.

Table 4. Overall Heat Transfer Coefficient for the Submerged Heat Exchanger.

\begin{tabular}{rccc}
\hline $\begin{array}{c}\text { Run } \\
\text { No. }\end{array}$ & $\begin{array}{c}\text { Flow Rate, } \\
\mathrm{L} / \mathrm{s}\end{array}$ & $\begin{array}{c}\text { Approx } \\
{ }^{\circ} \mathrm{C}\end{array}$ & \\
\hline & & & \\
1 & 2.1 & 40 & 13.0 \\
2 & 0.8 & 40 & 10.4 \\
3 & 2.1 & 49 & 11.0 \\
4 & 1.2 & 49 & 12.0 \\
5 & 0.8 & 49 & 1.2 \\
6 & 0.4 & 49 & 8.9 \\
7 & 2.1 & 70 & 13.4 \\
8 & 1.3 & 70 & 12.8 \\
9 & 0.8 & 70 & 12.8 \\
10 & 2.5 & 70 & 14.6 \\
\hline
\end{tabular}

The effectiveness of the heat exchanger mats was also determined from the experimental data. For the experimental conditions, the effectiveness is given by:

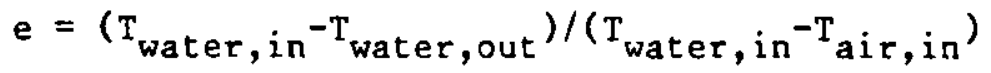


The effectiveness depends on the flow rate of the hot water. The lower the flow rate, the closer the temperature difference in the numerator to the difference in the denominator, and the closer the effectiveness to one.

The results of the effectiveness calculations based on the experimental data are given in Table 5. For a water flow rate of $2.1 \mathrm{~L} / \mathrm{s}$, the average effectiveness is 0.0641 ; for $1.2 \mathrm{~L} / \mathrm{s}$, it is 0.103 ; and for $0.8 \mathrm{~L} / \mathrm{s}, 0.133$.

When the heat exchanger is installed in the pond, its effectiveness will be higher than it was in these laboratory tests because convective heat transfer from the tubes will be faster in salt water then it was in air.

Table 5. Laboratory Effectiveness of the Submerged Heat Exchanger.

\begin{tabular}{rcccc}
\hline $\begin{array}{c}\text { Run } \\
\text { No. }\end{array}$ & $\begin{array}{c}\text { Inlet Water Temp., } \\
{ }^{\circ} \mathrm{C}\end{array}$ & $\begin{array}{c}\text { Outlet Water Temp., } \\
{ }^{\circ} \mathrm{C}\end{array}$ & $\begin{array}{c}\text { Air Temp., } \\
{ }^{\circ} \mathrm{C}\end{array}$ & $\begin{array}{c}\text { Effectiveness, } \\
(\mathrm{e})\end{array}$ \\
\hline & & & & \\
1 & 41.0 & 40.1 & 26.7 & 0.0622 \\
2 & 41.1 & 39.3 & 26.6 & 0.122 \\
3 & 49.0 & 47.8 & 26.2 & 0.0535 \\
4 & 49.1 & 47.0 & 27.6 & 0.0982 \\
5 & 48.8 & 45.9 & 27.0 & 0.130 \\
6 & 48.4 & 43.9 & 27.5 & 0.215 \\
7 & 70.4 & 67.7 & 27.2 & 0.0766 \\
8 & 71.6 & 67.1 & 26.5 & 0.0999 \\
9 & 71.3 & 64.7 & 27.0 & 0.148 \\
10 & 66.9 & 62.4 & 27.0 & 0.111 \\
\hline
\end{tabular}

4.6 HEAT TRANSFER EXPERIMENTS WITH THE LIQUID-TO-AIR HEAT EXCHANGER

Laboratory experiments were conducted to evaluate the heat transfer characteristics of the liquid-to-air heat exchanger. The test runs consisted of circulating warm water from the MCTF system through the heat exchanger while the blower was blowing air through it, and recording the inlet and outlet temperatures on both the air side and the water side. Three hot water temperatures were used, and for each one thermocouple readings were taken for several flow rates. The experimentally obtained temperatures were used to determine performance factors such as the overall heat transfer coefficient and the effectiveness of the liquid-to-air heat exchanger. 


\subsubsection{Experimental Configuration and Procedure}

During the laboratory experiments, the blower and the ductwork were assembled in the same configuration they would have when installed at the solar pond. The air filter duct was attached to the suction side of the blower, and the transition duct, flow-straightening duct, heat exchanger, and exit duct were attached in order on the exit side of the blower. The only difference between the experimental configuration and the pond configuration was that only one air filter was installed in the filter duct instead of the full panel of four filters. As described in section 4.5.1, Figures 15 and 16 show some of the system's components as they stood during the tests.

The experiment was conducted by circulating hot water from the MCTF system through the liquid-to-air heat exchanger and recording the inlet and outlet temperatures registered by the thermocouples on both the air side and the water side. The experiment was run with three water temperatures, and readings were taken for several flow rates at each temperature. The blower was on throughout the tests. Readings were made with the velocity control plates completely off, and with them covering half the exit area. The first six runs were made before the thermocouples had been installed in the air duct; therefore, only the water inlet and outlet temperatures were recorded for these runs. But for the last five runs, both the air and the water temperatures were monitored. Erom the experimentally obtained temperatures the heat lost by the water and the heat gained by the air could be determined, and the heat transfer performance of the heat exchanger evaluated.

\subsubsection{Experimental Results and Analysis}

The experimental results for the eleven runs are given in Table 6 . The rate at which energy was lost by the water in each of the 11 runs was calculated by multiplying the flow rate, heat capacity, and temperature change together. The heat gained by the air in each of the last five runs was calculated in a similar manner.

Because energy is conserved, the heat lost by the water should be equal to the heat gained by the air in each of the runs. The results of the calculations are given in Table 7. As expected, the calculated heat gained by the air does not differ much from the calculated heat lost by the water. Because the measurement of the water flow rate is more reliable than the measurement of the air flow rate, the calculated heat lost by the water for each run will be used to determine the heat transfer characteristicr of the heat exchanger. 
Table 6. Experimental Data for the Liquid-to-Air Heat Exchanger

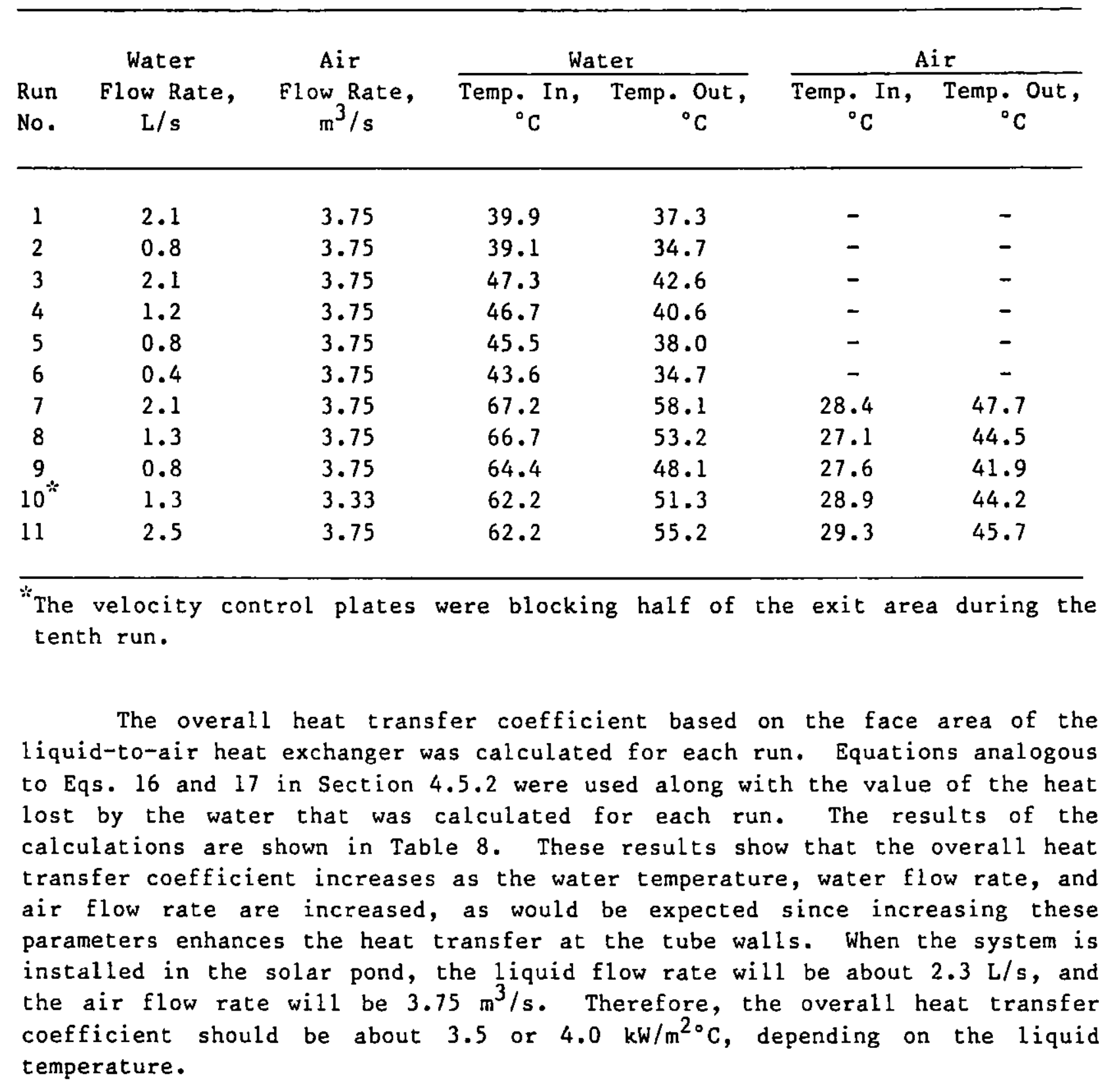


Table 7. Comparison of the Heat Gained By the Air Stream and the Heat Lost by the Water Stream of the Liquid-to-Air Heat Exchanger

Run Heat Lost by Water, Heat Gained by Air, Percent Difference No. $\quad \mathrm{kW}$

\begin{tabular}{rrrl}
\hline 1 & 23.2 & - & - \\
2 & 14.9 & - & - \\
3 & 40.8 & - & - \\
4 & 30.3 & - & - \\
5 & 25.6 & - & - \\
6 & 14.0 & 81.3 & 1.11 \\
7 & 80.4 & 73.7 & 4.88 \\
8 & 70.1 & 60.5 & 9.09 \\
9 & 55.0 & 57.9 & 2.24 \\
10 & 56.6 & 69.4 & 3.89 \\
11 & 72.1 & & \\
\hline
\end{tabular}

Table 8. Overal1 Heat Transfer Coefficient of the Liquid-to-Air Heat Exchanger

\begin{tabular}{|c|c|c|c|c|}
\hline $\begin{array}{l}\text { Run } \\
\text { No. }\end{array}$ & $\begin{array}{c}\text { Water } \\
\text { Flow Rate, } \\
\text { L/s }\end{array}$ & $\begin{array}{c}\text { Air } \\
\text { Flow Rate, } \\
\mathrm{m}^{3} / \mathrm{s}\end{array}$ & $\begin{array}{l}\text { Approx. } \\
\text { Water Temp., } \\
{ }^{\circ} \mathrm{C}\end{array}$ & $\begin{array}{l}\text { Overall Heat Transfer } \\
\text { Coefficient, } \\
\mathrm{kW} \mathrm{m}{ }^{-2}{ }^{\circ} \mathrm{C}^{-1}\end{array}$ \\
\hline 1 & 2.1 & 3.75 & 38 & 3.37 \\
\hline 2 & 0.8 & 3.75 & 38 & 2.53 \\
\hline 3 & 2.1 & 3.75 & 45 & 3.77 \\
\hline 4 & 1.2 & 3.75 & 45 & 3.28 \\
\hline 5 & 0.8 & 3.75 & 45 & 3.06 \\
\hline 6 & 0.4 & 3.75 & 45 & 2.17 \\
\hline 7 & 2.1 & 3.75 & 60 & 3.91 \\
\hline 8 & 1.3 & 3.75 & 60 & 3.71 \\
\hline 9 & 0.8 & 3.75 & 60 & 3.39 \\
\hline 10 & 1.3 & 3.33 & 60 & 3.54 \\
\hline 11 & 2.5 & 3.75 & 60 & 4.21 \\
\hline
\end{tabular}


The effectiveness of the liquid-to-air heat exchanger was calculated for each run using the experimental data. The effectiveness is given by one of the two equations given below, depending on whether the air stream or the water stream has the smaller value for the product of the mass flow rate and the heat capacity. If the air stream has a smaller value for the product of flow rate and heat capacity, the effectiveness is given by:

$$
e=\left(T_{a i r}, \text { out }^{-T_{a i r}, \text { in }}\right) /\left(T_{\text {wat } \epsilon r, n^{-}} \mathrm{T}_{\text {air, in }}\right)
$$

Jf the water stream has a smaller value for the product of flow rate and heat capacity, the effectiveness is given by:

$$
e=\left(T_{\text {water, }} \text { in }^{-T_{\text {water, out }}}\right) /\left(\mathrm{T}_{\text {water, }} \text { in }^{-T_{\text {air, in }}}\right)
$$

For each run, the value of the product of the flow rate and the heat capacity was calculated for both the air stream and the water stream, then the appropriate equation ( 18 or 19$)$ was used with the experimental data to determine the effectiveness. The results are given in Table 9.

\begin{tabular}{|c|c|c|c|}
\hline $\begin{array}{l}\text { Run } \\
\text { No. }\end{array}$ & $\begin{array}{c}\text { Air } \\
\text { Flow Rate } \\
W{ }^{\circ} C^{-1}\end{array}$ & $\begin{array}{c}\text { Water } \\
\text { Flow Rate } \\
\text { W }{ }^{\circ} \mathrm{C}^{-1}\end{array}$ & $\begin{array}{c}\text { Effectiveness } \\
\text { (e) }\end{array}$ \\
\hline 1 & 4200 & 8600 & 0.461 \\
\hline 2 & 4200 & 3400 & 0.399 \\
\hline 3 & 4200 & 8600 & 0.500 \\
\hline 4 & 4200 & 5000 & 0.384 \\
\hline 5 & 4200 & 3400 & 0.430 \\
\hline 6 & 4200 & 1600 & 0.537 \\
\hline 7 & 4200 & 8800 & 0.496 \\
\hline 8 & 4200 & 5200 & 0.439 \\
\hline 9 & 4200 & 3400 & 0.443 \\
\hline 10 & 3800 & 5200 & 0.454 \\
\hline 11 & 4200 & 10300 & 0.498 \\
\hline
\end{tabular}

Table 9. Effectiveness of the Liquid-to-Air Heat Exchanger

For a water flow rate of $0.8 \mathrm{~L} / \mathrm{s}$, the average effectiveness was 0.424 ; for 1.2 $\mathrm{L} / \mathrm{s}$, it was 0.426 ; and for $2.1 \mathrm{~L} / \mathrm{s}, 0.486$.

These data show that although the effectiveness is slightly higher for the higher water flow rates, it is not strongly dependent on water flow rate or temperature. The average effectiveness for the eleven runs is 0.458 . 
Because the experimental configuration is nearly the sane as that at the pond, the effectiveness at the pond should be close to this value. The minor differences between the situation at the pond and the experimental situation are that a $50 / 50$ mixture of ethylene glycol and water will be circulated through the heat exchanger instead of fresh water, and the entering air temperature will likely be lower. A liquid flow rate of about $2.3 \mathrm{~L} / \mathrm{s}$ will be used at the pond.

\subsection{EXTENDED OPERATION OF THE ENTIRE SYSTEM}

During the previous tests the pump had been left out of the system while the MCTE facility was used as the source of water. For the final laboratory test the pump was installed in the system so that the entire loop could be run for an extended period of time. After the pump was installed in the system, the loop was filled with water through its drain pipe, and the air was carefully bled from the system. The pump was turned on, and the closed loop was allowed to run continuously for eight hours. The system performed well throughout this test. The flow meters registered $2.31 \mathrm{~L} / \mathrm{s}$. 
5. EXPERIMENTAL RESULTS FOR THE SUBMERGED HEAT EXCHANGE SYSTEM AT THE RSGSP

\subsection{PRELIMINARY EXPERIMENTS}

The submerged heat extraction system was installed at the ANL RSGSP as described in Sec. 3.2.1. The systein was operated for short periods of time during August and September 1984 to evaluate performance factors and to investigate effects of the heat extraction operation on solar pond stability. The effects of this operation are visible in the heat storage zone temperature history plotted in Fig. 4. Instead of the usual small temperature increase in August, there was a relatively sharp decrease in 1984. The heat extraction system performed well during these tests, and no detrimental effects on gradient zone stability were observed.

\subsection{SIMULATION OF GRAIN DRYING}

In October 1984, the submerged heat exchange system was operated continuously to simulate grain drying. During this period, approximately $1.0 \times 10^{11} \mathrm{~J}(100 \mathrm{MM}$ Btu) were extracted from the pond, and the heat storage zone temperature fell from approximately $61^{\circ} \mathrm{C}$ to $44^{\circ} \mathrm{C}$. The temperature histories at several locations in the system during this period are plotted in Fig. 17. The power output of the system, in terms of heating the ambient air, is shown in Fig. 18. The energy extracted from the pond could have been used to dry approximately $290 \mathrm{~m}^{3}$ ( 8,130 bushels) of corn from $25 \%$ to $15 \%$ moisture content. The heat extraction could easily have continued into November and December; but at a slightly reduced rate from the approximately $50 \mathrm{~kW}$ of October.

Fig. 19 shows temperature profiles of the solar pond taken before, during, and after the period of continuous heat extraction. The September profile was taken before heat extraction began, and the shape of the profile, especially that in the heat storage zone (lower $1.0 \mathrm{~m}$ ), is typical of the ANL. RSGSP during the fall when no heat is extracted. The October profile was taken during the middle of the heat extraction period, and the November profile was taken at the very end of the extraction period. As is evident from Eig. 19, heat extraction established a strong temperature stratification in the heat storage zone and lower portion of the gradient zone.

The temperature stratification in the lower part of the gradient zone is caused by the rapid decrease in temperature at the level of the heat exchanger. Part of the thermal energy that was stored in the gradient zone is then conducted downward to the heat exchanger, effectively increasing the size of the storage zone. The temperature stratification improves the hydrodynamic stability of the solar pond because with both salinity and temperature acting to stabilize the gradient, there is no chance for instability to occur during the submerged heat extraction process. 


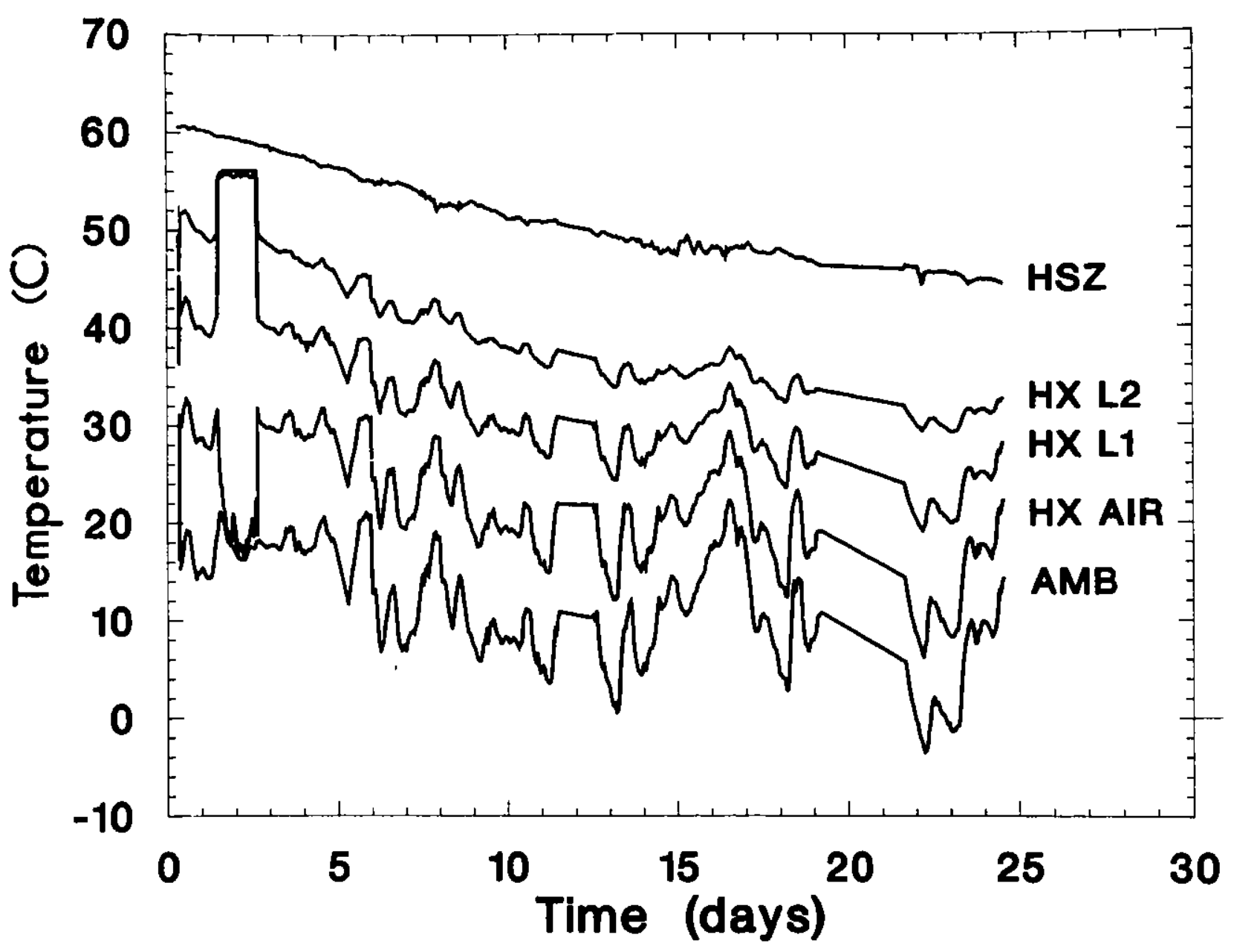

F1g. 17. Temperature histories during submerged heat extraction 


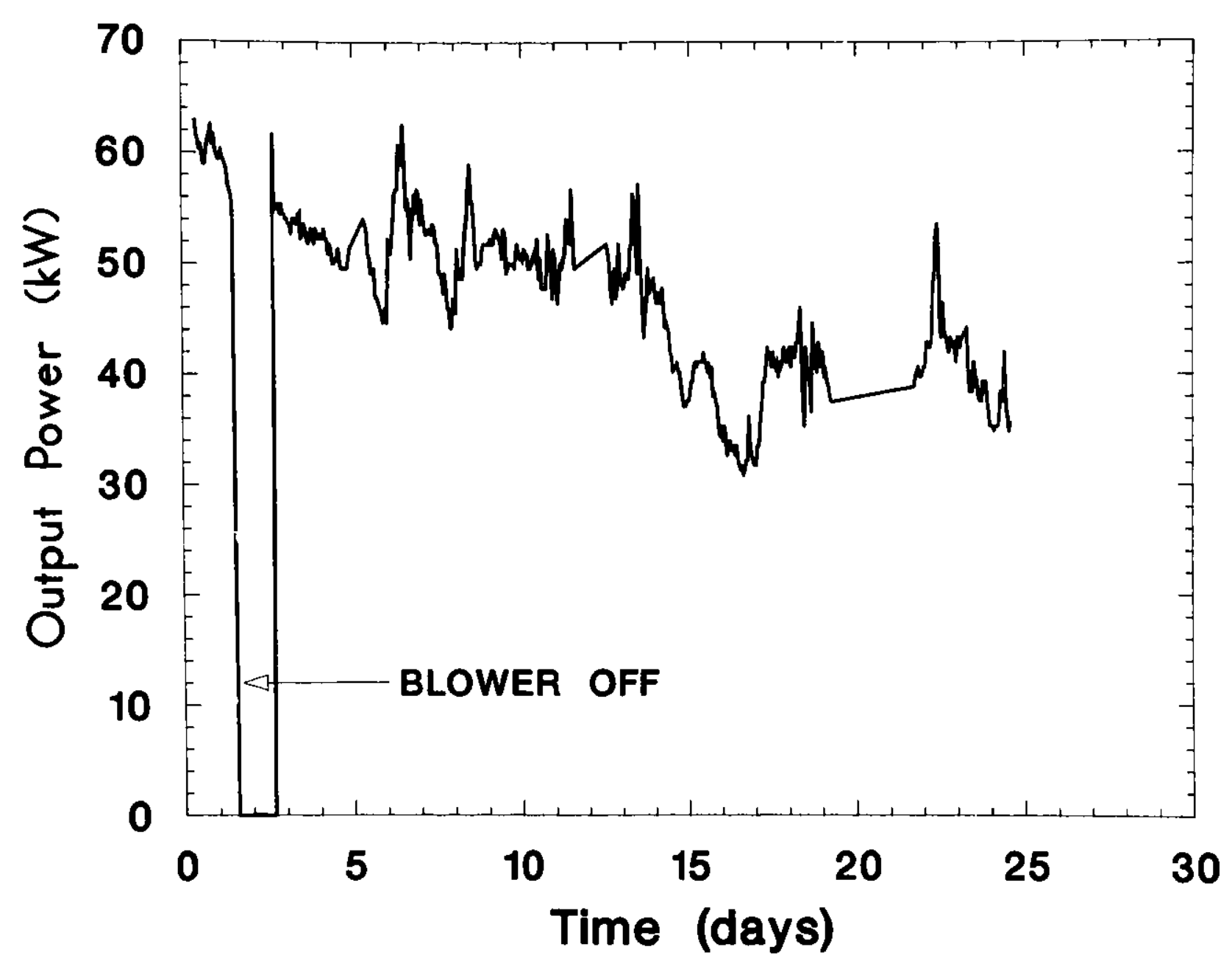

Fig. 18. Thermal power output during submerged heat extraction 


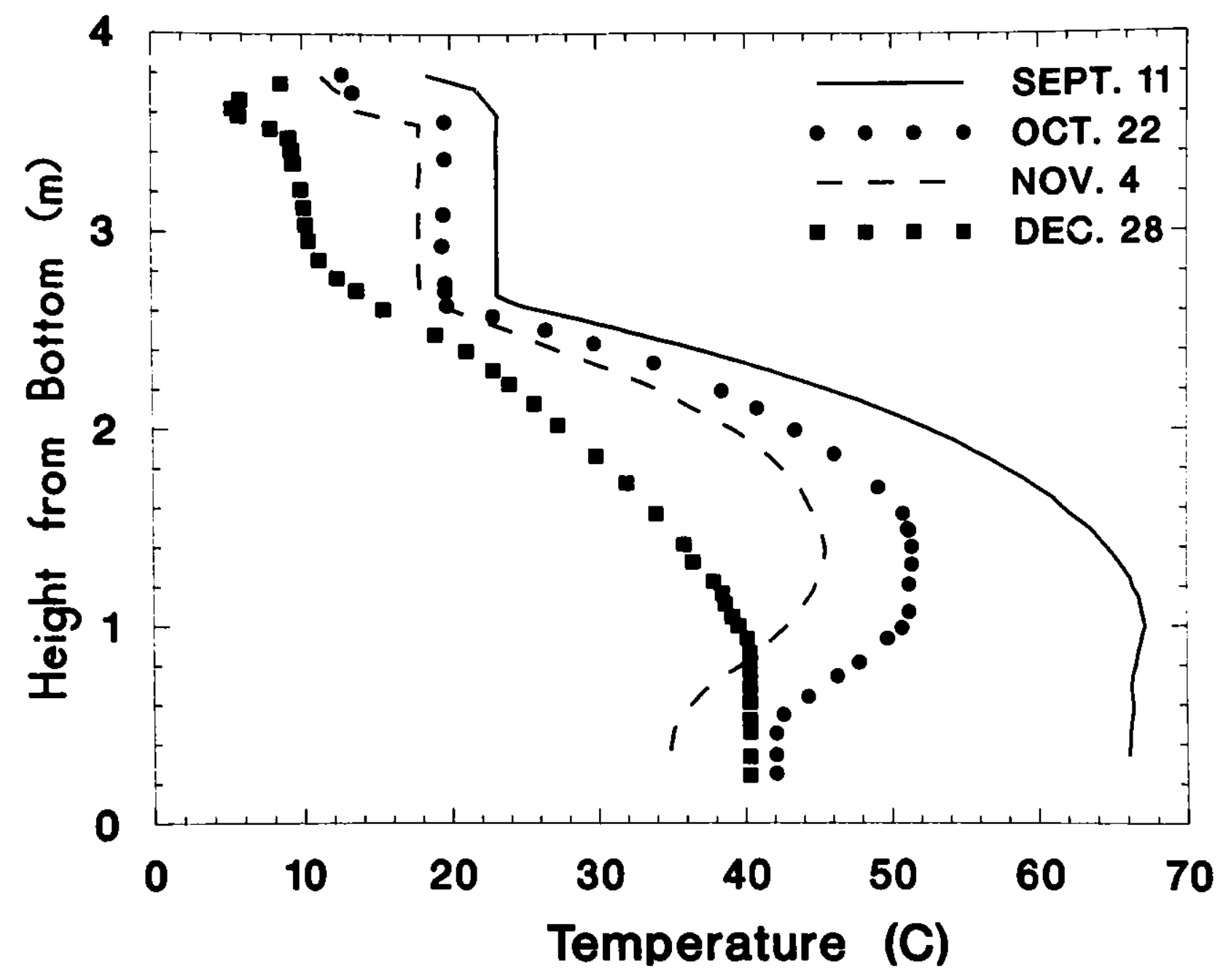

F1g. 19. Temperature profiles before, during, and after submerged heat extraction 
The temperature stratification below the heat exchanger is due to natural convection heat transfer between the heat exchanger outer surface and the fluid in the heat storage zone. As the heat exchange tubes pick up heat, the adjacent pond fluid cools and falls toward the bottom of the pond. The relatively cold plume of descending fluid spreads out over the bottom of the pond, producing stratification. The resulting colder temperature at the bottom of the pond is beneficial by reducing ground heat loss. In fact, during and after the heat extraction period, the temperature of the ground below the pond was warmer than the bottom of the pond, and some of the heat that had been lost to the ground earlier in the year was returned to the pond. This was verified by temperature measurements from thermocouples located under the pond, as shown in the temperature profile in Fig. 20. The influx of heat from the ground was responsible for the very small drop in storage zone temperature in November and December.

\subsection{NATURAL CONVECTION THROUGH THE HEAT EXCHANGE TUBES}

Even when the pump is turned off, heat is transferred from the heat storage zone of the pond to the surface by conduction and natural convection through the heat exchange tubes. The typical temperature difference between the heat storage zone of the pond and the surface is $40^{\circ} \mathrm{C}$. This temperature difference is sufficiently large to induce natural convection through the heat exchange tubes, which are filled with aqueous ethylene glycol. Evidence of this heat transfer could be seen in the winter when the ice near the tubes was melted.

The heat transferred by conduction and natural convection from the heat storage zone of the pond to the surface was estimated, making the assumptions that the tubes are vertical, the tube walls are adiabatic, and the temperature difference between the bottom of the tubes and the top of the tubes does not change with time. The method described by Edwards and Catton [37] was used to estimate the Nusselt number. Once the Nusselt number was known, the total heat transfer through the fluid in the tubes could be calculated by multiplying by the conductive heat transfer, which was easily calculated since the thermal conductivity of aqueous ethylene glycol was known.

In the method of Edwards and Catton, the Nusselt number is estimated using

$$
\mathrm{Nu}=1+\sum_{k=1}^{\mathrm{M}} \mathrm{N}_{k}\left(1-\mathrm{Ra}_{k} / \mathrm{Ra}\right),
$$




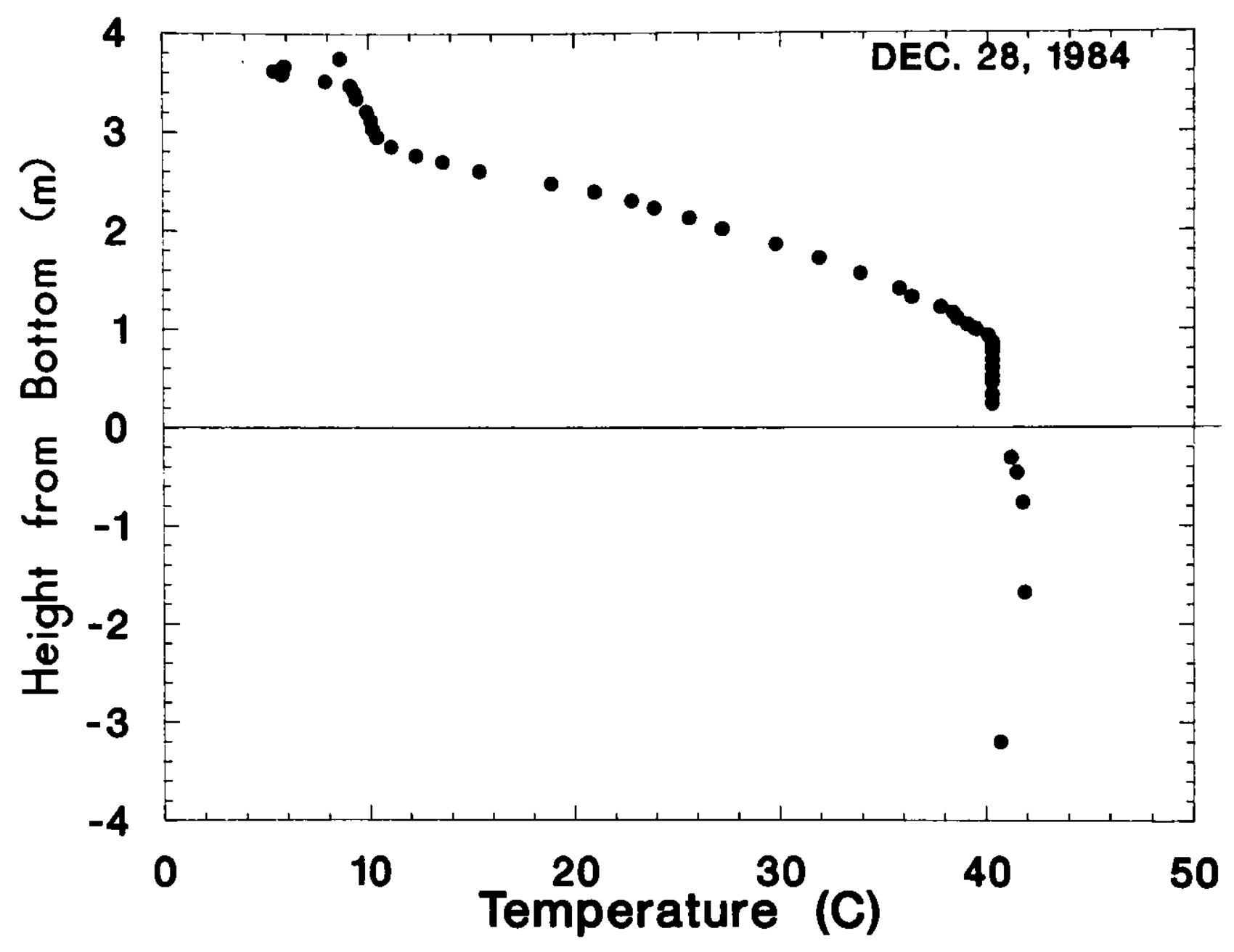

Fig. 20. Temperature profile after heat extraction, showing pond and ground temperatures 
where

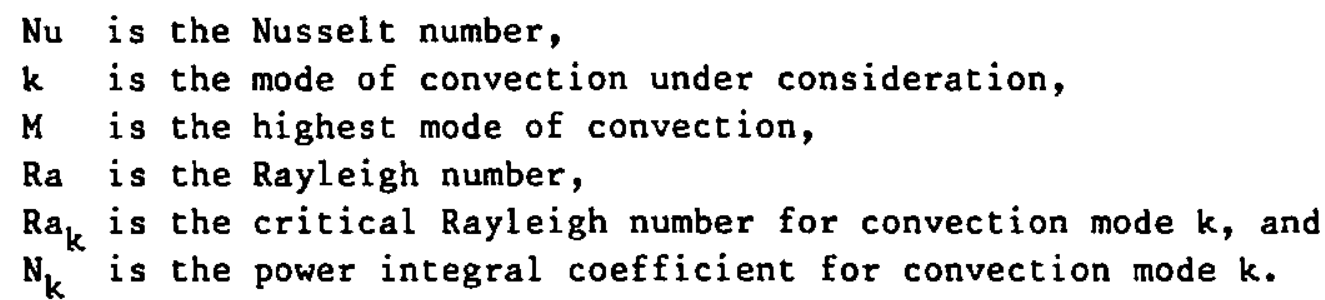

The Rayleigh number can be calculated using

$$
R \mathbf{a}=g \propto L^{3} \Delta T /(\nu \kappa),
$$

where

$g$ is the acceleration of gravity,

$\alpha$ is the coefficient of thermal exparision,

$\mathrm{L}$ is the length of the tube,

$\Delta T$ is the temperature difference across the tube,

$v$ is the kinematic viscosity of the fluid in the tube, and

$x$ is the thermal diffusivity of the fluid in the tube.

The critical Rayleigh numbers, $\mathrm{Ra}_{k}$ can be estimated using

$$
R a_{k}=\left(a_{k}^{2}+b_{k}^{2}\right)^{3} / a_{k}^{2} \text {, }
$$

where

$a_{k}$ is the horizontal wave number and

$b_{k}$ is the vertical wave number.

For a long circular cylinder with adiabatic side walls, the following equations hold for the wave numbers:

$$
\begin{aligned}
& a_{k}=5.75 \mathrm{~L} / \mathrm{d}, \\
& b_{k}=k \pi,
\end{aligned}
$$

where $d$ is the diameter of the cylinder.

Finally, the power integral coefficient, $N_{k}$, is a constant for each mode of convection and varies between 1.435 and 2.000 , depending on the values of the horizontal and vertical wave numbers.

In this method of estimating the Nusselt number, first the Rayleigh number is calculated for the situation in question, then values of $\operatorname{Ra}_{k}$ and $N_{k}$ are determined for successive values of $k$. As long as $R a_{k}$ is less than $R a$, the kth mode of convection makes its contribution to the Nusselt number by adding the term $\mathbb{N}_{k}\left(1-R a_{k} / R a\right)$ to its value. When $R a_{k}$ is greater than $R a$, the summation is stopped and the Nusselt number has been calculated. 
The heat exchange tubes of the pond's submerged heat exchanger have a vertical length of $2.0 \mathrm{~m}$, and an inside diameter of $0.00944 \mathrm{~m}$. The Rayleigh number for a tube, calculated using $E_{q} .22$, was found to be $4.18 \times 10^{12}$.

$R a_{k}$ for $k=1$ was calculated using Eqs. 23, 24, and 25. The results of the calculations were $a_{1}=1220, b_{1}=3.14$, and $R_{1}=2.20 \times 10^{12}$. Since $\mathrm{Ra}_{1}$ is less than Ra, the first term in the summation of Eq. 21 must be added to one, and $\mathrm{Ra}_{2}$ must be calculated. It was stated earlier that the constant $\mathrm{N}_{\mathrm{k}}$ varies between 1.435 and 2.000 , depending on the values of $a$ and $b$. In this situation $a$ is very large, and $N_{k}$ will be equal to 2.000 no matter what value $b$ has. Because many iterations would be required before $R a_{k}$ would exceed $R a$, a computer program was written to calculate the Nusselt number using this method. The program calculated successive values of $R a_{k}$ and if the current value of $\mathrm{Ra}_{k}$ was less than $4.18 \times 10^{12}$, the quantity $2.000\left(1.0-\mathrm{Ra}_{\mathrm{k}} / 4.18 \times 10^{12}\right)$ was added to the current value of the Nusselt number, and the next value of $\mathrm{Ra}_{k}$ was calculated. The result was an estimated value of 125 for the Nusselt number.

The Nusselt number is the ratio of the total heat transfer to the conductive heat transfer. Therefore, the total heat transferred through the fluid can be calculated by multiplying the Nusselt number by the conductive heat transfer through the fluid. Since the thermal conductivity of aqueous ethylene glycol is known, the conductive heat transfer through the fluid can be calculated using Eq. 26 .

$$
Q_{\text {cond }}=K \text { A } \Delta T / L \text {, }
$$

where

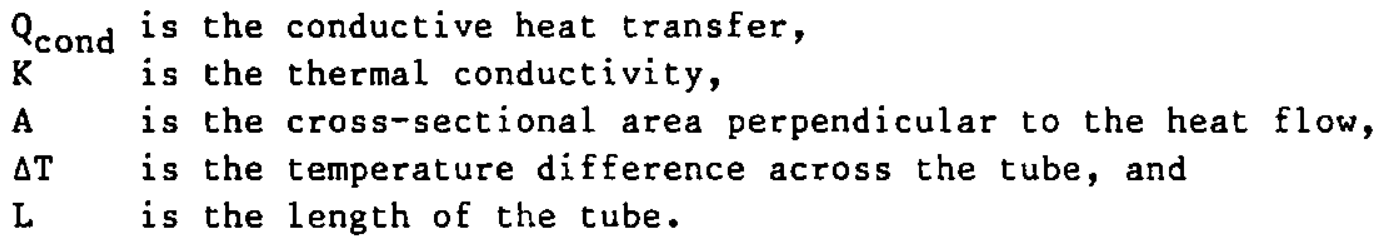

The conductive heat transfer through the fluid in each tube, calculated using Eq. 26, was found to be $2.12 \mathrm{Joule} / \mathrm{hr}$, or $0.588 \mathrm{~mW}$. Therefore, the total heat transferred through the fluid in each tube is equal to 0.0736 Watts. But heat will also be conducted through the plastic walls of each tube. The amount of heat conducted through the tube walls was calculated using Eq. 26, and the value was added to the total heat transferred through the fluid to obtain a value of $0.0737 \mathrm{~W}$ for the total heat transferred through each tube of the submerged heat ex:hanger. Since the heat exchanger contains 96 tubes, the total heat transferred from the heat storage zone of the pond to the surface by conduction and natural convection is $7.08 \mathrm{~W}$.

The calculation of the heat transfer from the heat storage zone of the pond to the surface was repeated assuming that the 96 heat transfer tubes were replaced by two tubes--an inlet and an outlet, each with an inside diameter of 2 in. Using the method of Edwards and Catton, the Nusselt number was 
estimated to be 396. The conductive heat transfer through the fluid was calculated using Eq. 26 as $0.0171 \mathrm{~W}$. Therefore, the total heat transfer through the fluid is $6.75 \mathrm{~W}$. The calculated conductive heat transfer through the tube wall (again using Eq. 26) was added to the total heat transfer through the fluid to obtain a value of $6.75 \mathrm{~W}$ for the total heat transfer through each tube. Therefore, the total heat transferred from the heat storage zone of the pond to the surface by conduction and natural convection through the two tubes is $13.5 \mathrm{~W}$.

The diameter of the largest tube in which no convection from the heat storage zone of the pond to the surface would take place was calculated. If the heat transfer tubes were small enough, no natural convection would take place within them because natural convection would be suppressed by the friction force that the wall would exert on the fluid. Using the method of Edwards and Catton, the largest diameter for which natural convection is suppressed can be calculated by finding the diameter that causes $R_{1}$ to be equal to Ra. For this case, it was found that an inside tube diameter of $C .00804 \mathrm{~m}$, or $8.04 \mathrm{~mm}$, gave $\mathrm{Ra}_{1}$ a value of $4.18 \times 10^{12}$. Therefore, if the heat exchange tubes had an inside diameter of $8.04 \mathrm{~mm}$ or less, natural convection through the tubes would be completely suppressed.

The estimation of the heat transferred through the heat exchange tubes described above assumed that the tubes ran vertically from the heat storage zone to the surface. Actually, since the tubes follow the bank of the pond, they are inclined at an angle of 45 degrees with respect to the horizontal. Because the inclined configuration has an effect on the natural convection, a second calculation of the heat transferred through the tubes was made. A correlation described by Edwards, Arnold, and Wu [38] was used to estimate the Nusselt number for a heat exchange tube inclined at a 45 degree angle. As in the previous calculation, it was assumed that the tube walls were adiabatic, and the temperature difference across the tubes was constant. The correlation was written for natural convection in long rectangular cells, but because the frictional effects in a long rectangular cell are similar to those in a circular tube, the correlation should be adequate for the calculation.

The method described by Edwards, Arnold, and wu for inclined rectangular cells is very similar to the method of Edwards and Catton that was used for the vertical tube calculation. The Nusselt number is estimated using

$$
\mathrm{Nu}=1+\sum_{k=1}^{\mathrm{M}} \mathrm{N}_{\mathrm{k}}\left[1-\mathrm{Ra}_{\mathrm{k}} /(\mathrm{Ra} \cos \mathrm{A})\right],
$$

where $A$ is the angle of inclination with respect to the vertical and all the other symbols mean the same as for Eq. 21 . 
The parameters $R a, R_{k}$, and the vertical wave number $b$ are given by the same equations as in the previous method (Eqs. 22, 23, and 25, respectively). But the horizontal wave number, $a_{k}$, is given by:

$$
a_{k}=a_{0}^{2}+b_{k}^{2 / 2} \text {. }
$$

where

$$
a_{0}{ }^{2}=[8.5 /(1+0.25 L / D)+15](L / D)^{2} .
$$

The values for $a_{k}$ will again be large because $L / D$ is large, so once again $N_{k}$ will be equal to 2.000 for all iterations.

A heat exchange tube running from the heat storage zone of the pond to the surface at an angle of 45 degrees has a length of $2.83 \mathrm{~m}$ and an inside diameter of $0.00944 \mathrm{~m}$. For this case, the correlation yielded a Nusselt number of 304. Using Eq. 26, the conductive heat transfer through the liquid was calculated to be 0.000416 Watts for each tube and the conductive heat transfer through the tube wall was calculated to be $0.000135 \mathrm{~W}$. Therefore, the total heat transferred through each tube by conduction and natural convection is $0.140 \mathrm{~W}$. Since there are 96 tubes, the total heat transferred from the heat storage zone to the surface is $13.4 \mathrm{~W}$.

The calculation was repeated, assuming that the 96 small tubes were replaced by two tubes with an inside diameter of 2 in., each inclined at an angle of 45 degrees. Using the method of Edwards, Arnold, and Wu, the Nusselt number was estimated to be 536. Using Eq.26, the heat conducted through the fluid was calculated to be $0.0121 \mathrm{~W}$, and the heat conducted through the cube walls was calculated to be $0.00123 \mathrm{~W}$. Therefore, the total heat transferred by conduction and natural convection through each tube is $6.46 \mathrm{~W}$, and the total heat transferred from the heat storage zone of the pond to the surface is $12.9 \mathrm{~W}$.

Summarizing the results, for the case of 96 tubes with an inside diameter of $0.00944 \mathrm{~m}$ running vertically from the heat storage zone of the pond to the surface, the estimated total heat transfer is $7.08 \mathrm{~W}$. If the same tubes are inclined at an angle of 45 degrees, the estimated total heat transfer is $13.4 \mathrm{~W}$. If the 96 small tubes are replaced with two tubes with an inside diameter of $2 \mathrm{in}$. running vertically through the pond, the estimated heat transfer is $13.5 \mathrm{~W}$; and if the two large tubes are inclined at an angle of 45 degrees, the estimated heat transfer is $12.9 \mathrm{~W}$. These results show that although the smallest heat loss from the heat storage zone to the surface occurs for the case of the 96 tubes running vertically, the heat transferred through the tubes does not depend strongly on the tube size or the angle of inclination. The heat transferred is of the same order of magnitude for all four cases.

Assuming that the temperature gradient through the gradient zone and the upper convecting zone of the pond is linear, the temperature difference 
between the heat storage zone and the surface is $40^{\circ} \mathrm{C}$, and the thermal conductivity of the salt water maintains a constant value of $0.632 \mathrm{~W} /\left(\mathrm{m}{ }^{\circ} \mathrm{C}\right)$, a value of $12.6 \mathrm{~W} / \mathrm{m}^{2}$ was calculated for the heat loss from the heat storage zone to the surface due to conduction through the gradient zone. Since the total surface area is $1000 \mathrm{~m}$, the total heat lost due to conduction through the gradient zone is $12.6 \mathrm{~kW}$. Therefore, the heat lost from the heat storage zone due to conduction and natural convection through the heat exchange tubes is only about 0.1 percent of the heat lost due to conduction through the gradient zone. Since this heat loss is such a small percent of the total, it is of no major concern.

\subsection{REMOVAL OF THE SUBMERGED HEAT EXCHANGER}

The submerged heat exchanger was removed from the solar pond in May of 1985. Bringing the two heat exchange mats to the surface $f$ rom the heat storage zone was easy because the heat exchanger was designed to sink when filled with aqueous ethylene glycol, but float when filled with air. The pump was connected to the mats on its suction side, and to a metal drum on its discharge side. When the pump was turned on, the ethylene glycol flowed from the mats into the drum, and the mats floated to the surface. From there the mats were floated one by one to the shore and were carefully lifted out of the water. Two people completed the entire removal operation in one afternoon.

After the heat exchange mats were out of the pond, the tubes were examined for evidence of fouling or degradation. The outside surface of the tubes was essentially free of debris and algae, and the inside surface was very clean. Fouling of the heat exchanger appears to have been minimal. The tubes also showed no signs of degradation of the plastic. The polyproylene tubes performed well in the solar pond environment. 


\section{EFFECTS OF STRATIFICATION ON HEAT TRANSFER PERFORMANCE}

\subsection{HEAT EXCHANGER EFFECTIVENESS}

As discussed in the previous chapter, the power output of the heat extraction system decreased with time. This was expected to occur as the pond temperature decreased. In order to determine how well the heat exchange system performed, it is necessary to examine the effectiveness as a function of time. The effectiveness of the total system is given by

$$
e_{\text {tot }}=\frac{T_{\text {a1r,out }}-T_{\text {amb }}}{T_{H S Z}-T_{\text {amb }}} \text {, }
$$

where $\mathrm{T}_{\mathrm{HSZ}}$ is taken at the level of the heat exchanger. The value of $e_{\text {tot }}$ as a function of time during the grain drying simulation is shown in Fig. 21 . The graph clearly shows a decrease with time. In order to determine where this decrease occurs, it is necessary to plot the effectiveness of the two components. The effectiveness of the air side of the heat exchanger is given by

$$
e_{a 1 r}=\frac{T_{a 1 r, o u t}-T_{a m b}}{T_{11 q, \text { In }}-T_{a m b}} .
$$

the value of $e_{a 1 r}$ as a function of time is shown in Fig. 22. It appears to be constant in time. The effectiveness of the liquid side of the heat exchanger is given by

$$
e_{11 q}=\frac{T_{11 q, \text { out }}-T_{11 q, \text { in }}}{T_{H S Z}-T_{11 q, 1 n}} .
$$

The value of $e_{11 q}$ as a function of time is shown in Fig. 23. While there are fluctuations, the long-term trend is a decrease in effectiveness of the liquid side.

Several hypotheses were offered to explain the decrease in effectiveness. The most obvious degradation would be fouling due to algae growth on the outside of the submerged tubes. As discussed in Sec. 5.4, examination of the tube array upon bringing the tubes to the surface showed that no algae was present. A second hypothesis is that salt formed on the outside of the tubes as the pond cooled of $f$. This is a possibility because the heat storage zone (HSZ) is saturated. The salt would dissolve from the tubes when the bundle was brought to the surface and would not have been noticed. This hypothesis was rejected because of the time dependence of the effectiveness. One would expect that more salt would form, and the effectiveness would decrease when the liquid inlet temperature decreased, the relative cold tubes acting as a nucleation site. A decrease in 1iquid inlet temperature occurred during times of low ambient temperature. However, the 


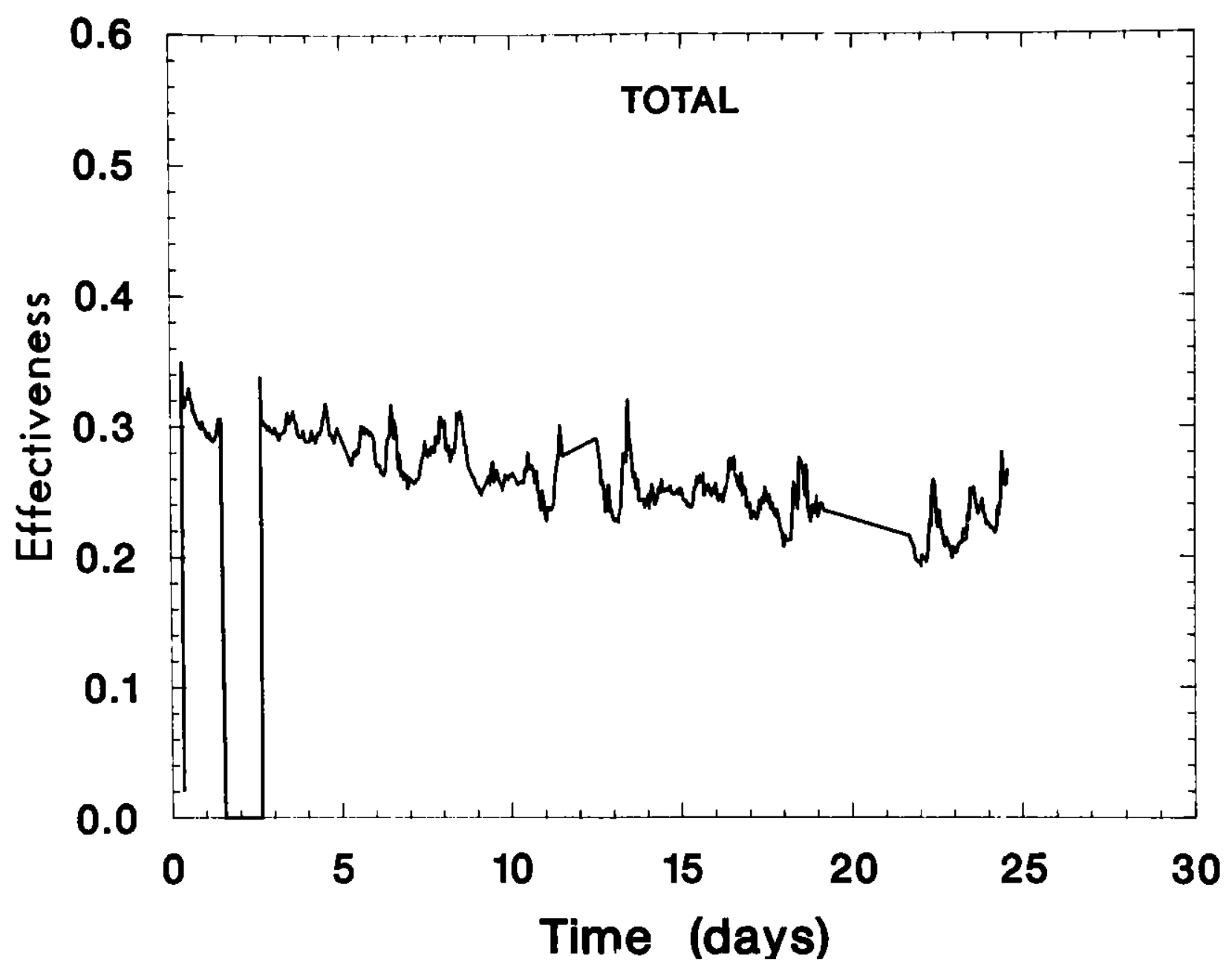

Fig. 21. Total heat exchanger effectiveness during grain drying 


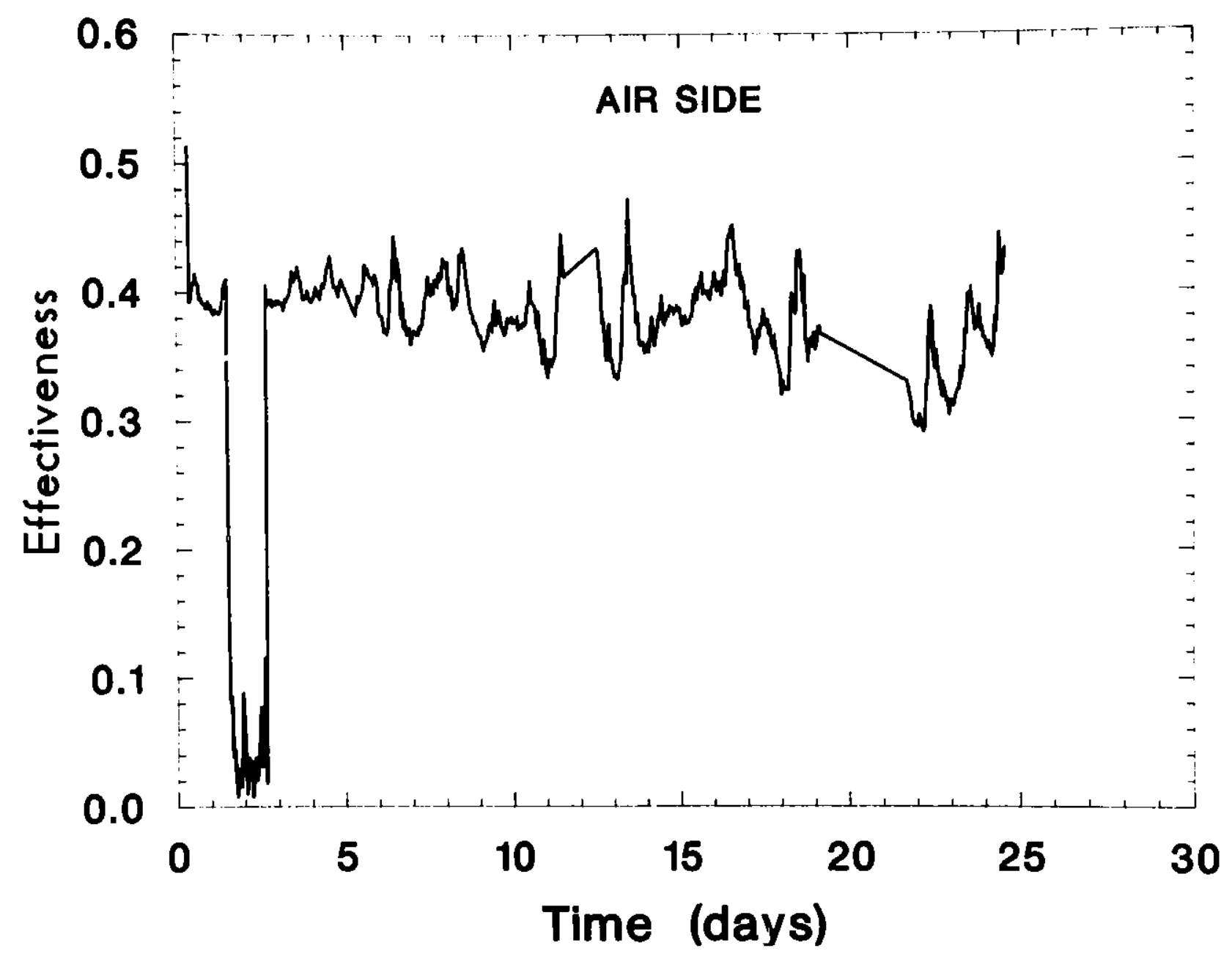

Fig. 22. Air-side effectiveness during grain drying simulation 


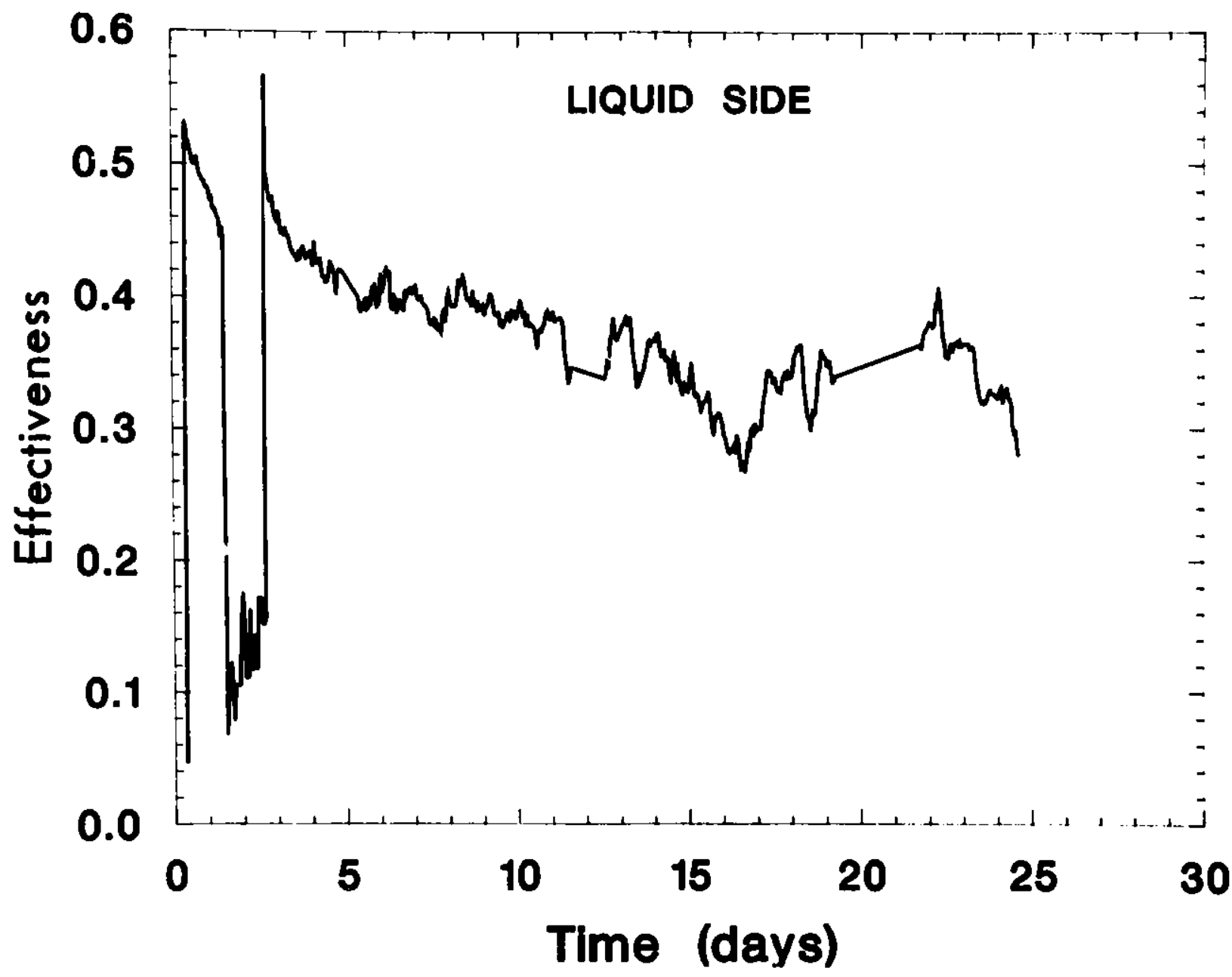

Fig. 23. Liquid-side effectiveness during grain drying simulation 
effectiveness increased during times of low ambient temperature and decreased during times of high ambient temperature, so this hypothesis was rejected. A third hyposthesis was that the insulation deteriorated with time, but the time dependence of the effectiveness in this case would be the same as for salt formation, and this hypothesis was also rejected.

A final hypothesis was that the stratification in the HSZ caused the decrease in effectiveness. This hypothesis is explored in the remaining sections of this chapter.

\subsection{LITERATURE SURVEY}

Natural convection heat transfer from a single horizontal tube has been discussed by in great detail by a number of researchers [39-47]. The theory for this phenomenon is well established and has been experimentally verified [48-50]. The effects of temperature-stratified surroundings on naturalconvection heat transfer from a horizontal surface has also been studied [5155]. In general, for a single horizontal tube in a stratified environment, the effect on heat transfer is small unless the stratification is significant across the tube diameter. According to this criterion, stratification is not significant in our case.

Because the heat exchange mats occupy a significant fraction of the pond surface area, it may behave more as a horizontal plate. The heat exchanger is also positioned close to the top of the HSZ, and the gradient zone will serve as a lid to fluid motion in the HSZ. Thus, the geometry of the surroundings, and the position of the heat exchanger in that geometry, may be important. Studies of tube arrays have less exhaustive than those for a single tube. Most of the studies are limited to heat transfer in unstratified media [56-59]. Only a few studies take into account the geometry of the container [60-64]. One may conclude from the literature survey that no one has studied the problem of the effects of stratification on the performance of a tube array in a finite box.

\subsection{MEASUREMENT OF WALL CONDUCTIVITY}

The Handbook of Plastics and Elastomers [33] gives a range of 0.084 to $0.173 \mathrm{~W} / \mathrm{m}^{\circ} \mathrm{C}$ for the thermal conductivity of polypropylene. Because it was important to know the thermal conductivity of the polypropylene heat exchange tubes more precisely than the relatively wide range given in the handbook, the thermal conductivity of ons of the tubes was determined experimentally.

To determine the thermal conductivity of the heat exchange tubes, a counter/flow double-pipe heat excharger was built by running one of the tubes through a $2.4 \mathrm{~m}$ length of $2 \mathrm{in.} \mathrm{CPVC} \mathrm{pipe.} \mathrm{During} \mathrm{the} \mathrm{experiment,} \mathrm{a} \mathrm{stream} \mathrm{of}$ hot water flowed through the inner tube, and a stream of cold water flowed through the outer pipe. Thermocouples on the inlet and outlet of each stream 
measured the water temperatures which were recorded by a data logger every minute. The flow rates were measured by timing how long it took for a certain mass of water to flow through the tube. From the experimental data, the rate at which heat was transferred from the hot stream to the cold stream could be calculated using the following equation:

$$
Q=m C_{p} \Delta T
$$

where

$Q$ is the rate of heat transfer,

$m$ is the mass flow rate of the water stream,

$C_{p}$ is the heat capacity of the water, and

$\Delta \mathrm{T}$ is the temperature change across the water stream.

Once $Q$ is known, the overall heat transfer coefficient, $U$, can be calculated using

$$
Q=U A \Delta T
$$

where

$U$ is the overall heat transfer coefficient,

$A$ is the area for heat transfer, and

$\Delta T$ is the temperature difference between the two streams.

Finally, the thermal conductivity can be calculated using

$$
U=1 /\left[1 / h_{0}+d / K+\left(A_{0} / A_{i}\right)\left(1 / h_{i}\right)\right],
$$

where

$$
\begin{aligned}
& h_{0} \text { is the outside film coef ficient, } \\
& d \text { is the wall thickness of the tube, } \\
& K \text { is the thermal conductivity of the tube, } \\
& A_{0} \text { is the outside area of the tube, } \\
& A_{i} \text { is the inside area of the tube, and } \\
& h_{i} \text { is the inside film coefficient. }
\end{aligned}
$$

The inside film coefficient, $h_{i}$, of the heat exchange tube can be estimated using the following equation, which was developed by Dittus and Boelter:

$$
\left.h_{i} D / k=0.023(D v p / \mu)^{0.8}\left(C_{p}\right) / k\right)^{0.3},
$$

where

$D$ is the inside diameter of the tube,

$k$ is the thermal conductivity of the water in the tube,

$v$ is the velocity of the water,

$p$ is the density of the water,

$C_{p}$ is the heat capacity of the water, and

$\mu$ is the viscosity of the water. 
Data were recorded at three hot water flow rates, while the cold water was maintained at the maximum flow rate that the faucet could deliver. Because the cold water flow rate was very large, there was little resistance to heat transfer on the outside surface of the heat exchange tube and the outside film coefficient, ho, can be neglected. Further, because the flow rate of the cold water was much higher than that of the hot water, there was essentially no temperature change across the inlet and the outlet of the cold stream. The temperature change and flow rate of the hot water stream were therefore used in Eq. 33 to determine how much heat was transferred from the hot stream to the cold stream.

The steady-state water temperctures for the three experimental hot water flow rates are given in Table 10. Applying Eqs. 33 through 36 to these data yields the results shown in Table 11 . The average experimental value for the thermal conductivity of the polypropylene heat exchange tubes is 0.149 $\mathrm{W} / \mathrm{m}^{\circ} \mathrm{C}$. This value is near the middle of the range given in the handbook.

Table 10. Steady-State Water Temperatues for Experimental Hot Water Flow Rates

$\begin{array}{cc}\text { Hot Water } & \text { Hot Water } \\ \text { Flow Rate, } & \text { Inlet Temp., } \\ \text { gal/s } & { }^{\circ} \mathrm{C}\end{array}$

Hot Water
Outlet Temp.,
${ }^{\circ} \mathrm{C}$

Cold Water Temp.,

${ }^{\circ} \mathrm{C}$

\begin{tabular}{lllll}
\hline First flow rate & 27.9 & 43.7 & 41.65 & 15.0 \\
Second flow rate & 48.9 & 45.3 & 44.1 & 15.0 \\
Third flow rate & 70.9 & 45.7 & 44.8 & 15.0 \\
\hline
\end{tabular}

Table 11. Results of Calculations for Experimental Flow Rates

\begin{tabular}{lllll}
\hline & $\begin{array}{c}Q, \\
W\end{array}$ & $\begin{array}{l}\mathrm{U}^{2} \\
\mathrm{~W} / \mathrm{m}^{\circ} \mathrm{C}\end{array}$ & $\begin{array}{c}\mathrm{h}_{\mathrm{i}} \\
\mathrm{W} / \mathrm{m}^{\circ} \mathrm{C}\end{array}$ & $\begin{array}{c}\mathrm{K}, \\
\mathrm{W} / \mathrm{m}^{\circ} \mathrm{C}\end{array}$ \\
\hline First flow rate & 238 & 89.9 & 2,470 & 0.150 \\
Second flow rate & 251 & 88.8 & 3,870 & 0.146 \\
Third flow rate & 267 & 92.2 & 5,220 & 0.150 \\
\hline
\end{tabular}




\subsection{DISCUSSION}

Although the measured tube thermal conductivity is higher than in the design estimate ( $\mathrm{Sec} .3 .1$ ), the natural-convection thermal resistance is less than $10 \%$ that of the tube wall. It is not clear that a change in the natural convection component can make a large impact in the effectiveness. It is suggested that the phenomenon should be investigated further in the laboratory under more controlled conditions. As additional hypothesis to be investigated is that the downward plumes from the outside tubes of the heat exchange mats plus the close proximity of the mats to the top of the HSZ serve to isolate the inner tubes of the mats and make them less effective for heat transfer. 


\section{BRINE WITHDRAWAL HEAT EXTRACTION SYSTEM}

\subsection{GENERAL CONCERNS}

Brine extraction from the solar pond is an alternative to use of the submerged heat exchanger. In the brine extraction method (see Fig. 3), hot brine is taken from the pond near the top of the heat storage zone (HSZ), passed through an external heat exchanger, and the cooled brine is returned to the pond near the bottom of the HSZ. The main advantage of this method, compared with the submerged heat exchanger method, is that there is no inefficiency associated with withdrawing the heat from the pond. The heat is available at the maximum possible temperature, i.e., the temperature at the top of the HSZ. A secondary advantage is that return of cold brine to the bottom of the HSZ could enhance the stratification in the HSZ, improving pond thermal efficiency by reducing heat loss to the ground. The major disadvantage of the brine extraction method is that one must be very careful that the process of brine extraction and reinjection does not deteriorate the gradient zone (GZ). A secondary disadvantage is that hot brine must be pumped around, and care must be taken that corrosion of the pump and external heat exchanger does not occur.

The following section describes considerations involved in the design of the brine withdrawal heat extraction system.

\subsubsection{Effect of Brine Extraction on Solar Pond Stability}

The effect on solar pond stability due to brine extraction and reinjection in the HSZ is not completely understood. Research in this area has been summarized by Zangrando [65]. The basic phenomenon appears to be that motion of the extracted fluid causes turbulence in the HSZ. The turbulent disturbance causes mixing of the HSZ and GZ near the GZ lower boundary. The resulting erosion of the $\mathrm{GZ}$ reduces pond thermal efficiency and increases the rate of salt transport upward. Extraction of the brine seems to cause far fewer problems than reinjection (the analogy is pulling rather than pushing a rope). The reinjected brine is much more likely to cause turbulence. But if the reinjected brine is cold enough to produce good stratification, then the turbulence produced should be confined to the bottom of the HSZ and should not affect the GZ.

The stability of a stratified flow is governed mainly by the Richardson number [66], defined by

$$
\operatorname{Ri}=g(1 / r \mathrm{dr} / \mathrm{dz}) /(\mathrm{dU} / \mathrm{dz})^{2} \text {, }
$$


where

$\mathrm{g}$ is the acceleration of gravity, $\mathrm{g}=9.8 \mathrm{~m} \mathrm{~s}^{-2}$,

$r$ is the density, in $\mathrm{kg} \mathrm{m}^{-3}$,

$z$ is the vertical coordinate (positive downward), in $m$, and

$\mathrm{U}$ is the horizontal velocity, in $\mathrm{m} \mathrm{s}^{-1}$.

Under the best of circumstances the flow is stable for $R i>0.25$. Several experiments with solar pond situations indicate that in practice a minimum of 0.85 is more typical [67]. We choose a design value of $R i=1.0$.

Another means of characterizing stratified flow from a source, or to a sink, is the Froude number,

$$
F r=U\left[B d^{2}(1 / r d r / d z)\right]^{-0.5},
$$

where

d is a characteristic length of the system (e.g. the depth of the HSZ), in $\mathrm{m}$.

The Froude number typically distinguishes tranquil from disturbed flow in free surface systems, with Fr $<1.0$ characterizing tranquil flow.

A further consideration for brine extraction is that the flow entering or leaving a diffuser should be laminar rather than turbulent. The parameter characterizing this aspect of the flow is the Reynolds number

$$
\operatorname{Re}=\mathrm{Ud} / \mathrm{n} \text {, }
$$

where

$\mathrm{n}$ is the fluid kinematic viscosity, in $\mathrm{m}^{2} \mathrm{~s}^{-1}$, and

$d$ is here the separation distance of the diffuser plates at

the outlet, in $\mathrm{m}$.

In Eq. 37 it is not immediately clear how to choose U, the horizontal velocity. In the most optimal situation $U$ should be known everywhere in the pond; however, this is not likely to be realized in practical situations. If $U$ is taken as the average velocity in the HSZ, then it is unlikely that any disturbance will be predicted. It seems more reasonable to take $U$ as the maximum velocity that occurs in the HSZ, i.e. the value immediately adjacent to the extraction diffuser. This definition is based on the assumption that a local disturbance at the GZ lower boundary will erode the GZ faster than phenomena occurring over the rest of the boundary area can repair. The value for $\mathrm{dr} / \mathrm{dz}$ is determined by the salt and temperature gradients at the GZ lower boundary. We can then use Eq. 37 to determine the maximum permissible fluid velocity. Knowing the allowed fluid velocity and desired heat extraction rate, we can determine the size of the extraction diffusers. 


\subsubsection{Diffuser Design}

Extraction Diffuser

As shown in Fig. 6, the salinity gradient in the RSGSP is nearly constant over the depth of the GZ. We take the value at the $\mathrm{GZ}$ lower boundary to be 10 \% $\mathrm{m}^{-1}$. As indicated in Fig. 7, the temperature gradient at the GZ lower boundary usually is close to zero. For conservative design purposes, however, we take the value as the average for the entire $\mathrm{Gz},--20^{\circ} \mathrm{C} \mathrm{m}^{-1}$. The density gradient is given by

$$
\mathrm{dr} / \mathrm{dz}=\mathrm{a} d \mathrm{~d} / \mathrm{dz}+\mathrm{b} d \mathrm{~d} / \mathrm{dz} \text {, }
$$

where

$$
\begin{aligned}
& a=d r / d T \text { and } \\
& b=d r / d S .
\end{aligned}
$$

For $\mathrm{NaCl}$ solutions at $\mathrm{T}=70^{\circ} \mathrm{C}$ and $\mathrm{S}=20 \%$,

$$
\begin{aligned}
a & =-0.54 \mathrm{~kg} \mathrm{~m}^{-3}{ }^{\circ} \mathrm{c}^{-1}, \\
b & =7.9 \mathrm{~kg} \mathrm{~m}^{-3} \%^{-1}, \\
r & =1125 \mathrm{~kg} \mathrm{~m}^{-3}, \text { and } \\
\mathrm{dr} / \mathrm{dz} & =79-11=68 \mathrm{~kg} \mathrm{~m}^{-4}
\end{aligned}
$$

For the calculation of $\mathrm{dU} / \mathrm{dz}$, we set $\mathrm{dz}$ as the distance between the Gz lower boundary and the diffuser. For simplicity, we assume $\mathrm{dz}=0.1 \mathrm{~m}$. $\mathrm{dU}$ is the maximum $f$ luid velocity at the diffuser inlet (assuming $U=0$ at the $G Z$ lower boundary). Setting $\mathrm{Ri}=1.0$, we solve $\mathrm{Eq} .37$ to obtain

$$
\begin{aligned}
U_{\max } & =d z[g \mathrm{dr} / \mathrm{dz} /(\mathrm{rRi})]^{0.5} \\
& =(0.1 \mathrm{~m})\left[\left(9.8 \mathrm{~m} \mathrm{~s}^{-2}\right)\left(68 \mathrm{~kg} \mathrm{~m}^{-4}\right) /\left(1150 \mathrm{~kg} \mathrm{~m} \mathrm{~m}^{-3}\right)\right]^{0.5} \\
& =0.076 \mathrm{~m} \mathrm{~s}^{-1} .
\end{aligned}
$$

For a working velocity, we divide this by a factor of 2 for safety. We take $\mathrm{U}_{\max }=0.04 \mathrm{~m} \mathrm{~s}^{-1}$. We now use Eq. 39 to calculate the maximum separation distance between the diffuser plates. The flow should be laminar if $\operatorname{Re}<2000$. Solving for d in Eq. 39,

$$
\begin{aligned}
\mathrm{d} & =(2000)\left(5.6 \times 10^{-7} \mathrm{~m}^{2} \mathrm{~s}^{-1}\right) /\left(0.04 \mathrm{~m} \mathrm{~s}^{-1}\right) \\
& =0.028 \mathrm{~m} .
\end{aligned}
$$


For a fixed flow rate, reduction of the distance between the diffuser plates results in an increased flow velocity just outside the diffuser. To ensure that there is no disturbace to the $\mathrm{GZ}$, we must increase the distance between the diffuser and the GZ Lower boundary.

We note that both $d$ and $U_{\max }$ are below the limits set by Tabor [68], based on a Froude number argument.

We assume a maximum extraction flow rate of $V=2.2 \times 10^{-3} \mathrm{~m}^{3} \mathrm{~s}^{-1}$

$\mathrm{gpm})$. The exit area is then given by

$$
\begin{aligned}
A & =V / U_{\max }=\left(2.2 \times 10^{-3} \mathrm{~m}^{3} \mathrm{~s}^{-1}\right) /\left(0.04 \mathrm{~m} \mathrm{~s}^{-1}\right) \\
& =0.055 \mathrm{~m}^{2} .
\end{aligned}
$$

If the diffuser is in the shape of a circle, the required perimeter is given by

$$
\begin{aligned}
\mathrm{P} & =\mathrm{A} / \mathrm{d}=\left(0.055 \mathrm{~m}^{2}\right) /(0.028 \mathrm{~m}) \\
& =1.96 \mathrm{~m} .
\end{aligned}
$$

If the diffuser is a semicircle, then the diffuser diameter is

$$
\begin{aligned}
D & =2 \mathrm{P} / \pi=(2)(1.96 \mathrm{~m}) /(3.14159) \\
& =1.25 \mathrm{~m} .
\end{aligned}
$$

\section{Injection Diffuser}

For design of the injection diffuser, again we start with Eq. 37, but now we take $\mathrm{dz}=0.5 \mathrm{~m}$, approximately half the depth of the HSZ. Here we assume that the density gradient is produced by temperature stratification in the HSZ. For a worst case, we assume that the injection temperature is $5^{\circ} \mathrm{C}$ lower than the extraction temperature, so that $\mathrm{dT} / \mathrm{dz}=5^{\circ} \mathrm{C} \mathrm{m}^{-1}$. Then

$$
\begin{aligned}
\mathrm{dr} / \mathrm{dz} & =\left(-0.54 \mathrm{~kg} \mathrm{~m}^{-3}{ }^{\circ} \mathrm{C}^{-1}\right)\left(-5^{\circ} \mathrm{C}\right) \\
& =2.7 \mathrm{~kg} \mathrm{~m}^{-4} .
\end{aligned}
$$

Solving for $U_{\max }$ in Eq. 37 ,

$$
\begin{aligned}
U_{\max } & =(0.5 \mathrm{~m})\left[\left(9.8 \mathrm{~m} \mathrm{~s}^{-2}\right)\left(2.7 \mathrm{~kg} \mathrm{~m}^{-4}\right) /\left(1150 \mathrm{~kg} \mathrm{~m}^{-3}\right)\right]^{0.5} \\
& =0.076 \mathrm{~m} \mathrm{~s}^{-1} .
\end{aligned}
$$


We should have no trouble if we use the same diffuser for injection as we did for extraction.

The Froude number for this case is

$$
\begin{aligned}
F r & =\left(0.04 \mathrm{~ms}^{-1}\right)\left[\left(9.8 \mathrm{~ms}^{-2}\right)(1.0 \mathrm{~m})^{2}\left(2.7 \mathrm{kgm}^{-4}\right) /\left(1150 \mathrm{kgm}^{-3}\right)\right]-0.5 \\
& =0.26 .
\end{aligned}
$$

From pp. 110-122 of Ref. 66, we note that for Froude numbers at and below this value, we should expect that the injected cold brine remain at the bottom of the HSZ, and that the HSZ be stratified. For Froude numbers above this value, the HSZ is likely to be mixed, although there should be minimal effect on the GZ (much higher $d r / d z$ ). Thus, at our maximum flow rate, we will need to maintain a temperature difference of at least $5^{\circ} \mathrm{C}$ between the extraction and injection diffusers if we wish to maintain stratification in the HSZ. This simple analysis ignores several of the effects discussed in Sec. 2.1, however.

For the heat extraction experiments, it will be necessary to have diffusers of several sizes to operate the pond under conditions where some GZ erosion becomes evident. The $1.25 \mathrm{~m}$ diameter diffuser is the largest size needed. The diffusers will be in the form of semicircles because they will be mounted near the pond side wall for easy adjustment. The spacing between the diffuser plates will also be adjustable so that the effect of different Reynolds numbers on pond stability can be tested.

\subsubsection{Effects of Brine Saturation}

Because the bottom of the ANL solar pond is filled with nearly saturated salt solution, there is a danger that when the brine cools off, it will crystallize in the heat exchange system, plugging up the external brineto-air heat exchanger and possibly the diffuser as well. It is recommended that the diffusers be periodically brought to the surface (say, once a day), and low-salinity surface water be circulated through the heat exchanger to clear the system of any crystallized salt. The amount of plugging is difficult to estimate beforehand, so the amount of needed flushing will have to be determined experimentally.

A good way to decrease the plugging problem is to position the extraction diffuser somewhat above the salt pile. This will result in the upward movement of the GZ lower boundary and a decrease in the salinity of the HSZ. In this case, the heat exchange process will act to stabilize the boundary by decreasing the temperature below the heat exchanger.

A similar general problem also relates to pumping salt brine. The major problem in pumping salt solution is the effect of salt crystals. The effect is especially severe for intermittent pumping. When the pump is turned off, the liquid tends to remain in the pump and in the pump seals. The water 
evaporates, leaving behind the salt crystals. When the pump is started up again, the salt crystals are usually set in motion before they have a chanct to redissolve. Their action is abrasive, particularly on seals. In the case of mechanical seals, heavy leakage may result and the seals are expensive and difficult to repair. Packing seals require some leakage anyway and will be subject to the same scoring problems. Note that the pumping of a saturated brine is likely to always pose this problem, even if the pumps are always on. Intermittent pumping will always suffer this problem no matter what part of the solar pond is being pumped. If an extensive fresh water supply is available, then perhaps the pumps can be rinsed. A more likely procedure is the dismantling and cleaning of the pump every time it is turned off. In some mechanical seals, liquid is continuously circulated through the seals. This may alleviate most of the problem if the system works as designed. Packing seals always require some leakage for lubrication, although when gritty liquids are handled, clean water under pressure is forced into the stuffing box.

\subsection{SYSTEM DESCRIPTION}

The brine withdrawal heat extraction system consists of an air-side component, a liquid-side component, and a liquid-to-air heat exchanger. The liquid-side component pumps hot brine from the HSZ of the pond to the heat exchanger and then returns the cooled brine back to the HSZ. The air-side component takes ambient air and blows it across the coils of the heat exchanger. The end product is heated air. In the grain drying simulation the heated air is discharged to the environment. In a commercial system the heated air would pass through a bin filled with moist grain.

The air-side component is the same as that used in the submerged heat exchanger experiments. It consists of a centrifugal blower powered by an electric motor, an inlet duct with air filters and bird screen, and an outlet duct. The only change from the submerged heat exchanger experiments is that the outlet ductwork was turned on its side so that the inlet and outlet of the liquid-to-air heat exchanger could be from the sidé.

The brine-to-air heat exchanger consists of a set of aluminum-finned tubes. The finned height is $42 \mathrm{~cm}$. The length is $102 \mathrm{~cm}$. The tubes are 1.6 $\mathrm{cm}$ diameter, composed of $70 / 30$ Cupro Nickel, and arranged in six rows. Plastic CPVC pipe is installed on the inlet and outlet ports to facilitate installation of instruments and connection to the 1 iquid-side component.

The liquid-side component consists of an extraction diffuser, a pump, an injection diffuser, and connecting plastic pipe and rubber steam hose. The extraction diffuser withdraws brine from the pond and delivers it to the pump. The brine then passes from the pump to the heat exchanger and then back to the pond via the injection diffuser. A $5 \mathrm{~cm}$ inner diameter hose connects the extraction diffuser to the pump inlet. A $3.8 \mathrm{~cm}$ inner diameter hose 
connects the pump outlet to the heat exchanger and the heat exchanger to the injection diffuser. The hoses are covered with foamed pipe insulation.

The brine pump is a plastic centrifugal pump, with magnetic coupling between the motor and the impeller to eliminate the shaft seal and avoid leakage. The impeller and magnet are made from polypropylene. The pump housing is made of ryton. The electric motor is $120 \mathrm{~V}$, single phase, $560 \mathrm{~W}$ ( $3 / 4 \mathrm{HP})$. The pump is mounted at the top of the pond berm, approximately 70 $\mathrm{cm}$ above the pond surface.

The inlet diffuser and outlet diffuser are made from acrylic plastic and attached to CPVC pipe that leads to the surface. The diffusers consist of two $1 \mathrm{~cm}$ thick plates separated by spacers. The shape of the plates is approximately semicircular. The diffusers are mounted on a small platform so that the diffuser plates are oriented horizontally in the pond. Each platform can slide up and down on two PVC pipes that are placed on the west bank of the pond. The back of each diffuser is toward the pond wall and the gap at this straight edge is covered by a thin strip of acrylic sheet. The CPVC pipe enters the diffuser just in front of the back edge. The extraction diffuser has a diameter of $60 \mathrm{~cm}$ and a gap of $2.2 \mathrm{~cm}$. The injection diffuser, shown in Fig. 24, has a diameter of $65 \mathrm{~cm}$ and a gap of $0.6 \mathrm{~cm}$. The CPVC pipe that is connected to the extraction diffuser has an inner diameter of $7.6 \mathrm{~cm}$ and the CPVC pipe that is connected to the injection diffuser has an inner diameter of $3.8 \mathrm{~cm}$. The extraction diffuser gap and pipe diameter are made large to reduce the pressure drop on the suction side of the pump.

Injection tests were performed at the pond surface to test the laminar nature of the flow around the diffusers. In separate tests, pond surface water was pumped through each of the diffusers and back to the pond surface. For each diffuser the flow was nearly uniform, with the maximum flow about twice the average flow. When the top of the diffuser gap was about $1 \mathrm{~cm}$ below the surface of the pond, surface ripples were barely noticeable, indicating that flow to and from the diffusers during heat extraction should be laminar.

Instrumentation for the liquid-side of the system consists of a flow meter, an inlet thermocouple to the heat exchanger, an outlet thermocouple to the heat exchanger, and a flow visualization port, which consists of a $10 \mathrm{~cm}$ long piece of acrylic pipe threaded into the CPVC plastic pipe at the outlet of the heat exchanger. The flow meter is the same paddle wheel type sensor that was used in the submerged heat extraction experiments.

The approximate cost of the brine withdrawal heat extraction system is shown in Table 12. 


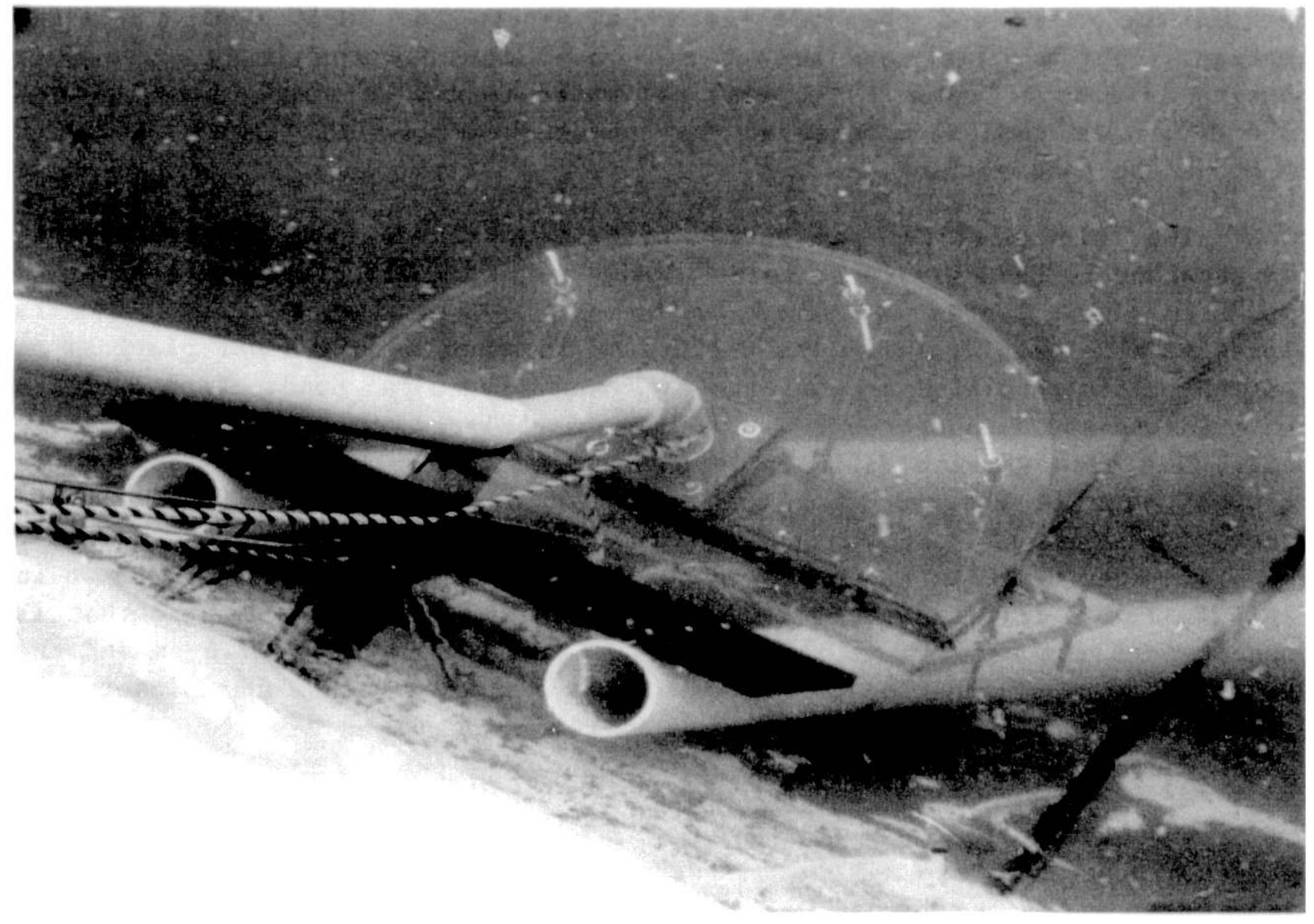

Fig. 24. Injection diffuser 
Table 12. Cost of brine withdrawal heat extraction system.

\begin{tabular}{lr}
\hline & $\begin{array}{r}\text { Cost, } \\
1984 \text { US } \$\end{array}$ \\
\hline Item & 700 \\
Pump & 2,200 \\
Brine-to-Air HX & 500 \\
Hosfusers and Insulation & 1,000 \\
Blower & 1,150 \\
Ductwork & 2,000 \\
Electrical & 450 \\
$\quad$ Total & 8,050 \\
\hline
\end{tabular}

\subsection{RESULTS}

The heat extraction system was installed in the RSGSP and tested for several hours during several consecutive days in August. The tests were satisfactory, and the system was turned off. In October, initial attempts to turn the system back on were frustrated by salt deposits in the CPVC pipes, which had apparently formed during the month-long idle period when the diffusers were left in place. The pipes for both the inlet and outlet diffusers were almost completely filled with salt crystals, which completely blocked the flow of brine. After the diffuser pipes were taken apart, the salt cleaned out of the pipes, and the pipes put back together, the system worked smoothly. Another minor problem with the system occurred during the first few days of the grain drying simulation, when the blower would shut of $f$ after several hours of operation. This problem was traced to the thermal overload breakers, which were replaced.

Using the brine withdrawal heat extraction system, continuous heat extraction from the RSGSP began Oct. 22, 1985, and lasted until Dec. 1, 1985. During this 40 day period a total of $225 \times 10^{9} \mathrm{~J}$ of energy were extracted. As with the submerged heat extraction experiments, the system was run to simulate grain drying. The experiment was run in two phases. During the first phase, which lasted from Oct. 22 to Nov. 4, the extraction diffuser was located $67 \mathrm{~cm}$ above the pond bottom. During the second phase, Nov. 4 to Dec. 1 , the extraction diffuser was $85 \mathrm{~cm}$ above the pond bottom. During both phases the injection diffuser was $39 \mathrm{~cm}$ above the pond bottom. The estimated error in measuring these heights was about $5 \mathrm{~cm}$. 
The pump rate was $2.65 \mathrm{~L} / \mathrm{s}$ (42 $\mathrm{gpm}$ ) during phase 1 and $2.31 \mathrm{~L} / \mathrm{s}$ (37 gpm) during phase 2. A lower pump rate occurred in phase 2 because when the diffuser was raised, the CPVC pipe attached to it was also raised, requiring a larger net positive suction head for the pump. During phase 1, approximately a $2.5 \mathrm{~cm}$ thickness of the HSZ was circulated through the heat exchange system every hour. The cycling time to circulate the fluid in the HSZ between the two diffusers is about 11 hours. During phase 2, approximately $2.2 \mathrm{~cm} / \mathrm{hr}$ was circulated, with a residence time of $21 \mathrm{hr}$.

The temperature histories at several points in the heat extraction system during the 40 day period are shown in Fig. 25. The L-IN (liquid in) temperature corresponds to the temperature of the HSZ. The power output of the system, in terms of heating the ambient air, is shown in Fig. 26. The energy extracted from the system could have been used to dry approximately 650 $\mathrm{m}^{3}$ (18,300 bushels) of corn from $25 \%$ to $15 \%$ moisture content. Fig. 27 shows the effectiveness of the heat exchange system, which averaged about 0.6 .

The temperature profile before heat extraction began is shown in Fig. 28. Contrasting the profile in Fig. 28 with the profiles in Fig. 18, at the end of 1984 the boundary between the HSZ and the gradient zone was at approximately $0.9 \mathrm{~m}$, whereas the boundary was at approximately $0.5 \mathrm{~m}$ by 0ct. 1985. This is attributed to the depletion of the salt piles at the bottom of the pond. Because the top of the HSZ is also the upper boundary of the saturated brine, it was decided to initially place the extraction diffuser at $0.67 \mathrm{~m}$, a position above the saturated region, in order to avoid pumping saturated brine and salt crystallization in the heat exchanger.

Selected temperature profiles in the lower $2 \mathrm{~m}$ of the pond for the first phase of the experiment, are shown in Fig. 29. Prominent features noticeable in the figure are:

- A temperature gradient just above the injection diffuser during the first day of phase 1 ,

- A rapid increase in the height of the HSZ upper boundary during the first several days of phase 1 to approximately 0.8 $\mathrm{m}$, as denoted by the mixed zone of constant temperature,

- A more or less constant height of the HSZ upper boundary at $0.8 \mathrm{~m}$ for the remainder of phase 1 ,

- A temperature inversion forming in the lower part of the gradient zone, and

- No effect on the upper part of the gradient zone.

At the beginning of the second phase of the experiment at day 12.65 , the extraction diffuser was raised to a height of $0.85 \mathrm{~m}$. The purpose of this movement was to try to duplicate the temperature gradient formed at the injection diffuser, and see if the gradient zone lower boundary would erode further. Selected temperature profiles in the lower $1.5 \mathrm{~m}$ of the pond for the second phase are shown in Fig. 30. Also shown in the figure is a profile 


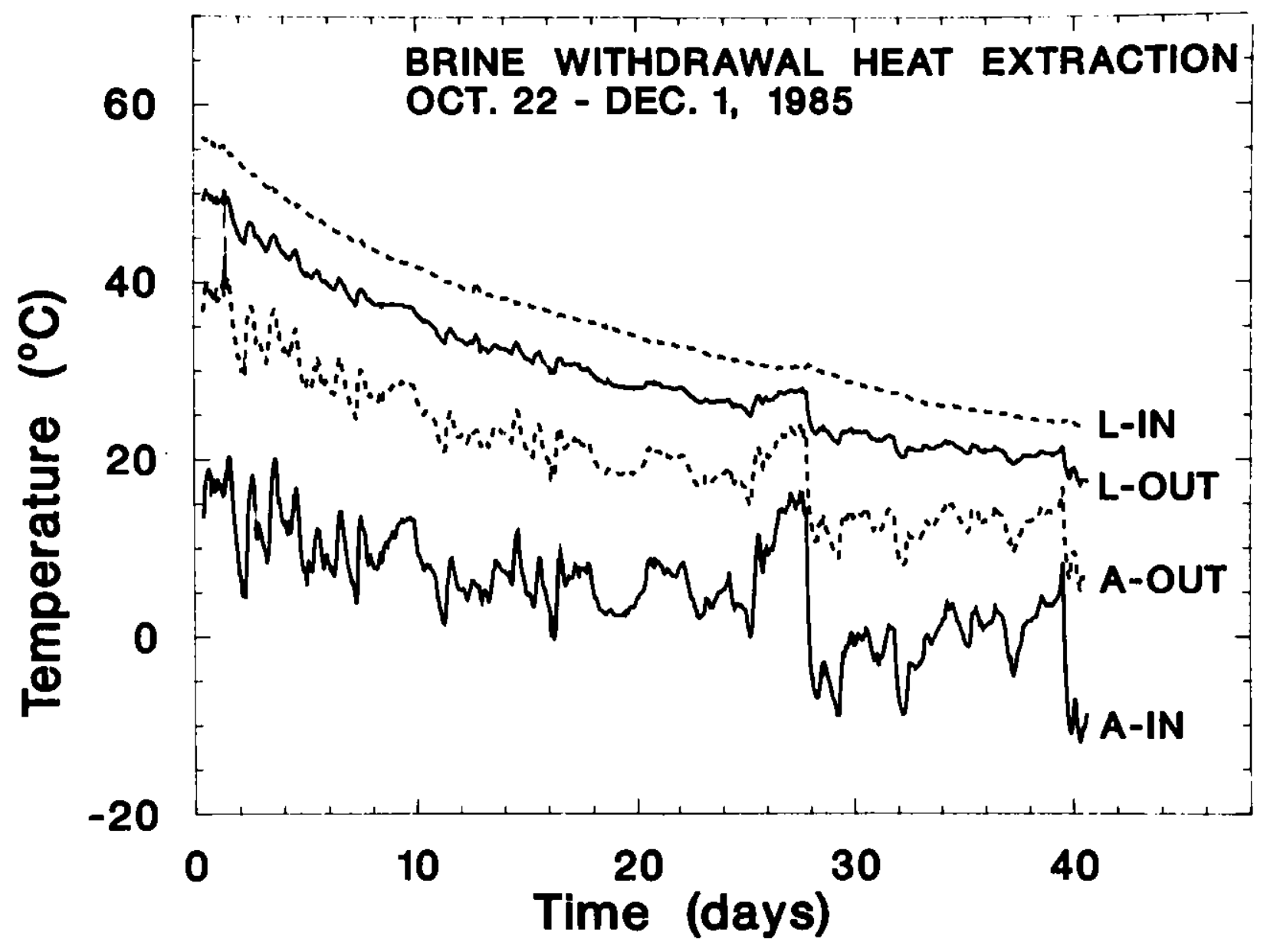

F1g. 25. Temperature histories during brine withdrawal heat extraction 


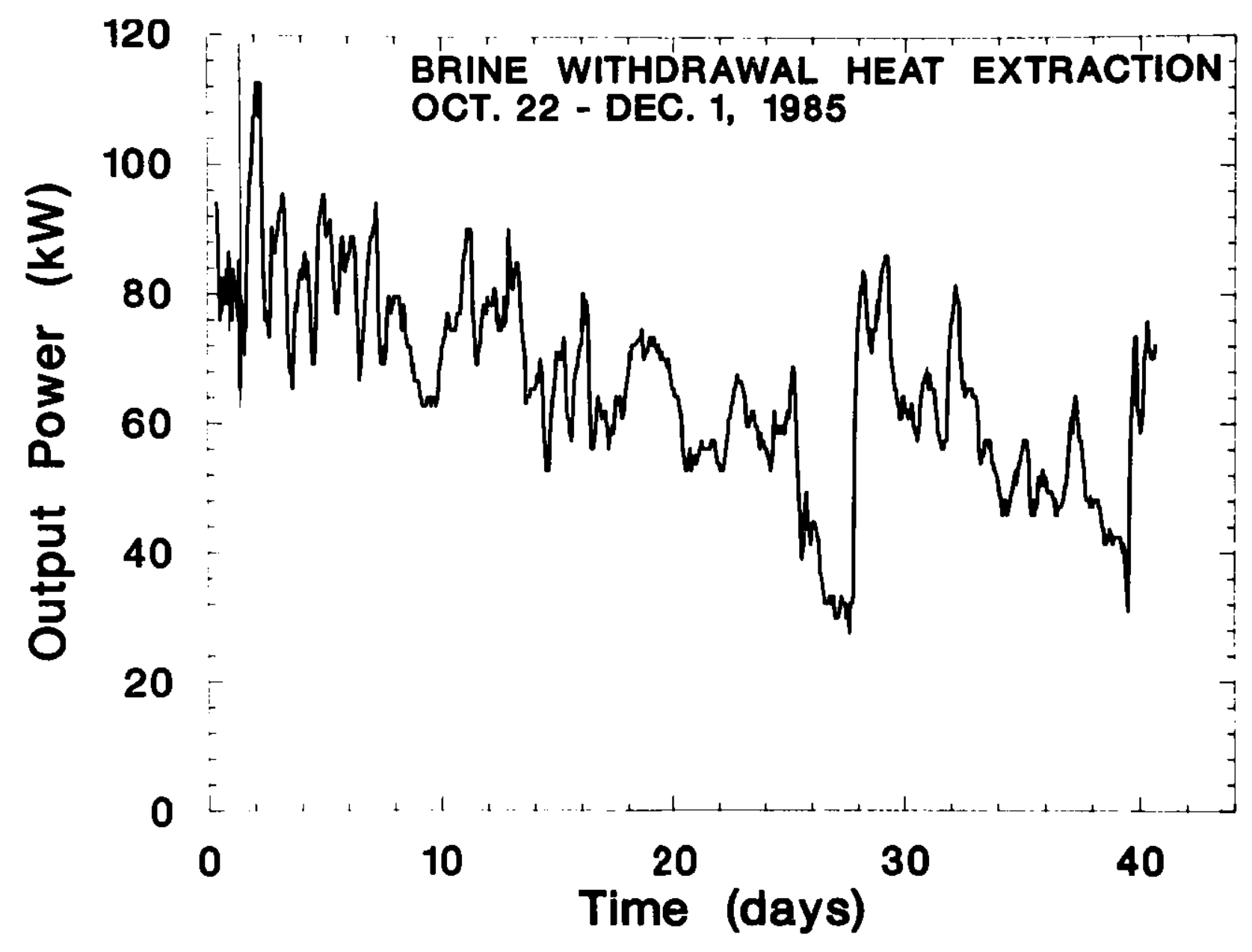

Flg. 26. Thermal power output during hrine withdrawal heat extraction 


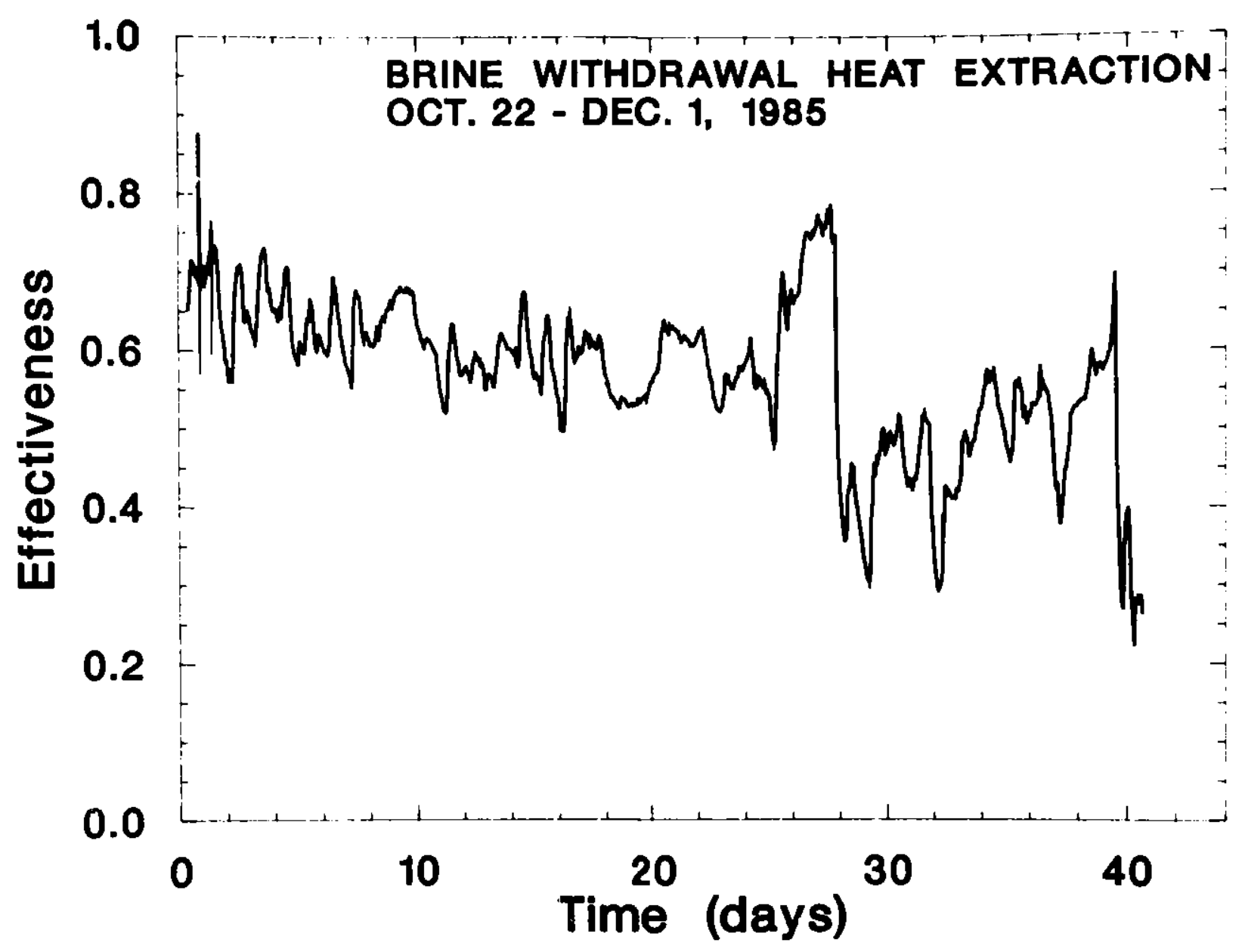

Flg. 27. Heat exchanger effectiveness during brine withdrawal heat extraction 


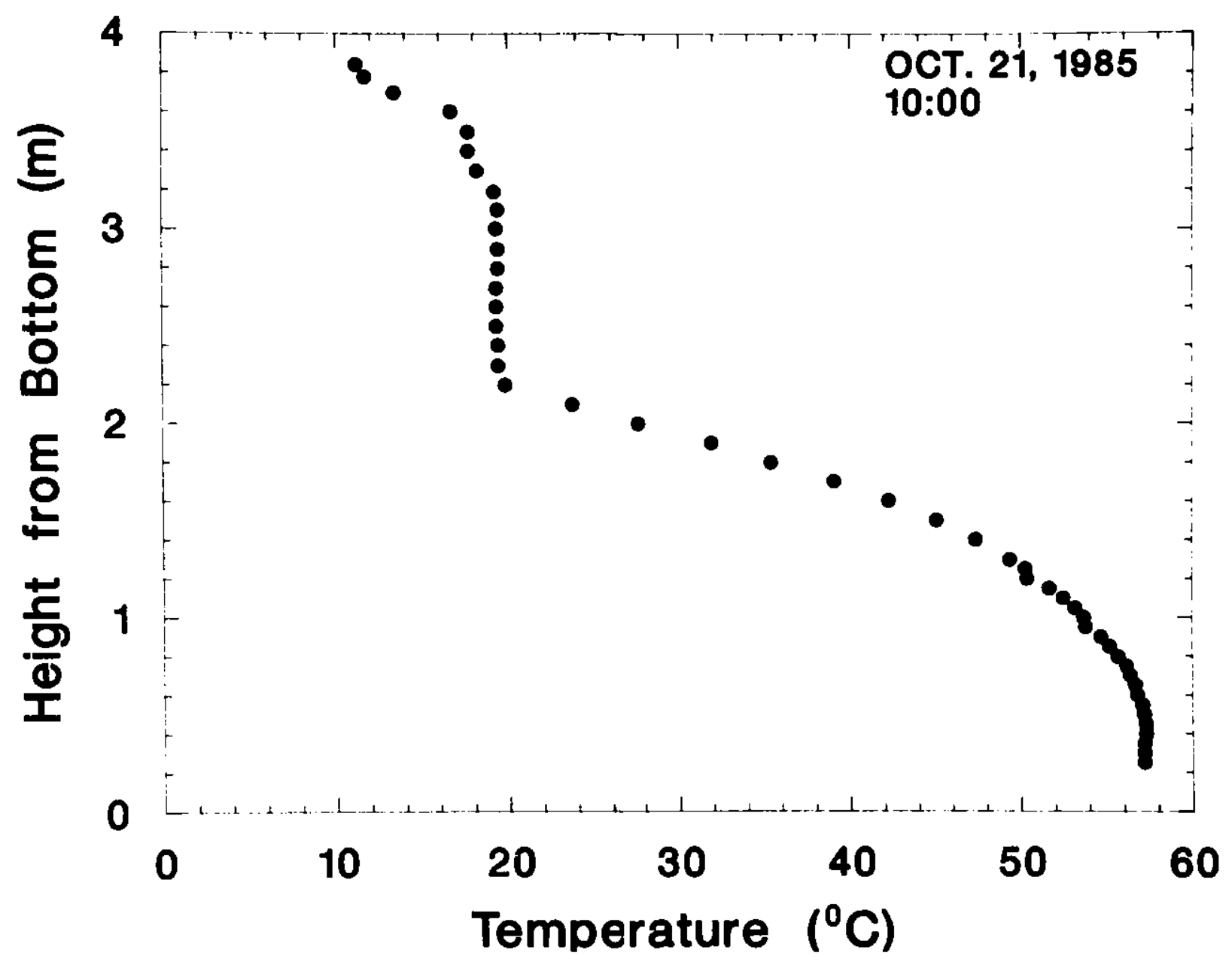

Fig. 28. Temperature profile before brine withdrawal heat extraction 


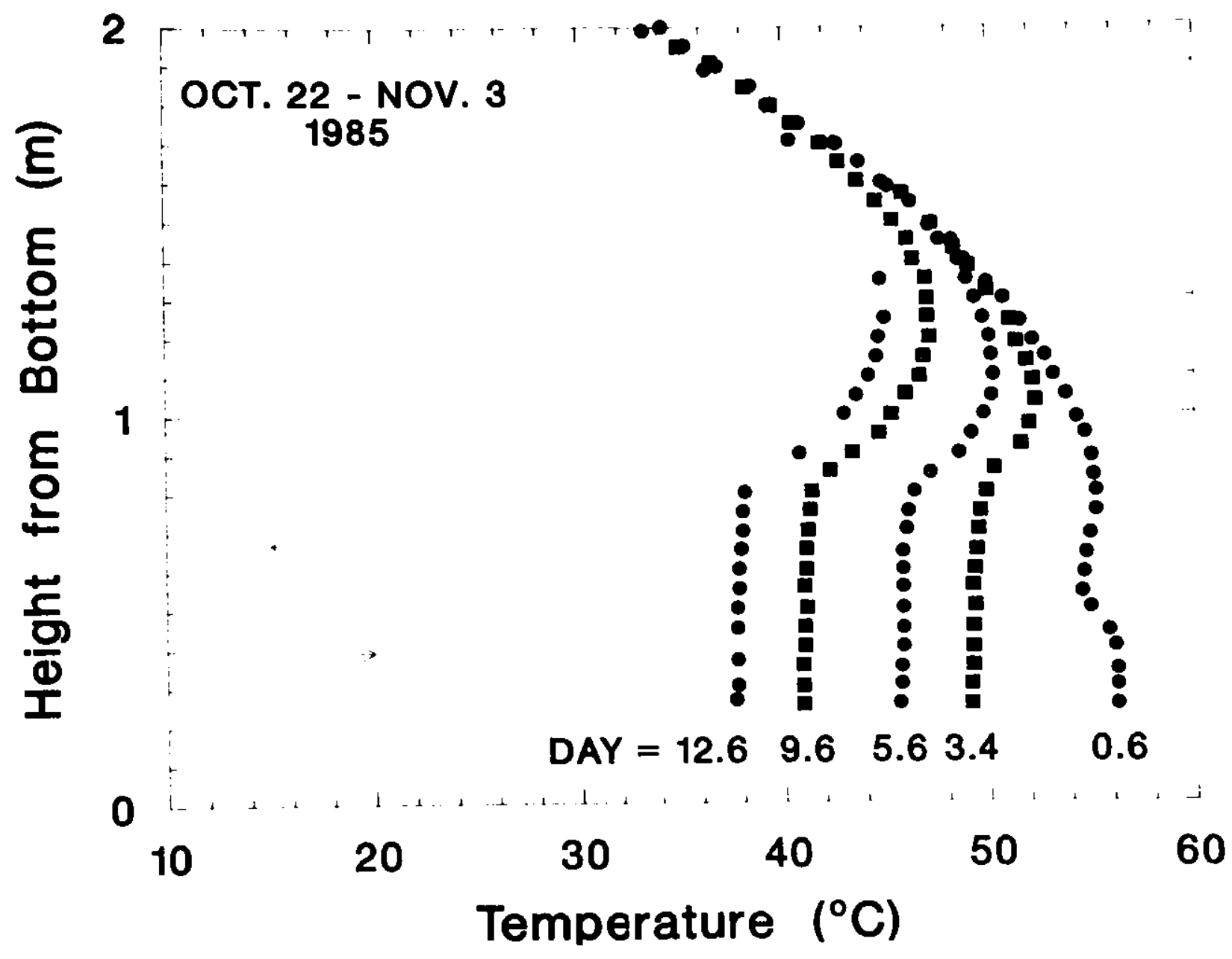

Fig. 29. Temperature profiles during first phase of brine withdrawal heat extraction 


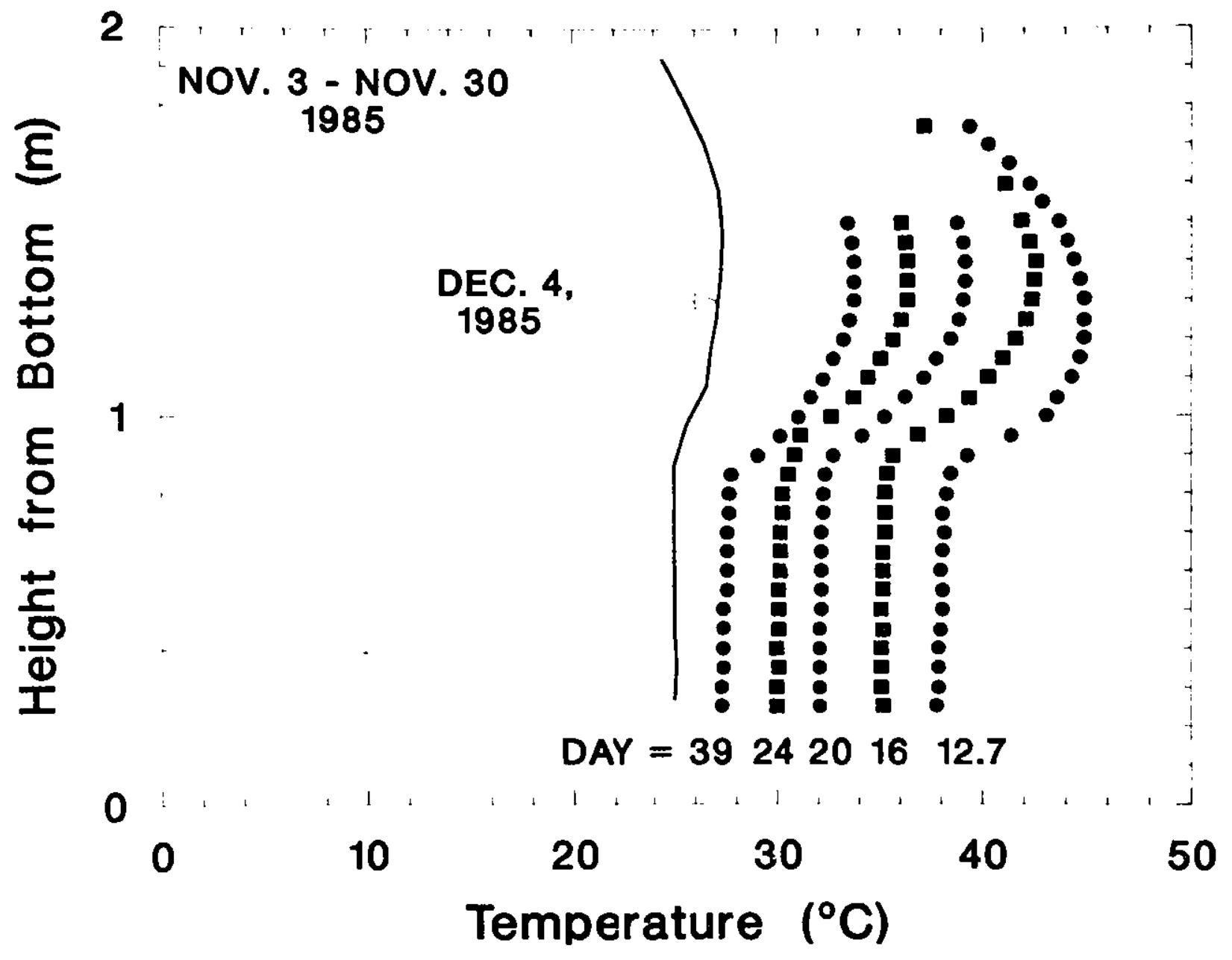

Fig. 30. Temperature profiles during second phase of brine withdrawal heat extraction 
for Dec. 4, several days after the experiment ended. Prominent features noticeable in the figure are:

- An increase in the HSZ height to $0.85 \mathrm{~m}$ during the first several days, after which it remained constant, and

- A continuation of the temperature inversion in the lower part of the gradient zone.

The temperature gradient above the injection diffuser also formed during the early part of phase 2. Several temperature profiles that illustrate the behavior are shown in Fig. 31. The temperature gradient was observable approximately 0.3 days after the diffuser was moved and had disappeared after about 1.2 days.

The formation of a temperature gradient above the injection diffuser occurs because relatively low-salinity water from within the gradient zone is being injected into the higher-salinity HSZ. The colder, less salty water is still less dense than the high-salinity water at the level of injection. The injected water will tend to rise by buoyancy forces to its level of equal density. For example, initially in phase 1 , the brine at the injection level is saturated at about $27 \%$ salinity and a temperature of $57^{\circ} \mathrm{C}$. The corresponding density is $1.185 \mathrm{gm} / \mathrm{mL}$. The extracted brine has a salinity of about $25 \%$ and a temperature of $57^{\circ} \mathrm{C}$, with a density of about 1.168. The injected brine has a salinity of about $25 \%$ and a temperature of $50^{\circ} \mathrm{C}$, corresponding to a density of about 1.172 , which occurs about $60 \mathrm{~cm}$ above the pond bottom.

As the cold stream rises, it mixes with the native fluid. The stream becomes somewhat more salty, rising to a lower height. The native fluid becomes somewhat less salty. Some of the water below the injected stream will become entrained and mixing will also occur to a small depth below the injection diffuser. As the process continues, saltier water from lower in the HSZ will rise to the level of the extraction diffuser and the injected brine will then be saltier than the initial injected brine. This later saltier brine will rise to a level below the initial charge of injected brine. In this way the salt gradient forms on both sides of the diffuser. Mixing of less salty water from above the extraction diffuser complicates the process, but the basic description is still valid. As the rapid rate of heat extraction continues, the less salty brine eventially becomes too cold. The temperature gradient is larger than the salt gradient can support, and the entire HSZ mixes.

Figure 32 shows a complete temperature profile after termination of the experiment. Comparing Fig. 32 with Fig. 28, one concludes that the bulk of the gradient was unaffected by the heat extraction process. The lower gradient zone boundary was controlled by the position of the extraction diffuser. Once the thermal inversion formed, the boundary was within $5 \mathrm{~cm}$ of the extraction level. 


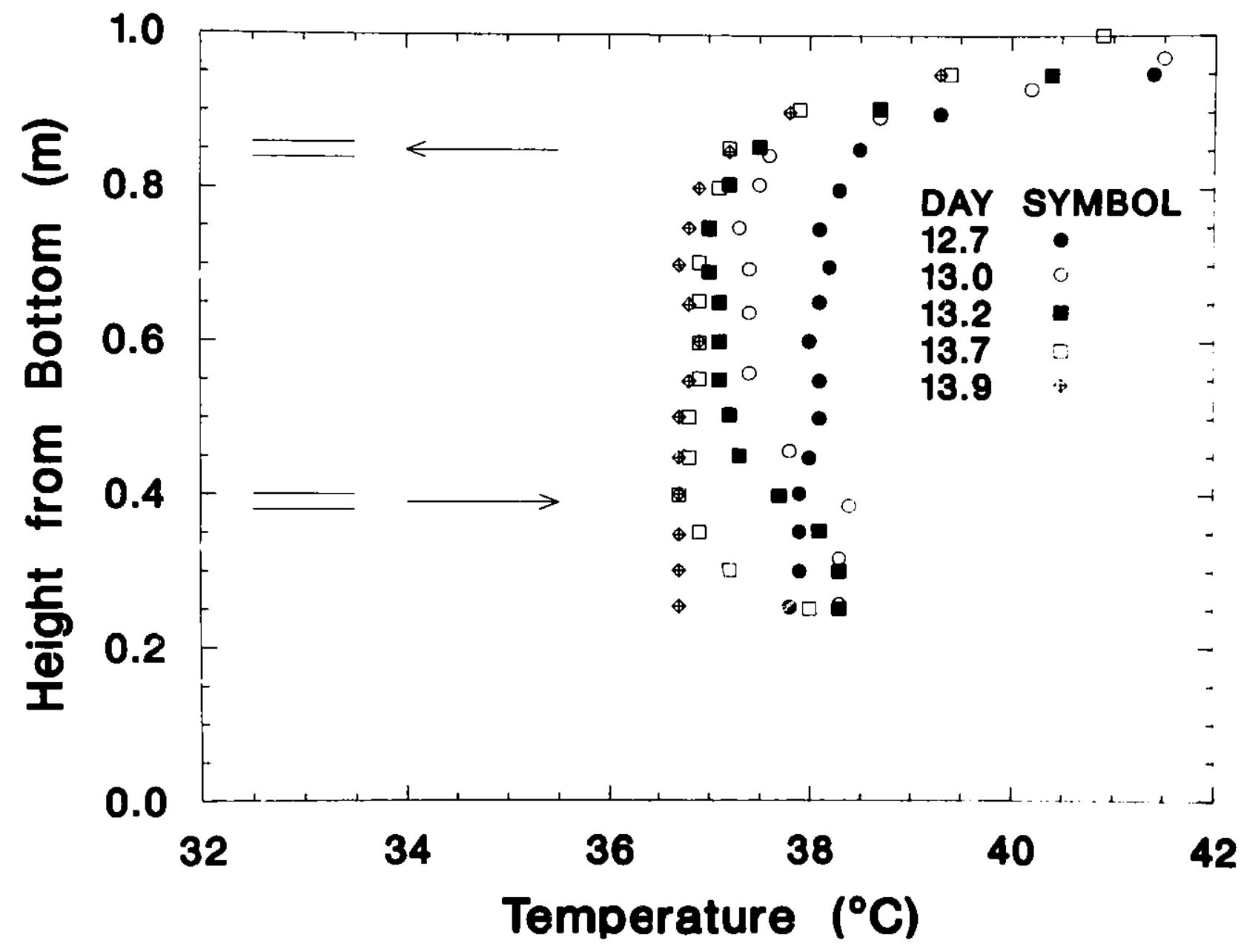

F1g. 31. Temperature profiles after extraction diffuser repositloning 


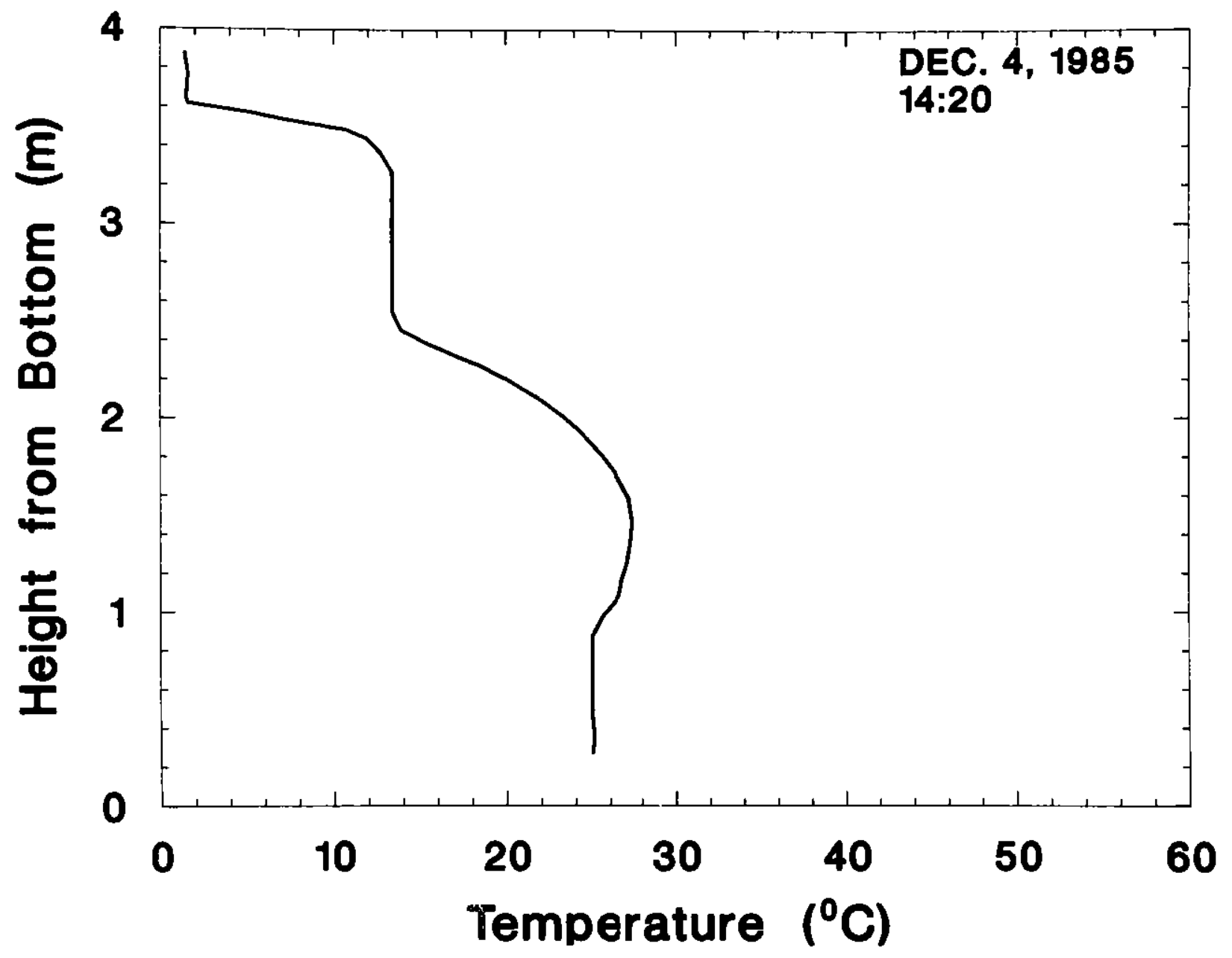

Fig. 32. Temperature profile after brine withdrawal heat extraction 


\section{CORROSION OF MATERIALS IN SALT GRADIENT SOLAR PONDS}

\subsection{INTRODUCTION}

Corrosion of materials at solar ponds is an important concern. In general, the experience at the ANL RSGSP over five years of operation is that metal components corrode more quickly around and in a solar pond than in other water bodies. Instruments located around the periphery of the pond also exhibit more corrosion failure than would be expected around a fresh-water pond. Even aircraft cables, which are made of a particularly corrosionresistant stainless steel, will corrode after three to $f$ ive years if they are suspended in the pond. The general practice at the ANL RSGSP has been to make components that pass into the pond or that are directly exposed to brine from plastic, if possible. Poly-vinyl-chloride (PVC) is used for most structures. Chlorinated CPVC (CPVC) is used when high temperatures are expected.

One of the major concerns in the design of the brine-to-air heat exchanger is the selection of the heat exchanger material. Sea water is one of the most severe of the natural corrosive agents. Although for many metals sea water is more corrosive than fresh water or concentrated NaCl solutions, it is likely that the hot concentrated brine from the solar pond will be equally corrosive, if not more so. It is true that ferrous metals, such as iron pipe, can rest on the bottom of a solar pond without any signs of corrosion. This is due to the lack of oxygen below the surface of the pond. However, the heat exchanger environment is much more severe. Oxygen may be introduced into the system via hose leaks, and the circulation of brine is likely to be turbulent. It is best to design the system for anticipated harsh conditions, so material selection is rrucial.

\subsection{CORROSION PROPERTIES OF MATERIALS}

The material in this section summarizing the corrosive actions of hot brine on several metals is taken from Refs. 69 and 70 .

\subsubsection{Steel}

Ferrous metals have remarkably steady corrosion when fully immersed in tranquil sea water [69]. Stainless steel, as well as aluminum and its alloys, derive excellent corrosion resistance from self-repairing protective oxide films that render them passive. Repair of the film depends on access of oxygen, and in crevices this is often inadequate. This may also be the case in the oxygen-deprived environment of the solar pond. The principal attack on these materials is pitting; the general erosion rate of mild steel in sea water is $\simeq 0.1 \mathrm{~mm} / \mathrm{yr}$, the pitting of stainless steel may yield a local rate (at the pit) of $0.3-1.3 \mathrm{~mm} / \mathrm{yr}$. The corrosion depends on $\mathrm{pH}$ and increases significantly at higher temperatures. In terms of a heat exchanger, the 
pitting would soon result in leaks, requiring periodic (say once a year) replacement of the tubes.

\subsubsection{Titanium}

Titanium [69], a very high-cost material, is intrinsically very reactive in the presence of oxygen and forms a tenacious passivating film, giving it corrosion resistance in a wide range of media, especially acids. Titanium is resistant to most neutral salts (e.g., solar pond brine), even at high temperatures.

\subsubsection{Monel}

Monel [70], consisting of $67 \%$ nickel and 30\% copper, is used where high strength and resistance to corrosion are required. It is very resistant to many common corrosives, such as sea water, even at elevated temperatures. Its high cost makes it unlikely for use in a solar pond heat exchanger, but it could be quite useful for small parts such as hose couplings. It is a stock item for many commercially available fittings.

\subsubsection{Copper}

Although copper [70] is a member of the noble metal group (1.ike gold), it is not inert. However, copper resists attack quite well under most corrosive conditions. General corrosion on copper is a well-distributed attack of an entire surface with little or no localized penetration, and it is the least damaging of all forms of attack. Copper metals resist corrosion in many environments because on initial exposure they react with one or more constituents of the environment, thereby forming an inert surface layer of protective reaction products. Coppernickel and nickelsilver (65Cu-17Zn-18Ni) both have good resistance in $\mathrm{NaCl}$ solutions and sea water. The corrosion rate of copper in quiescent sea water is $<0.05 \mathrm{~mm} / \mathrm{yr}$. The corrosion rate of coppernickel is $<0.025 \mathrm{~mm} / \mathrm{yr}$ under the same conditions. In both cases the instantaneous corrosion rate decreases as the duration of the exposure increases.

The resistance of these alloys to corrosion by sea water is partly the result of their inherent insolubility in sea water, but more because of their ability to form films of corrosion products that resist erosion by turbulently flowing seawater carrying entrained air. The velocity limits are:

$\begin{array}{ll}\text { Copper } & 0.9 \mathrm{~m} \mathrm{~s}^{-1} \\ \text { C70600 (90Cu-10Ni) } & 3.0 \mathrm{~m} \mathrm{~s}^{-1} \\ \text { C71500 (70Cu-30Ni) } & 4.5 \mathrm{~m} \mathrm{~s}^{-1}\end{array}$

If velocity limits are exceeded, or at locations under deposits or debris, corrosion can be as high as $0.125 \mathrm{~mm} / \mathrm{yr}$. 
Coppernickel $30 \%(\mathrm{C} 71500)$ has the best resistance of any of the copper alloys to impingement attack and to corrosion by most acids and waters. It is being used in increasing quantities under severe corrosive conditions where longer 1 ife is desired. The cost of coppernickel $30 \%$ is approximately 2.5 times that of pure copper.

The heat exchanger discussed in Sec. 5.1 was composed of copper tubes with aluminum fins. With a maximum flow rate of $12 \mathrm{gpm}$ through each tube of $3 / 4$ in. inside diameter, the flow velocity is $2.7 \mathrm{~m} \mathrm{~s}^{-1}$. This flow velocity would definitely cause rapid corrosion of the copper tubes with hot brine. However, the velocity would be well within the margin of safety for the $30 \%$ coppernickel tubes. 


\section{CONCLUSIONS}

Results of the heat extraction experiments performed at the ANL RSGSP indicate that both submerged and brine withdrawal heat extraction are viable options in the use of salt gradient solar ponds. For both methods a heat extraction system was designed, constructed, and operated without problems for extended periods of time. Even at relatively high rates of heat extraction, neither system caused any unwanted or unexpected erosion of the gradient zone.

Because both systems can operate reliably, the choice of which option to use will be determined mainly by the application. For an end application such as grain drying, where the end product from the pond is heated air, the brine extraction system is probably desirable, because it provides a higher heat exchanger effectiveness and lower cost. For the two systems reported here, which are in the $50 \mathrm{~kW}$ range, the cost of the submerged heat extraction system was $\$ 0.22 / \mathrm{W}$, and the cost of the brine withdrawal heat extraction system was $\$ 0.12 / W$. On the other hand, there are many applications, such as space heating of buildings, where pumping brine must be avoided. For such applivations, the submerged heat exchanger might be desirable. The cost of a plastic-tube submerged heat exchanger in this case is approximately equivalent to the cost of a brine-to-1iquid heat exchanger. 


\section{ACKNOWLEDGEMENTS}

This work is funded by grant ENR AEl2 from the Illinois Department of Energy and Natural Resources. The authors are greatly indebted to $R$. Swager of ENR for helpful management of the grant. The ANL RSGSP was built by funds obtained from the U.S. DOE under Contract W-31-109-ENG-38. Salt for the RSGSP was donated by the Morton Salt Company.

The authors are very grateful to C. MacCracken, president of the Calmac Manufacturing Corp., Englewood, New Jersey, for donating the material for the submerged heat exchanger.

A number of ANL personnel contributed to the fabrication and testing of the heat exchangers. The work of A. Mele and F. Piotrowski is especially acknowledged. In addition, ANL summer students M. Mattox and B. Makkinejad contributed to the installation and testing of the submerged heat exchanger at the RSGSP.

Gratitude is also extended to D. Voss for help in preparation of the manuscript. 


\section{REFERENCES}

1. Y. S. Cha, W. T. Sha, and J. R. Hull. "Design, Construction, and Initial Operation of the ANL Research Salt Gradient Solar Pond." Report ANL-81-55 (Aug. 1981).

2. J. R. Hull, Y. S. Cha, W. T. Sha, and W. W. Schertz. "Construction and First Year's Operational Results of the ANL Research Salt Gradient Solar Pond." Proc. Am. Solar Energy Soc., pp. 197-202, Houston (June 1982).

3. J. R. Hull and K. E. Kasza. "Heat Extraction from Salt Gradient Solar Ponds for Agricultural Purposes." Proc. Alternative Energy in the Midwest - Research and Applications, pp. 5.3-5.12, Schaumberg, Illinois (Feb. 1985).

4. J. R. Hull, A. B. Scranton, and K. E. Kasza. "Solar Pond Heat Removal Using a Submerged Heat Exchanger." Proc. Int. Solar Energy Soc., Montreal, Canada (June 1985).

5. J. R. Hull, K. V. Liu, Y. S. Cha, and W. T. Sha. "Solar Pond Salt Gradient Instability Prediction by Means of a Thermohydraulic Computer Code." Proc. Am. Sec. of Int. Solar Energy Soc., pp. 812-816, Philadelphia (May 1981).

6. J. R. Hull. "Computer Simulation of Solar Pond Thermal Behavior." Solar Energy 25, 33-40 (1980).

7. J. R. Hull. "Calculation of Solar Pond Thermal Efficiency with a Diffusely Reflecting Bottom." Solar Energy 29, 385-389 (1982).

8. J. R. Hull, K. V. Liu, W. T. Sha, J. Kamal, and C. E. Nielsen. "Dependence of Ground Heat Loss upon Solar Pond Size and Perimeter Insulation: Calculated and Experimental Results." Solar Energy 33, 25-33 (1984). Preliminary results published in Proc. Int. Solar Energy Soc., pp. 661-666, Brighton, England (Aug., 1981).

9. J. R. Hul1, J. Kamal, and C. E. Nielsen. "Time Dependence of Ground Heat Loss from Solar Ponds." Proc. Am. Solar Energy Soc., pp. 381-385, Minneapolis (May 31-June 4, 1983).

10. J. R. Hull. "Solar Pond Ground Heat Loss to a Moving Water Table." Solar Energy 35, 211-217 (1985).

11. D. Hillis, N. Sather, C. Panchal, H. Stevens, J. Hull, and A. Thomas. "A Study of Small Scale Solar Pond/OTEC (SPOTEC) Power Systems." Proc. Am. Solar Energy Soc., Pp. 443-446, Minneapolis (May 31-June 4, 1983). 
12. Y. S. Cha, W. T. Sha, and W. W. Schertz. "Modeling of the Surface Convective Layer of Salt-Gradient Solar Ponds." ASME J. Solar Energy Eng. 104, 293-298 (1982).

13. T. A. Newell and J. R. Hul1. "Depth. Sounding Diagnostic Measurements of Salt Gradient Solar Ponds." ASME J. Solar Energy Eng. 107, 160-164 (1985)

14. J. R. Hull. "Passive Stabilization of Gradient Zone Boundaries in Solar Ponds." Proc. Am. Solar Energy Soc., Anaheim (1984).

15. J. R. Hull. "Gradient Zone Boundary Control in Salt Gradient Solar Ponds." U.S. Patent No. 4,429,683 (February 7, 1984).

16. T. A. Newell and R. E. Boehm. "Gradient Zone Constraints in a SaltStratified Solar Pond." ASME J. Solar Energy Eng. 104, 280-285 (1982).

17. J. R. Hull. "Solar Ponds Using Ammonium Salts." Accepted for publication in Solar Energy (Nov. 1985).

18. J. R. Hull. "Stability and Economics of Solar Ponds Using Ammonium Salts." Proc. ASME Solar Energy Div. Conf., Anaheim, California (April 1986).

19. J. R. Hul1. "Membrane Stratified Solar Ponds." Solar Energy 25, 317-325 $(1980)$.

20. J. R. Hul1. "Method and Means of Preventing Heat Convection in a Solar Pond. U.S. Patent No. 4,241,724 (Dec. 30, 1980).

21. Y. S. Cha, W. T. Sha, and S. L. Soo. "Effects of Friction and Extraction on the Stability of Solar Ponds." J. Solar Energy Eng. 105, 356-362 (1983).

22. J. R. Hull and C. E. Nielsen. "Solar Ponds". Chap. 1.5 .4 in Vol. III of Solar Thermal Energy Conversion Technology Status and Assessment. F. de Winter (ed.), MIT Press. To be published (1987).

23. C. E. Nielsen, "Salt Transport and Gradient Maintenance in Solar Ponds," Proc. Am. Solar Energy Soc., Pp. 179-184, Houston (June 1982).

24. C. E. Nielsen, "Experience with Heat Extraction and Zone Boundary Motion," Proc. Am. Solar Energy Soc., pp. 405-410, Minneapol is (May 31June 4,1983 ).

25. L. J. Wittenberg, "Vugraphs of Miamisburg Solar Pond Evaluation Study," MLM-MU-82-64-0003, Seminar on Salt Gradient Solar Pond Research, Washington D. C. (April 1982). 
26. A. Akbarzadeh and R. W. G. MacDonald, "Introduction of a Passive Method for Salt Replenishment in the Operation of Solar Ponds," Solar Energy 29, 71-76 (1982).

27. J. Kamal and C. E. Nielsen, "Convective Zone Structure and Zone Boundaries in Solar Ponds," Proc. Am. Solar Energy Soc., pp. 191-196, Houston (June 1982).

28. C. F. Kooi, "Salt Gradient Solar Pond with Reflecting Bottom: Application to the 'Saturated' Pond," Solar Energy 26, 113-120 (1981).

29. C. F. Kooi, "The Steady State Salt Gradient Solar Pond," Solar Energy 23, 37-45 (1979).

30. R. L. Cole, J. R. Hull, Yu Lwin, and Y. S. Cha. "Comparison of Testing Methods for Latent Heat Storage Devices," Argonne National Laboratory Report ANL-82-89 (Feb. 1983).

31. D. L. Elwell, T. H. Short, and P. C. Badger, "Stability Criteria for Solar (Thermal-Saline) Ponds," Proc. Am. Sec. Int. Solar Energy Soc., pp. 16/29-33, Or1ando (June, 1977).

32. W. M. Rohsenow and J. P. Hartnett (eds.), Handbonk of Heat Transfer, McGraw-Hil1 (1973).

33. C. A. Harper (ed.), Handbook of Plastics and Elastomers, McGraw-Hill (1975).

34. L. E. Sissom and D. R. Pitts, Elements of Transport Phenomena, McGrawHill (1972), p. 459 .

35. People's Solar Sourcebook, Catalog from Solar Usage Now, Inc. (1979).

36. M. Pacetti and P. Principi. "Operation and Preliminary Data of a Small Experimental Solar Pond." Report WP/SP-3, Universita di Ancona, Italy (Nov. 1983).

37. D. K. Edwards and I. Catton. "Prediction of Heat Transfer by Natural Convection in Closed Cylinders Heated from Below." Int. J. Heat Mass Trans. 12, 23-30 (1969).

38. D. K. Edwards, J. N. Arnold, and P. S. Wu. "Correlations for Natural Convection Through High L/D Rectangular Cells." ASME J. Heat Trans. 101, 741-743 (1979).

39. C. C. Chen and R. Eichhorn, "Natural Convection from Spheres and Cylinders Immersed in a Thermally Stratified Fluid", ASME J. Heat Trans. 101, 566-569 (1979). 
40. S. W. Churchill and H. H. S. Chu, "Correlating Equations for Laminar and Turbulent Free Convection from a Horizontal Cylinder", Int. J. Heat Mass Trans. 18, 1049-1053 (1975).

41. R. M. Fand and J. Brucker, "A Correlation for Heat Transfer by Natural Convection from Horizontal Cylinders that Accounts for Viscous Dissipation", Int. J. Heat Mass Trans. 26, 709-726 (1983).

42. B. Gebhart, "Nàtural Convection Flows and Stability", Adv. in Heat Trans. $\underline{9}, 273-348$ (1973).

43. Y. Jaluria, Natural Convection Heat and mass Transfer, Pergamon Press (1980).

44. V. T. Morgan, "The Overall Convective heat Transfer from Smooth Circular Cylinders", Adv. in Heat Trans. 11, 199-264 (1975).

45. J. A. Peterka and P. D. Richardson, "Natural Convection from a Horizontal Cylinder at Moderate Grashof Numbers", Int. J. Heat Mass Trans. 12, 749752 (1969)。

46. R. E. Powe, "Bounding Effects on the Heat Loss by Free Convection from Spheres and Cylinders", ASME J. Heat Trans. 96, 558-560 (1974).

47. Y. T. Shee and S. N. Singh, "Natural Convection from a Horizontal Cylinder at Small Grashof Numbers", 20th ASME/AIChE National Heat Transfer Conf., pp. 67-74, Milwakee (1981).

48. G. D. Raithby and K. G. T. Hollands, "Laminar and Turbulent Heat Transfer by Natural Convection", Int. J. Heat Mass Trans. 17, 1620-1622 (1974).

49. G. D. Raithby and K. G. T. Hollands, "A General Method of Obtaining Approximate Solutions to Laminar and Turbulent Free Convection Problems", Adv. in Heat Trans. $11,265-315$ (1975).

50. G. D. Raithby and K. G. T. Hollands, "Laminar and turbulent Free Convection from Elliptic Cylinders, With a Vertical Plate and Horizontal Circular Cylinder as Special Cases", ASME J. Heat Trans. 98, 72-80 (1976).

51. R. F. Boehm and R. S. Alder, "Natural Convection Arising from Stripwise Heating on a Horizontal Surface", Int. J. Heat Mass Trans. 16, 853-855 (1973).

52. J. Goodman, "Ambient Temperature Stratification Effects in Laminar Free Convection", Int. J. Heat Mass Trans. 16, 1949-1950 (1973). 
53. K. Himasekhar and Y. Jaluria, "Laminar Buoyancy-Induced Axisymetric Free Boundary Flows in a Thermally Stratified Medium", Int. J. Heat Mass Trans. 25, 213-221 (1982).

54. R. A. Wirtz, and C. M. Chiu, "Laminar thermal Plume Rise in a Thermally Stratified Environment", Int. J. Heat Mass trans. 17, 323-329 (1974).

55. K. T. Yang, J. L. Novotny, and Y. S. Cheng, "Laminar Free Convection from a Nonisothermal Plate Immersed in a Temperature Stratified Medium", Int. J. Heat Mass Trans. 15, 1097-1109 (1972).

56. G. F. Marsters, "Arrays of Heated Horizontal Cylinders in Natural Convection", Int. J. Heat Mass Trans. 15, 921-933 (1972).

57. E. M. Sparrow and J. E. Niethammer, "Effect of Vertical Separation Distance and Cyclinder Temperature Imbalance on Natural Convection for a Pair of Horizontal Cylinders", ASME J. Heat Trans. 103, 638-644 (1981).

58. E. M. Sparrow and D. S. Boessneck, "Effect of Transverse Misalignment on Natural Convection from a Pair of Parallel, Vertically Stacked, Horizontal Cylinders", ASME J. Heat Trans. 105, 241-247 (1983).

59. E. M. Sparrow and D. R. Pfeil, "Enhancement of Natural Convection Heat Transfer from a Horizontal Cylinder due to Vertical Sh:ouding Surfaces", ASME J. Heat Trans. 106, 124-130 (1984).

60. F. P. Incropera and M. A. Yaghoubi, "Free Convection Heat Transfer from Heated Cylinders Immersed in a Shallow Water Layer", ASME J. Heat Trans. 101, 743-745 (1979).

61. F. P. Incropera and M. A. Yaghoubi, "Buoyancy Driven Flows Originating from Heated Cylinders Submerged in a Finite Water Layer", Int. J. Heat Mass Trans. 23, 269-278 (1980).

62. S. Ostrach, "Natural Convection in Enclosures", Adv. Heat Trans. 8, 161227 (1972).

63. I. Tokura, H. Saito, K. Kishinami, and K. Muramoto, "An Experimental Study of Free Convection Heat transfer from a Horizontal Cylinder in a vertical Array Set in Free Space Between Parallel Walls", ASME J. Heat Trans. 105, 102-107 (1983).

64. B. I. Fu and S. Ostrach, "The Effects of Stabilizing Thermal Gradients on Natural Convection Flows in a Square Enclosure", 20th ASME/AIChE National Heat Transfer Conf., pp. 91-104, Milwakee (1981).

65. F. Zangrando, "Heat and Mass Extracticin from Solar Ponds," Report SERI/TR-252-1569 (April 1982). 
66. C-S. Yih, Stratified Flows, pp. 246-273, Academic Press (1980).

67. L. J. Wittenberg and D. E. Etter, "Heat Extraction From a Large Solar Pond," ASME Winter Meeting, Phoenix (Nov. 1982).

68. H. Tabor, "Non-convecting solar ponds," Phil Trans. R. Soc. Lon. A 295, 423-433 (1980); also "Solar ponds -Corrections," Solar Energy 30, 85 (1983).

69. L. L. Schreir (ed.), Corrosion, Vol. 1. Newnes-Butterworth, London (1976).

70. American Society for Metals, Metals Handbook (1978, 1979). 
Distribution for ANL-86-17

Internal:

$\begin{array}{lll}\text { J. W. Allen } & \text { J. R. Hull (20) } & \text { W. T. Sha } \\ \text { Y. S. Cha } & \text { K. E. Kasza } & \text { R. S. Zeno } \\ \text { R. L. Cole } & \text { K. V. Liu } & \text { ANL Patent Dept. } \\ \text { H. Drucker } & \text { A. I. Michaels } & \text { ANL Contract File } \\ \text { A. V. Fraioli } & \text { W. W. Schertz (5) } & \text { ANL Libraries } \\ \text { A. J. Gorski } & & \text { TIS Files (5) }\end{array}$

Externa1:

DOE-TIC, for distribution per UC-59A (243)

Manager, Chicago Operations Office, DOE

Components Technology Division Review Committee:

P. Alexander, Flopetrol Johnston Schlumberger, Houston

D. J. Anthony, General Electric Co., San Jose

A. A. Bishop, U. Pittsburgh

B. A. Boley, Northwestern U.

R. N. Christensen, Ohio State U.

R. Cohen, Purdue U.

R. E. Scholl, URS, San Francisco

J. Weisman, U. Cincinnati

A. Akbarzadeh, Victorian Solar Energy Council, Melbourne, Australia

J. F. Atkinson, State Univ. of New York, Buffalo

S. Ayyash, Kuwait Inst. for Scientific Research, Safat, Kuwait

C. Batty, Utah State U.

R. S. Beniwal, U. Rajasthan, Jaipur, India

R. Boehm, U. Utah

H. C. Bryant, U. New Mexico

W. W. S. Charters, U. Melbourne, Australia

S. H. Cho, Korea Inst. of Energy and Resources, Daejon, Korea

M. Collares-Pereira, LNETI, Lisboa, Portugal

R. B. Collins, Australian Solar Ponds, Alice Springs, Australia

P. Damshala, U. Tennessee, Chattanooga

R. Dedolph, Gravimechanics Co., Naperville, IL

J. Doria, Universidad Complutense, Madrid, Spain

M. A. El-Hadidy, Univ, of Petroleum and Minera1s, Dhahran, Saudi Arabia

D. Engdah1, California Dept. of Water Resources, Sacramento

R. P. Fynn, Ohio Agricultural R\&D Center, Wooster

H. P. Garg, Indian Inst. of Technology, New Delhi, India

M. Gnininvi, Universite du Benin, Lome, Togo

P. Golding, Ohio State U.

D. R. F. Harlemann, Massachusetts Inst. Technology

H. Healey, Florida Solar Energy Center, Cape Canaveral

S. Hightower, U. S. Bureau of Reclamation, Denver

J. M. Huacuz, Instituto de Investigaciones Electricas, Cuernavaca, Mexico

F. P. Incropera, Purdue U.

W. C. Irwin, Tennessee Valley Authority, Chattanooga

V. V. N. Kishore, Central Salt and Marine Chemicals, Bhavnagar, India

Z. Lavan, Illinois Inst. Technology, Chicago

G. W. Lin, Energy Research Labs., ITRI, Taipei, Taiwan

C. D. MacCracken, Calmac Manufacturing Co.: Englewood, NJ

B. P. Marett, U. Melbourne, Parkville, Australia 
J. M. Mehta, General Electric Co., Cincinnati

F. Morse, Office of Solar Heat Technologies, USDOE

S. Moustafa, California Polytechnic Inst., San Luis Obispo

R. K. Multer, Rindge, NH

D. Neeper, Los Alamos National Lab.

T. A. Newell, U. Illinois, Urbana

C. E. Nielsen, Ohio State U.

U. Ortabasi, Univ, of Queensland, St. Lucia, Australia

S. M. Pate1, Tata Energy Res. Inst., Pondicherry, India

R. L. Reid, U. Texas, El Paso

S. L. Sargent, DOE Site Office, Golden, CO

S. G. Schladow, Univ of Western Australia, Nedlands, Australia

A. Scranton, Furdue U.

G. Siegel, Tennessee Valley Authority, Chattanooga

$\mathrm{J}$. Srinivasan, Indian Inst. of Technology, Bangalore, India

R. Swager, Illinois Dept. of Energy and Natural Resources, Springfield

D. Tinaut, Instituto de Optica, Madrid, Spain

E. Wilkins, U. New Mexico

L. Wittenberg, U. Wisconsin, Madison

$\mathrm{K}$. Woods, Woods and Associates, Naperville, IL

F. Zangrando, Solar Energy Research Inst. 